NBER WORKING PAPER SERIES

\title{
MARGINAL TAX RATES AND INCOME: NEW TIME SERIES EVIDENCE
}

\author{
Karel Mertens \\ José L. Montiel Olea \\ Working Paper 19171 \\ http://www.nber.org/papers/w19171
}

\author{
NATIONAL BUREAU OF ECONOMIC RESEARCH \\ 1050 Massachusetts Avenue \\ Cambridge, MA 02138 \\ June 2013, Revised September 2017
}

We thank the editor, Robert Barro, and the referees for their suggestions and comments, Daniel Feenberg for assistance with the US Individual Income Tax Public Use Sample, Glenn Follette for providing data, and Andrew Fieldhouse, Bryce Little, Qifan Han and Jianing Zhai for superb research assistance. We also thank Levon Barseghyan, Gregory Besharov, Lorenz Kueng, Kristoffer Nimark, Morten Ravn, Barbara Rossi and participants at various seminars and conferences for useful comments. Financial support from the Cornell Institute for the Social Sciences is acknowledged. The views in this paper are those of the authors and do not necessarily reflect the views of the Federal Reserve Bank of Dallas, the Federal Reserve System, or the National Bureau of Economic Research.

NBER working papers are circulated for discussion and comment purposes. They have not been peer-reviewed or been subject to the review by the NBER Board of Directors that accompanies official NBER publications.

(C) 2013 by Karel Mertens and José L. Montiel Olea. All rights reserved. Short sections of text, not to exceed two paragraphs, may be quoted without explicit permission provided that full credit, including $\odot$ notice, is given to the source. 
Marginal Tax Rates and Income: New Time Series Evidence

Karel Mertens and José L. Montiel Olea

NBER Working Paper No. 19171

June 2013, Revised September 2017

JEL No. E6,E62,H2,H24

\begin{abstract}
$\underline{\text { ABSTRACT }}$
Using new narrative measures of exogenous variation in marginal tax rates associated with postwar tax reforms in the US, this study estimates short run tax elasticities of reported income of around 1.2 based on time series from 1946 to 2012. Elasticities are larger in the top $1 \%$ of the income distribution but are also positive and statistically significant for other income groups. Previous time series studies of tax returns data have found little evidence for income responses to taxes outside the top of the income distribution. The different results in this study arise because of additional efforts to account for dynamics, expectations and especially the endogeneity of tax policy decisions. Marginal rate cuts lead to increases in real GDP and declines in unemployment. This study also presents evidence that the responses are to marginal tax rates rather than average tax rates. Counterfactual tax cuts targeting the top $1 \%$ alone have short-run positive effects on economic activity and incomes outside of the top $1 \%$, but increase inequality in pre-tax incomes. Cuts for taxpayers outside of the top $1 \%$ also lead to increases in incomes and economic activity, but with a longer delay.
\end{abstract}

\author{
Karel Mertens \\ Department of Economics \\ Cornell University \\ 404 Uris Hall \\ Ithaca, NY 14853 \\ and NBER \\ km426@cornell.edu \\ José L. Montiel Olea \\ Columbia University \\ Department of Economics \\ Office 1020 \\ 1022 International Affairs Building \\ New York, NY 10027 \\ montiel.olea@gmail.com
}

A data appendix is available at http://www.nber.org/data-appendix/w19171 


\section{Introduction}

To what extent do marginal tax rates matter for individual decisions to work and invest? The answer is essential for public policy and its role in shaping economic growth. The empirical literature studying US tax returns, surveyed in Saez, Slemrod and Giertz (2012), concludes that reported pre-tax incomes react only modestly to marginal tax rates and attributes evidence of larger responses for top incomes to tax avoidance rather than real economic effects. In contrast, many macro studies find that indicators of real activity such as GDP, investment and employment respond significantly to changes in taxes, e.g. Romer and Romer (2010), Barro and Redlick (2011) or Mertens and Ravn (2013). This is puzzling, since the macro evidence for real economic effects of taxes should be apparent in market incomes reported on tax returns.

This study reconciles the time series evidence on the aggregate responses to marginal tax rates by combining existing macro methodologies with the reported income measures of Piketty and Saez (2003), as well as newly constructed series on average marginal tax rates for the 1946-2012 period. Existing time series estimates of the elasticity of reported income with respect to net-of-tax rates (one minus the marginal tax rate) are close to zero in the aggregate. As a contribution to the public finance literature, we show that adopting specifications that address central concerns related to timing, expectations, and in particular the endogeneity of tax policy, leads to statistically significant short run elasticities centered around a value of 1.2 for all taxpayers.

At the core of the identification strategy are new measures of the impact of a number of federal tax reforms on average marginal tax rates. The selection of tax reforms is based on the Romer and Romer $(2009,2010)$ narrative account of postwar US tax policy, focusing on individual income and payroll tax changes implemented within a year of their legislation to avoid anticipation effects. The tax elasticity estimates are obtained by using these measures as 'proxies' for exogenous tax rate innovations in structural vector autoregressions as in Mertens and Ravn (2013), or alternatively as instruments for tax rates in local projections similar to Barro and Redlick (2011). This paper also contributes to the macro literature by developing the narrative identification approach for marginal rather than average tax rate shocks, and by analyzing responses along the income distribution.

The regression results indicate that incomes in the top $1 \%$ of the income distribution display the strongest short 
run response to tax rates, which is consistent with the notion that high income tax payers display more avoidance behavior. However, contrary to prior time series studies of tax return data, we also find statistically significant elasticities for lower income groups and narrower wage income measures. Moreover, marginal rate cuts lead to increases in real GDP and declines in the unemployment rate that are broadly consistent with existing macro results. Simple calculations suggest aggregate hours elasticities of 0.37 on the intensive margin and 0.41 on the extensive margin, which is within the range of the quasi-experimental labor supply evidence surveyed in Chetty, Guren, Manoli and Weber (2013).

In addition, we present new evidence to determine whether real economic activity responds primarily to marginal tax rates, or to average tax rates. Combining measures of the impacts of the Romer and Romer $(2009,2010)$ reforms on both, we estimate the consequences of counterfactual tax experiments that lead to an innovation in marginal tax rates but not in average tax rates, and vice versa. We find that marginal rate changes lead to very similar income responses regardless of the change in the average tax rate. There is, on the other hand, no evidence for any effect on incomes when average tax rates decline but marginal rates do not. This implies that the reforms with a direct impact on marginal tax rates are the key events generating the real economic effects estimated by the narrative macroeconometric studies. Our findings indicate that substitution effects, rather than income effects or aggregate demand stimulus, are central to the transmission of federal tax policy changes observed in the postwar period.

Finally, we analyze the impact of counterfactual tax reforms cutting marginal tax rates only for the top $1 \%$ or the bottom $99 \%$ in the income distribution. The associated short run reported income elasticity for the top $1 \%$ is estimated to be around 1.5. In the short run, a top marginal rate cut in raises real GDP, lowers aggregate unemployment and also has a measurable positive effect on incomes outside of the top 1\%. Nevertheless, marginal rate cuts targeting top incomes lead to greater income inequality. These results have implications for the interpretation of the observed correlation between top marginal tax rates and top income shares, see Piketty, Saez and Stantcheva (2014). Causal explanations based on avoidance or rent-seeking alone cannot explain the finding that top marginal rate cuts have real economic effects and spill over to lower income groups. Targeted cuts for the bottom $99 \%$ also generate positive effects on reported incomes and aggregate economic activity, but with a delay of several years. This delay may help explain why broader responses to tax rates have been harder to detect empirically. 


\section{Income and Average Marginal Tax Rates}

\subsection{Existing Evidence on Income Responses to Taxes}

The responsiveness of incomes reported to tax authorities, typically measured by the elasticity of taxable income, or ETI for short, has received much attention as an indicator for the distortionary effects of taxes, see Saez, Slemrod and Giertz (2012). The interpretation of an ETI measure depends on the definition of 'taxable income'. As much of the recent literature, we focus on broad measures of gross market income, i.e. before government transfer payments and before the various adjustments and deductions allowed by the tax code. These broad ETI measures are generally informative about the efficiency and revenue implications of tax policy changes, and can in some cases be used as a sufficient statistic for optimal tax analyis. ${ }^{1}$

A large public finance literature has obtained quasi-experimental ETI estimates using US tax return data in a variety of ways. The analysis of the 1981 reform by Lindsey (1987) used cross-sectional data and counterfactual income simulations to document very large elasticities centered around 1.6. To better control for confounding factors, panel data studies of the 1986 reform starting with Feldstein (1995) exploited heterogeneity in marginal tax rate changes to establish treatment and control groups and make difference-in-difference comparisons. The combined evidence from the 1980s reforms in Lindsey (1987), Feldstein (1995), Auten and Carroll $(1995,1999)$ and others pointed to large short run ETIs in a range of 0.7 to over 3.0, although broadening the sample of taxpayers, the definition of income or the set of controls yields estimates towards the lower end of that range. Subsequent event studies of reforms in the 1990s, such as Sammartino and Weiner (1997), Carroll (1998) or Giertz (2010), instead obtained lower values of close to 0 up to 0.5 . This confirmed growing suspicions that the estimates for the 1980 s were largely artifacts of insufficient controlling and/or of certain attributes of these reforms leading to highly transitory effects, see Slemrod $(1995,1996)$.

Diff-in-diff case studies, however, offer no definitive answer because there are many other determinants of relative income changes that are hard to control for and because it must be assumed either that there is no tax change for the control group or otherwise that the ETIs are identical for both groups. ${ }^{2}$ To overcome some of these difficulties,

\footnotetext{
${ }^{1}$ See for instance Feldstein (1999), Saez (2001), Chetty (2009), Diamond and Saez (2011) or Badel and Huggett (2015).

${ }^{2}$ Blundell et al. (1998), Slemrod (1998), Triest (1998), Goolsbee (1999) and Saez et al. (2012) discuss the empirical issues.
} 
one strategy is to assume ETIs are roughly time-invariant and cumulate evidence from a number of tax reforms. ${ }^{3}$ Empirical models that under reasonable assumptions restrict unobservable confounding influences on income growth to have zero mean allow for averaging out those influences over time. For instance, Gruber and Saez (2002) use a long panel dataset from 1979 to 1990 to exploit richer variation in tax rates during that period and find an elasticity of income (before deductions and exemptions) of close to zero in the sample of all tax returns. Starting with Feenberg and Poterba (1993), most studies adopting a broader time perspective, however, use more aggregated data that is available for different and/or longer sample periods. By gathering evidence from multiple reforms, such studies have further confirmed the view that the reported income responses observed for the 1980s reforms were anomalies. In time series regressions of top income shares on net-of-tax rates over the 1950-1990 period, Slemrod (1996) for instance finds that the elasticity drops considerably when the last five years containing the 1986 reform are excluded. Goolsbee (1999) uses aggregate data to obtain separate short run diff-in-diff elasticities for seven reforms between 1920 and 1975 and finds that the largest estimate is far below those for the 1980s reforms. In aggregate time series regressions, Saez (2004) and Piketty, Saez and Stantcheva (2014) find small and statistically insignificant elasticities for all tax units and moderate but significant elasticities for top incomes. Collecting diff-in-diff evidence from reforms during the interwar period, Romer and Romer (2014) find elasticities for top incomes around 0.20. In their survey of the available evidence, Saez, Slemrod and Giertz (2012) acknowledge there are no truly convincing estimates of long run ETIs but conclude that the best available estimates are in a range of 0.12 to 0.40 . There is much evidence for larger short run ETIs for high income tax payers which they attribute mostly to better access to avoidance opportunities. Beyond that, Saez et al. (2012) argue, there is no compelling evidence for any real economic responses to marginal tax rates.

The conclusions from the ETI literature are at odds with the recent macro empirical literature that exploits policy reforms as quasi-experiments to identify the effects of taxes on aggregate real economic variables such as GDP, unemployment or investment. Starting with Romer and Romer (2010), 'narrative approach' studies have consistently estimated substantial short and medium run effects of taxes on economic activity. For instance, Romer and Romer (2010) find that a policy-induced increase in federal tax liabilities of 1\% of GDP lowers GDP by 3\% and investment

\footnotetext{
${ }^{3}$ Another strategy is to look for features in the tax code that generate differential tax rates for narrower but more similar groups of taxpayers. Unfortunately the results may not be more broadly representative and, while the case for identification may become more convincing, the identifying variation in tax rates is typically smaller. Taxpayers may not be aware of the minute details of the tax code and/or have insufficient incentive to respond to small changes, see Chetty (2012). The findings may therefore be less relevant for larger changes in marginal tax rates.
} 
by $9 \%$ after two years. Mertens and Ravn (2013) find that a one percentage point decrease in the personal average tax rate raises GDP by $1.5 \%$ and lowers the unemployment rate by 0.5 percentage points within a year. Also using tax reforms for identification, Cloyne (2013) and Hayo and Uhl (2014) find remarkably similar results for the UK and Germany, while Leigh, Pescatori and Guajardo (2014) find large contractionary effects of tax based fiscal consolidations in OECD countries. The lack of evidence for real substitution effects in the ETI literature is also puzzling in light of a closely related labor supply literature that uses tax experiments and hours or employment as outcome variables. Based on their reading of the recent evidence, Chetty, Guren, Manoli and Weber (2013) view elasticities of aggregate hours of 0.5 for a permanent tax change and 0.75 for a transitory tax change as realistic. As broader measures of the behavioral response, ETIs should be at least as large as these labor supply elasticities.

The conflicting evidence on the real effects of taxes between the ETI and macro literatures cannot be easily resolved by any of the explanations for the gap between micro and macro labor supply elasticities, since the public finance evidence includes analyses of aggregate time series. ${ }^{4}$ One potential explanation is that most of the macro studies focus on average rather than marginal tax rates. Many reforms impact differently on both and any aggregate demand effects due to changes in disposable income may feature more prominently in the macro estimates. Using the Romer and Romer $(2009,2010)$ tax policy measure as an instrument, Barro and Redlick (2011) however find that a one percentage point cut in the AMTR raises per capita GDP by around $0.5 \%$ in the following year. This estimate is statistically significant and amounts to a short run GDP elasticity to the net-of-tax rate of 0.36 , which should be a lower bound for the elasticity of personal income. By comparing results from specifications with average tax rates, Barro and Redlick (2011) also tentatively conclude that the response is mainly to marginal rather than average tax rates.

The main objective of this paper is to investigate the main claims of both the ETI and macro literatures on the real effects of tax changes and expose the sources of the disagreement. To include more historical variation in tax rates, we employ newly extended time series on postwar AMTRs that are discussed next.

\footnotetext{
${ }^{4}$ See Keane and Rogerson (2012) and Chetty et al. (2013) for the debate on micro and macro labor supply elasticities.
} 


\subsection{Average Marginal Tax Rates 1946-2012: Description and Stylized Facts}

Figure 1 depicts estimates of annual US average marginal tax rates from 1946 to 2012 for the aggregate economy and within different income brackets. The series combine federal individual income tax rates and contribution rates under the Old-Age, Survivors and Disability Insurance and Medicare Hospital Insurance programs. The tax rates and income rankings reflect the population of potential tax units, defined as all married men and singles aged 20 or more. The upper panel of Figure 1 shows two AMTR measures for all tax units that differ primarily in the income concept used for weighting. The first measure is based on a broad concept of labor income used by Barro and Redlick (2011) that includes wages, self-employment, partnership, and S-corporation income. The other aggregate series, as well as the series for top and bottom tax units in the lower panel of Figure 1, use an income concept from Piketty and Saez (2003) that includes non-labor income but excludes capital gains and government transfers. The percentiles are for the distribution of the Piketty and Saez (2003) definition of income across potential tax units. ${ }^{5}$

Figure 2 shows the income tax component. The first series for all tax units updates the measure of Barro and Redlick (2011) to include observations post 2006. The series based on the Piketty and Saez (2003) income concept extend those of Saez (2004) by almost 30 years using data from the IRS Statistics of Income. The social security tax rates in Figure 3 are constructed from data published by the SSA, as well as individual IRS tax returns. The series for all tax units are updates of Barro and Sahasakul (1986). The series for top and bottom tax units are entirely new. Appendix A provides full details on the construction of the tax rates. One limitation of the series is that social security benefits depend partially on earnings. In principle, marginal changes in benefits should be netted out to obtain the tax component. In practice the inclusion of social security has no major implications for the results in this paper. Another limitation is that the series do not include state-level taxes. The amount of short run variation in aggregated state-level marginal tax rates is very small, see Barro and Redlick (2011), such that this omission is unlikely to be important.

The tax rates for all tax units in Figure 1 display an upward trend starting at around $20 \%$ right after WWII and rising to over $35 \%$ at the beginning of the 1980 s. The main source of this trend is the gradual expansion of social

\footnotetext{
${ }^{5}$ Piketty and Saez $(2003,2007)$ provide a detailed description of the income data, which for most years is based on public use files containing around 100,000 returns. In the postwar period, the top $1 \%$ income share was about $11 \%$ after the war, declined to $8 \%$ in the 1960 s and 1970s and has gradually risen since to about $19 \%$ in 2012 . The top $10 \%$ share was about $1 / 3$ after the war and has risen since the late 1970 s to about $48 \%$ in 2012.
} 
security contributions from less than $1 \%$ in 1946 to around $9 \%$ since the early 1990s, see Figure 3. The upward trajectory accelerates in the 1970 s because of rapid increases in income tax rates primarily due to high inflation and bracket creep. In the 1980s, the continuing rise in social security rates is largely offset by decreases in income tax rates. The income tax component appears stationary over the postwar period and is typically in the $20 \%-25 \%$ range. The tax rates by income in the lower panel of Figure 1 show a substantial decline in progressivity after 1980 . This decline is mostly the result of reforms in the 1980s but also partly due to the growing importance of the regressive social security tax, which taxes individual earnings above a statutory ceiling at a zero marginal rate before 1994 and only at the lower hospital insurance rate afterwards.

In the short run, the tax rate series in Figure 1 display substantial variation that is predominantly driven by income taxes. The larger annual fluctuations in income tax rates reflect well known legislative changes. ${ }^{6}$ Because brackets and ceilings are imperfectly indexed, AMTRs also vary automatically with nominal income levels even in the absence of legislative changes. ${ }^{7}$ Changes in the social security rates are less important for the year-to-year variability in overall rates. ${ }^{8}$ To provide more insight into the sources of annual variation in tax rates, Figure 4 depicts estimates of the impact of policy driven statutory changes in overall tax rates (upper panel), as well as in the income tax and social security rates individually (lower left and right panels). The estimated statutory component in year $t$ is calculated as the difference between a counterfactual average marginal tax rate, calculated using the year $t-1$ income distribution and year $t$ rates and brackets deflated by any automatic adjustments between $t-1$ and $t$, and the actual year $t-1$ average marginal tax rate. The difference between actual and policy induced annual changes in tax rates thus captures the effect on AMTRs of the change in the income distribution relative to the previous year. This is of course only an 'effect' in a purely accounting sense and should not be given a causal interpretation.

\footnotetext{
${ }^{6}$ The most significant adjustments include the rate reductions in 1948 following the end of WWII, the tax increases in the 1950s during the Korean War; the 1964 Kennedy tax cuts; the 1968-1970 surcharge during the Vietnam War; the 1980s Reagan tax cuts and in particular the 1986 Tax Reform Act; the early 1990s Bush and Clinton tax increases; and the W. Bush tax cuts in the early 2000 s.

${ }^{7}$ Annual inflation adjustments to income tax brackets began only in 1985 and to date there is no real income indexation. De facto inflation adjustments started in 1985 although automatic indexing to the CPI did not begin until 1987. Some components of the tax code, such as the alternative minimum tax, have not been automatically indexed to inflation even after 1987. The American Taxpayer Relief Act of 2012 starts automatic indexation of the alternative minimum tax in 2013. All indexation occurs with significant delay and is applied roughly uniformly across the income distribution.

${ }^{8}$ Social security contributions depend on taxable maxima that have been automatically indexed to national average wage growth starting in 1975 . The many statutory changes to social security contribution rates and/or taxable earnings prior to the early 1990s are all permanent and gradual increases that are comparatively smaller in size. The most noticeable changes result from the Great Society initiatives under Johnson including the introduction of Medicare in 1966, the 1972, 1977 and 1983 amendments of Social Security and the expansion of the Medicare tax in the early 1990s. The only reduction is the temporary cut in contribution rates under Obama in 2011 and 2012.
} 
Table 1 quantifies some key characteristics of the combined AMTR series in Figure 1 and the sources of variation. The first eight columns provide first and second order properties of the tax rate levels and of changes in the net-of-tax rates by income group. The last three columns in Table 1 contain the contribution of statutory changes to the overall variation in annual net-of-tax rate changes. These are measured by the $R^{2}$ coefficient of regressions of net-of-tax rate changes on the statutory changes estimated for each income group separately as described above, i.e. by constructing a counterfactual tax rate that keeps the income distribution fixed and adjusts for automatic indexation.

Table 1 reveals a number of important features of the tax rate series. First, there is substantial variation in postwar AMTRs, most of which is driven by policy changes. The raw standard deviation of annual changes in net-of-tax rates for all tax units is $1.8 \%$ to $2.0 \%$. More than $85 \%$ of the variation is explained by statutory changes. Second, the federal income tax is the dominant source of fluctuations in income-weighted tax rates. Three quarters of the variation in net-of-tax rates for all tax units is explained by legislative changes to income taxes, whereas statutory changes in social security taxes account for $14 \%$ to $17 \%$. Third, there is considerable heterogeneity in tax rate variability across income groups. Annual percentage changes in net-of-tax rates are considerably more volatile for top incomes than for lower incomes, explaining $80 \%$ or more of the total variation. Not surprisingly, statutory changes in social security taxes contribute very little to the variation in top tax rates. For the bottom $90 \%$ and $99 \%$ groups, statutory social security changes on the other hand explain up to one fifth, respectively a quarter of the variation whereas statutory income tax changes account for up to 62\%, respectively 53\%. Fourth, the AMTRs remain very highly correlated across large sections of the income distribution. The lowest correlation, between the top $1 \%$ and bottom 90\%, is 0.70. The income specific AMTRs are all highly correlated with either of the series for all tax units: even the top $1 \%$ AMTR has a correlation of over 0.80 with the aggregate for all tax units. Finally, the two AMTR measures for all tax units are very highly correlated and none of the results below are very sensitive to which measure is chosen.

The initial analysis of the tax rates highlights some of the advantages and challenges of using aggregate time series to identify tax elasticities. The full postwar history of federal tax legislation clearly offers a rich amount of potential identifying variation and includes many large increases and decreases in tax rates. Policy-induced fluctuations in tax rates are especially large at the top of the income distribution. A longer time series perspective can therefore be particulary revealing about the behavioral responses of high income taxpayers in a way that is not too dependent on 
any particular reform. At the same time, the dominant role of the income tax in the variability of income-weighted tax rates means that any results are likely to be representative only for the middle and higher income classes. Many low income households have no federal income tax liabilities and variation in social security contributions is more limited. The large cross-correlations of tax rates among income groups also point to a potentially important role for general equilibrium effects in shaping the income response to tax rates. The vast majority of federal tax reforms are aggregate events that may influence the wage distribution, monetary policy and interest rates, or other fiscal policy instruments such as government spending and corporate and other taxes. In reality, the tax transmission mechanism is complex and ETI estimates based on aggregate series do not lead directly to any strong conclusions about microlevel elasticities. On the other hand, macro elasticities that incorporate all these effects provide a more complete measure of the ultimate distortionary effects of marginal tax rates that is useful for evaluating tax policies in practice.

\section{Preliminary Elasticity Estimates from Basic Time Series Regressions}

Before proceeding to the main analysis, it is useful to first consider some preliminary regressions that establish that the broader coverage of the income weighted tax rate series alone does not change the key conclusions of existing studies that use similar aggregate data. Saez (2004), Saez et al. (2012) and Piketty et al. (2014) estimate aggregate elasticities in time series regressions of income (before deductions and exemptions) in levels or top income shares on net-of-tax rates and polynomials of time. Using AMTR series covering 1960-2000 and including linear and quadratic trends, Saez (2004) finds an elasticity for all tax units of 0.20 that is not statistically significant. Separate regressions by income group result in a highly significant value of 0.50 for the top $1 \%$ and zero for the bottom $99 \%$. Using the top $1 \%$ income share instead of the level and adding a cubic time trend, Saez et al. (2012) obtain a highly significant top $1 \%$ elasticity of 0.58 in the $1960-2006$ sample. Piketty et al. (2014) use series for top statutory rates from 1913 to 2008 and obtain highly significant top $1 \%$ ETIs of 0.27 and 0.30 in the level and share regressions with a linear trend. Using our extended 1946-2012 AMTR series and the same regression specifications, we obtain a tightly estimated top $1 \%$ elasticity close to 0.60 in the level and share regressions and lower insignificant values in the others. ${ }^{9}$ As in Saez (2004), we also find that instrumenting with statutory changes to avoid endogeneity related to tax progressivity has little effect on these results. Static regressions with basic time controls therefore continue to produce results in

\footnotetext{
${ }^{9}$ In the 1946-2012 sample, the Saez (2004) level regressions yield values of 0.30 for all tax units, 0.61 for the top $1 \%$ and 0.37 for the bottom $99 \%$. Only the top $1 \%$ estimate is statistically significant. The top 1\% share regression of Saez et al. (2012) yields a highly significant value of 0.59 in the full sample. As in the original papers, we used AMTRs for the federal income tax only.
} 
line with a zero or small overall response and a moderately large response at the top. The latter, remains outside of the range obtained in the short run for the 1980s reforms.

Unfortunately, there are two broad reasons why these regressions do not yield reliable estimates of the aggregate causal effect of tax rates on reported income. The first reason is the failure to account for the dynamics of tax rates and the timing of the behavioral response. The second reason is the endogeneity of tax policy decisions.

If tax rate changes are permanent, the elasticity in level regressions measures the eventual long run response and should be insensitive to timing. If tax rates changes are instead transitory, than the timing of the income response becomes very important. In reality, many tax reforms affect tax rates only temporarily by including sunset provisions or because of subsequent reforms in the opposite direction. In the extreme case where tax rates are uncorrelated over time, the regressions will detect no effects if, for instance, the income response occurs entirely in years before or after the tax change. Any measurable response is likely to be partially delayed in practice, which can lead to a downward bias in the elasticity estimate. One reason is that statutory tax changes occur throughout the year before filing, such that the full income response may not be observed until the first year following the change. In addition, tax rates may also impact on investment and other dynamic decisions with lagged effects on reported incomes. There are also good reasons to believe that income responses partially lead tax rate changes. Many statutory tax rate changes are phased in gradually over multiple years or are implemented with long delays. ${ }^{10}$ In response to future changes in marginal tax rates, forward looking agents have incentives to allocate income generating activities optimally across time. There is indeed substantial empirical evidence for such anticipatory effects to taxes. ${ }^{11}$ The sign of the bias due to tax foresight is ex ante ambiguous and depends on the relative strength of intertemporal substitution versus income effects, among other things. Regardless, the complicated intertemporal linkages between tax rates and incomes cast doubts on the results from the static regressions.

The other major concern is that OLS or IV regressions with statutory tax rate changes as instrumental variables

\footnotetext{
${ }^{10}$ This is the case for instance for the marginal rate changes under the Revenue Act of 1964, the Economic Recovery Tax Act of 1981 , the 1986 Tax Reform Act or the Economic Growth and Tax Relief Reconciliation Act of 2001. Most adjustments to social security contribution rates have been implemented with multi-year lags.

${ }^{11}$ Kueng (2014) finds evidence in municipal bond yields that financial markets forecast federal tax rates remarkably well. The public finance literature documents anticipatory effects for a number of reforms, see Saez, Slemrod and Giertz (2012). For theory and evidence of real anticipatory effects, see Yang (2005), House and Shapiro (2006), McGrattan (2012), Mertens and Ravn (2012) and Leeper, Walker and Yang (2013).
} 
do not address the endogeneity of tax policy itself. Legislative reforms have a variety of motivations that are hardly independent of other influences on incomes or income shares. Tax policy has been actively used for macroeconomic stabilization and has systematically responded to temporary changes in military spending or other budgetary needs. ${ }^{12}$ Given a relatively broad consensus for expansionary effects of government spending, see Ramey (2011b), both channels make tax rates procyclical and induce a downward bias in the elasticity estimates. ${ }^{13}$ Bracket creep also remains an important source of reverse causality. Three of the largest rounds of statutory income tax rate cuts (part of reforms in 1964, 1981 and 2001) each followed periods of substantial bracket creep and effectively restored tax rates to historical averages. ${ }^{14}$ Sectoral shifts, demographic trends, trade policies or changing political preferences are among the many other possible factors that simultaneously shape the income distribution and tax policy decisions. Static regressions with time polynomials are unlikely to control for even the most important of all of these confounding factors.

To address some of these issues, we follow Slemrod (1996) and adopt specifications that include dynamic terms, as well as a number of control variables. The reported income measures are in constant 2010 dollars per tax unit and are the same as in Piketty and Saez $(2003,2007)$. These measures include all sources of market income before deductions and exemptions but exclude realized capital gains and government transfers. The tax rates are those in Figure 1 and include federal payroll taxes. Table 2 shows results for regressions of changes in log income on changes in the log net-of-tax rate of income group $j$ :

$$
\begin{aligned}
\Delta \ln \left(\text { income }_{t}^{j}\right) & =\beta \Delta \ln \left(1-A M T R_{t}^{j}\right)+[\text { controls }]+u_{t}, \text { and } \\
\ln \left(\text { income }_{t+1}^{j}\right)-\ln \left(\text { income }_{t-1}^{j}\right) & =\gamma \Delta \ln \left(1-\text { AMTR R }_{t}^{j}\right)+[\text { controls }]+v_{t} .
\end{aligned}
$$

\footnotetext{
${ }^{12}$ The Revenue Acts of 1950 and 1951 increased taxes to finance the war efforts in Korea. The Revenue and Expenditure Control Act of 1968 imposed a temporary 10 percent surcharge to prevent the economy from overheating and finance the escalation of the Vietnam war. The Tax Relief Reconciliation Act of 2001 introduced a new 10\% low income tax bracket to cushion the economic slowdown. The vast majority of increases in social security rates fund benefit expansions. The temporary cut in contribution rates under Obama in 2011 and 2012 was motivated by the continued weakness in the US economy. See Pechman (1987) or Romer and Romer (2009) for historical background and more examples.

${ }^{13}$ Parker and Vissing-Jørgensen (2010) document the procyclicality of top income shares. Ceteris paribus, procyclical tax rates then lead to downward bias for higher incomes also in income share regressions.

${ }^{14}$ Figures 2 and 4 (lower left panels) show that, while there were no major statutory income tax increases in the 1970s, high inflation and bracket creep caused AMTRs to rise by 6 to 8 percentage points. The 1955-1963 period and the mid to late 1990s also saw no significant legislative changes but rising tax rates due to (mostly real) increases in incomes.
} 
where $\Delta$ denotes the annual difference. By using differences instead of levels, these regressions now explicitly aim for short rather than longer run elasticities. The first equation includes annual reported income and tax rate changes, whereas the second equation uses two year income growth as the regressand. To the extent a tax change persists into the subsequent year, the second regression potentially produces a more meaningful short run estimate by measuring the income response after the first full year following a tax change, see also Barro and Redlick (2011). We focus on income levels rather than income shares primarily because of the high correlations of tax rates among the income groups and all of the prior evidence that elasticities vary with income. Another reason not to use income share regressions is the potential for spill-over effects of tax rate changes for one group on incomes in others.

Panel A first presents results for the regressions in (1) and (2) without including any additional controls. This yields short run elasticities that range from 0.55 for the top $1 \%$ to -0.49 for the bottom $90 \%$ in the same year of the tax change, and elasticities of 0.84 for the top $1 \%$ to -0.52 for the bottom $90 \%$ in the following year. As before, only for top incomes is there evidence for positive elasticities that are statistically significant at conventional confidence levels. The ETIs outside the top $1 \%$ and for all tax units are generally not significantly different from zero at either horizon. For the bottom $90 \%$ and $99 \%$ the same year estimates are significantly negative, suggesting that tax rate increases lead to higher income growth in those groups. To mitigate concerns about timing and endogeneity, Panel B includes two lags of income and net-of-tax rates of group $j$, as well as a large number of other lagged macroeconomic variables as controls. ${ }^{15}$ The predetermined variables are assumed to jointly contain information about the relevant history of events before time $t$ that determine income and tax rates from time $t$ onwards. These past events include tax rate changes, announcements of future tax rate changes, cyclical and other fiscal shocks or any other relevant causal factors that continue to influence current and future income and tax rates. Panel C instruments with the statutory changes in Figure 4 to further correct for any contemporaneous influence on income that also has an effect on tax rates because of progressivity. The results in Table 2 show that adding controls and instrumenting with statutory changes each raises the point estimates relative to the simple OLS estimates. The subsequent year top $1 \%$ elasticity increases to just above one in both panels $\mathrm{B}$ and $\mathrm{C}$ and instrumentation results in some evidence for a significant effect also in the top 5 to $1 \%$. The point estimates for the bottom $99 \%$ and $90 \%$ become positive or only mildly negative but remain insignificant. The first stage F-statistics are large in all cases, which is not surprising given that

\footnotetext{
${ }^{15}$ To make a clear comparison, the control set is identical as in the vector autoregressions and local projections of Section 4 and includes two annual lags of real GDP, the unemployment rate, inflation, the federal funds rate, government spending, the change in government debt held by the public and the real stock market price, as well as dummies for 1949 and 2008.
} 
changes in AMTRs are predominantly due to statutory changes.

One conclusion from panels $\mathrm{A}, \mathrm{B}$ and $\mathrm{C}$ in Table 2 is that switching to a short run specification and including richer controls raises the top $1 \%$ ETI from 0.6 to around 1. Despite being based on the entire postwar sample, this value is now more firmly in the range of short run responses associated with the 1980s reforms, which contradicts the view that these reforms were large anomalies. At the same time, the main conclusions of Saez (2004), Saez et al. (2012) and Piketty et al. (2014) remain intact. Moving outside of the top 1\% or 5\%, the elasticities drop off sharply and are generally insignificant. Based on the results in Table 2, the evidence for a sizeable response outside the top $1 \%$ or in the aggregate appears weak or nonexistent. The relatively large short run elasticities for the top $1 \%$ also do not contradict more modest long run responses. As Slemrod $(1995,1996)$ has documented for the 1986 reform, much of the short run response at the top may be due to transitory timing and avoidance effects rather than changes in real economic activity.

The main problem is that none of the reported income regressions discussed above resolves the endogeneity of tax policy. If any of the contemporaneous influences on income, such as cyclical or budgetary shocks, also systematically influences tax policy, then reverse causality remains a concern. The next section shows how the narrative approach of Romer and Romer (2010) can be used to address the endogeneity of tax policy, and that reverse causality concerns have important implications for ETI estimates based on aggregate time series.

\section{Dynamic Estimates of the Income Response to Marginal Tax Rates}

This section presents ETI dynamic estimates from structural vector autoregressive models (SVARs) and local projections (LP). In both cases, we identify the dynamic causal effects of exogenous tax policy interventions using narrative measures of exogenous variation in MTRs as a proxy variablelexternal instrument for policy shocks. Following Stock and Watson (2017), we refer to the joint use of SVAR or LP estimators and instrumental variables techniques as SVAR-IV and LP-IV, respectively.

The SVAR-IV/LP-IV analyses differ from univariate regressions in several ways. First, both approaches emphasize the need for including a sufficiently rich set of lagged macroeconomic controls to isolate unanticipated variation 
in both tax rates and reported income. Second, neither of the two methodologies assumes that all statutory changes in tax rates are exogenous; instead, they rely on a selection of policy reforms that are not driven by other contemporaneous events, such as recessions or wars, and that are not fully anticipated. Third, both approaches include a variety of other variables in a dynamic system, which enables the estimation of the full dynamic income effects and allows for general feedback mechanisms. In fact, both models allow us to identify the expected future trajectory of tax rates, which is important for interpreting ETI estimates. Finally, by including GDP and the unemployment rate as endogenous variables, SVAR-IV and LP-IV estimates reveal whether reported income effects are also associated with important changes in real economic activity.

\subsection{SVAR-IV Methodology}

Introduced by Sims (1980), SVARs are flexible time-series models that have been influential for evaluating the effects of monetary and fiscal policy interventions. ${ }^{16}$ Consider the following VAR representation for aggregate income and the marginal tax rate:

$$
\left[\begin{array}{c}
-\ln \left(1-\text { AMTR }_{t}\right) \\
\ln \left(\text { income }_{t}\right) \\
X_{t}
\end{array}\right]=d+A(L)\left[\begin{array}{c}
-\ln \left(1-\text { AMTR }_{t-1}\right) \\
\ln \left(\text { income }_{t-1}\right) \\
X_{t-1}
\end{array}\right]+\left[\begin{array}{c}
u_{t}^{\text {AMTR }} \\
u_{t}^{\text {income }} \\
u_{t}^{x}
\end{array}\right]
$$

where $X_{t}$ is a vector of control variables of dimension $d_{x}, A(L)$ is a $p-1$ lag polynomial and $p$ is the lag length.

The key assumption of an SVAR model is that the forecast-errors of (3) are a linear combination of a vector of structural exogenous shocks $v_{t}$; that is:

$$
\left[\begin{array}{c}
u_{t}^{A M T R} \\
u_{t}^{\text {income }} \\
u_{t}^{x}
\end{array}\right]=B v_{t}
$$

with $\mathbb{E}\left[v_{t}\right]=\mathbf{0}$ and $\mathbb{E}\left[v_{t} v_{t}^{\prime}\right]$ a diagonal matrix. We partition the vector of structural shocks as:

$$
v_{t} \equiv\left[v_{t}^{\tau},\left(v_{t}^{o}\right)^{\prime}\right]^{\prime}
$$

\footnotetext{
${ }^{16}$ See Ramey (2016) for a recent survey.
} 
where $v_{t}^{\tau}$ is a scalar shock that represents exogenous innovations in tax rates and $v_{t}^{o}$ is a vector containing all other structural shocks that affect the economy. A standard assumption is that there are (at least) as many shocks as endogenous variables: $\operatorname{dim}\left(v_{t}^{o}\right) \geq \operatorname{dim}\left(X_{t}\right)+1$. The validity of (4) is in practice determined by the selection of variables included in $X_{t}$ and the lag length $p$. An appropriate choice of $X_{t}$ and $p$ ensures that the VAR residuals correspond to unpredictable variation in the variables and therefore that all anticipated changes in marginal tax rates are controlled for.

In the SVAR model, the contemporaneous responses of average marginal tax rates, aggregate income, and control variables to exogenous changes in $v_{t}^{\tau}$ are captured by the first column of the matrix $B$, denoted $B_{1}$. We normalize $B_{1,1}=-1$, so that the baseline shock of interest is one that decreases $-\ln \left(1-\mathrm{AMTR}_{t}\right)$ in one unit upon impact, corresponding to a cut in tax rates. The $k$-th period ahead dynamic response of variable $i$ can be traced out using (3), following the formulae in Lütkepohl (1990), p. 116, equation (3).

The VAR residuals $u_{t}^{A M T R}, u_{t}^{\text {income }}$ and $u_{t}^{x}$ can be estimated by least-squares, but more assumptions are needed to identify the responses to exogenous innovations to tax rates $v_{t}^{\tau}$. The identification strategy follows exactly Mertens and $\operatorname{Ravn}(2013,2014)$ and Stock and Watson $(2008,2012)$ and relies on the availability of an proxy variable/external instrument $z_{t}$ for the latent structural tax shock $v_{t}^{\tau}$ that satisfies the identifying assumptions:

$$
\begin{array}{ll}
\mathbb{E}\left[z_{t} v_{t}^{o}\right]=\mathbf{0} & \text { (SVAR-IV exogeneity) }, \\
\mathbb{E}\left[z_{t} v_{t}^{\tau}\right]=\alpha \neq 0 & \text { (SVAR-IV relevance) } .
\end{array}
$$

The first condition states that $z_{t}$ is contemporaneously correlated with the shock to marginal tax rates $v_{t}^{\tau}$. The second condition requires $z_{t}$ to be contemporaneously uncorrelated with all other structural shocks contained in $v_{t}^{o}$. When these conditions hold, the dynamic responses to exogenous tax rates innovations are identified up to scale by the covariance between $z_{t}$ and the VAR residuals:

$$
\mathbb{E}\left[z_{t} u_{t}\right]=\alpha B_{1}
$$


with $u_{t}=\left[u_{t}^{A M T R^{\prime}}, u_{t}^{\text {income }}, u_{t}^{x \prime}\right]^{\prime}$. Thus, the variable $z_{t}$ can be used to obtain a consistent estimator of $\widehat{B}_{1}$ by regressing each of the entries of $\widehat{u}_{t}$ on $-\widehat{u}_{t}^{A M T R}$ using $z_{t}$ as an instrument. ${ }^{17}$ Section 4.3 describes the variable $z_{t}$ used to identify the dynamic responses of income and other macroeconomic variables to changes in marginal tax rates.

\subsection{LP-IV Methodology}

The LP-IV approach combines the method of local projections to estimate impulse response functions, as proposed by Jorda (2005), with the use of instrumental variables for identification. ${ }^{18}$ In contrast to the SVAR model, the local projections do not impose vector autoregressive dynamics for marginal tax rates or income.

Let $Y_{t+k}$ denote the $(t+k)$-th value of some macroeconomic variable of interest and let $W_{t}$ be a vector of control variables available at time $t$. The baseline LP-IV specification estimates the dynamic response of $Y_{t+k}$ to changes in the marginal tax rates at time $t$ is based on the model:

$$
Y_{t+k}=a+b^{\prime} W_{t}+\mathrm{IRF}_{k} \log \left(1-A M T R_{t}\right)+e_{t}
$$

By construction, the error term in (9) contains all contemporaneous, past, and future shocks that affect the best linear prediction of $Y_{t+k}$ beyond the marginal tax rate and the vector of control variables (both at time $t$ ). This interpretation compromises the typical exogeneity assumption made in linear regression models: since the AMTR is a policy variable it can respond to the present, past, and future state of the economy. Thus, the log net-of-tax rate can be correlated with the error term.

To estimate the parameter $\mathrm{IRF}_{k}$ in (9), the key assumption made in the LP-IV framework is that the random variable $z_{t}$ is an exogenous and relevant instrument for the average marginal tax rate in the conventional sense; that is:

$$
\begin{array}{lr}
\mathbb{E}\left[z_{t} e_{t}\right]=0 & \text { (LP-IV exogeneity), } \\
\mathbb{E}\left[z_{t}^{\perp} \log \left(1-A M T R_{t}\right)^{\perp}\right] \neq 0 & \text { (LP-IV relevance), }
\end{array}
$$

\footnotetext{
${ }^{17}$ The estimator of $\widehat{B}_{1}$ is thus given by $\widehat{B}_{1}=-\frac{1}{T} \sum_{t=1}^{T} z_{t} \widehat{u}_{t} / \frac{1}{T} \sum_{t=1}^{T} z_{t} \widehat{u}_{t}^{A M T R}$.

${ }^{18}$ See Ramey (2016), Ramey and Zubairy (2017), or Stock and Watson (2017) for discussions and recent applications of this approach.
} 
where $a_{t}^{\perp}$ denotes the residual of the population's best linear prediction of $a_{t}$ on a constant and the controls $W_{t}$.

Conceptually, it is possible to think of the exogeneity assumption for $z_{t}$ as imposing three different conditions. First, $z_{t}$ has to be contemporaneously exogenous. This condition requires us to focus on a subset of tax reforms that are not systematically related to other concurrent macroeconomic events. Second, $z_{t}$ has to be lag exogenous. This condition requires $z_{t}$ to be uncorrelated with all past information contained in $e_{t}$. For this condition to hold, the selection of control variables is crucial. For example, if $z_{t}$ includes tax reforms that respond to inherited deficit concerns (as it is in our case), $W_{t}$ has to be such that the past shocks that remain in $e_{t}$ are uncorrelated with $z_{t}$. Finally, $z_{t}$ has to be lead exogenous. This condition requires $z_{t}$ to be uncorrelated with future shocks to the economy. Lead exogeneity is less of a concern, as even if $z_{t}$ includes tax reforms that attempt to increase long-run growth, the structural shocks to the economy between time $t$ and time $t+k$ are, by definition, uncorrelated with any information available at time $t$. In addition to condition (10), LP-IV implicitly assumes that the controls $W_{t}$ are also exogenous in the standard sense; i.e., $\mathbb{E}\left[W_{t} e_{t}\right]=\mathbf{0}$. Such an assumption will hold, for example, whenever the data follows a vector autoregression and the vector $W_{t}$ coincides with the set of VAR right-hand-side variables.

The robustness of LP-IV models for the estimation of dynamic responses comes, however, at a price. As pointed out by Stock and Watson (2017), exogeneity of the instrument entails the potentially strong lag exogeneity assumption that is not required by SVARs: $z_{t}$ must be uncorrelated with past structural shocks that are not captured by the control variables. Assuming lag exogeneity can be avoided by assuming (4) and including all of the SVAR regressors in (3) in the LP-IV controls in $W_{t}$. However, if all predictable changes in marginal tax rates can indeed be controlled for by a vector autoregression in observables, then LP-IV estimates are not as efficient (asymptotically) as their SVAR counterparts.

\subsection{Construction of $z_{t}$ and Model Specifications}

\subsubsection{Construction of $z_{t}$}

The key step in both the SVAR-IV and LP-IV approaches is the construction of the $z_{t}$ variable used for identification. Most importantly, $z_{t}$ must satisfy the exogeneity conditions in (6) and (10), respectively, to eliminate bias due to the endogeneity of tax policy. In practice, we will proceed by assuming that all predictable changes in marginal 
tax rates are controlled for by including all of the SVAR regressors as controls in the LP-IV regressions. In that case, the SVAR requirement that $z_{t}$ is uncorrelated with all other contemporaneous macroeconomic influences is also sufficient in the LP-IV approach. To be a good proxy variable in the SVAR-IV model, $z_{t}$ must have a high correlation with the exogenous innovations in tax rates. As an instrumental variable in the LP-IV regressions, on the other hand, $z_{t}$ must correlate sufficiently strongly with the AMTR series to avoid weak instrument problems. To obtain a variable that optimally meets all of these requirements, we use new measures of the AMTR impact of a selection of historical changes to income tax rates and/or social security contributions.

The first important step in constructing $z_{t}$ is to collect instances of variation in tax rates that can reasonably be considered to be contemporaneously exogenous. Using a variety of historical sources, Romer and Romer (2009) conduct an extensive narrative analysis of all major postwar federal tax reforms. They propose a classification according to the primary motivation for the reforms into four main categories: responding to a current or planned change in government spending, offsetting other cyclical influences, addressing an inherited budget deficit, and attempting to increase long-run growth. The last two categories aim specifically at isolating tax policy changes that are not systematically related to other concurrent macroeconomic events. ${ }^{19}$ We adopt the same classification and focus on tax changes induced by all reforms affecting personal taxes that Romer and Romer (2009) classify as motivated by long-run considerations or as arising from inherited deficit concerns. All policy interventions classified by Romer and Romer (2009) as spending driven or business cycle related are omitted. In practice, this means that for instance the temporary wartime income tax hikes, the 2001 income tax cut, and the increases in social security rates funding benefit expansions are excluded. ${ }^{20}$

The second step in the construction of $z_{t}$ is to obtain measures that are highly correlated with the true surprise innovations to personal tax rates. Many of the reforms are implemented with a delay or have gradual multi-year phase-ins. To avoid policy variation with no or little element of surprise, we exclude all tax changes induced by reforms that were legislated at least one year before becoming effective. This means for instance that most rate cuts under the 1981 Economic Recovery Tax Act, which despite its name Romer and Romer (2009) view as mostly ide-

\footnotetext{
${ }^{19}$ Romer and Romer (2010) use the liability impact of tax reforms falling in these categories to identify tax multipliers. Barro and Redlick (2011) and Mertens and Ravn (2013, 2014) exploit the same classification for identifying the effects of tax policy.

${ }^{20}$ The temporary Obama payroll tax cuts postdate the Romer and Romer $(2009,2010)$ analysis but are excluded for being primarily motivated by the continuing weakness in the US economy following the 2007-2009 recession.
} 
ologically motivated, are not included in $z_{t}$. After the elimination of tax changes with delayed implementation, the selection procedure yields a total of 15 tax reforms between 1946 and 2012 with significant and immediate impact on personal tax liabilities. These reforms are listed in Table 3. The first four columns in Table 3 list the projected impact on tax liabilities according to contemporaneous official sources. Columns [1] and [3] report the liability impact due to changes in the rates and brackets of the federal individual income tax, and respectively, social security tax schedules. Columns [2] and [4] report the liability impact of other provisions without direct impact on average marginal tax rates, such as changes in deductions or coverage. Appendix A provides a description of the main provisions in each of these reforms, as well as the sources of the liability impact estimates.

The precise impact of the selected tax reforms in $z_{t}$ is measured by scoring the AMTR impact of the legislative change relative to pre-existing law. The scoring proceeds in a similar way as the calculation of the statutory component of annual changes in AMTRs shown in Figure 4. However, instead of comparing to the previous year AMTR, now the change is measured relative to the tax code that would have prevailed under prior law, i.e. in the absence of the legislative change. More precisely, the estimated impact in year $t$ of a given selected tax reform is the difference between a first counterfactual tax rate, calculated using the year $t-1$ income distribution and the current law rates and brackets deflated by any automatic adjustments between $t-1$ and $t$, and a second counterfactual tax rate based on the year $t-1$ income distribution and the prior law rates and brackets. The latter are obtained from official government publications sourced in appendix A. After scoring the tax reforms in this manner, eight out of the selected 15 tax reforms lead to a measurable change in AMTRs. These scores are shown in columns [5] to [12] in Table 3 and reflect key provisions of many of the more important reforms, such as the tax cuts of 1948 and 1964, the Tax Reform Act of 1986, the Bush-Clinton tax increases, as well as the acceleration in 2003 of earlier tax cuts. The time series $z_{t}$ for exogenous unanticipated changes in the aggregate AMTR are the scores in the years of the tax reforms shown in column [5] of Table 3, and zeros in all other years. Similarly, the time series for AMTR changes for the income subgroups consists of the scores in the corresponding columns of Table 3 in reform years, and zero in all other years.

Several features of the time series $z_{t}$ for unanticipated AMTR changes merit further discussion. First, the number of observations is small. Of the fifteen reforms listed in Table 3, eight include direct changes to the basic income tax rate schedules. The other seven selected reforms contain only provisions altering tax credits, deductions or cov- 
erage, which affect tax liabilities but do not have any direct AMTR impact, or at least not one that is easily picked up by the static scoring method. Appendix B.2 performs an analysis with an alternative instrument based on the tax liability impact of all 15 reforms, and also verifies the sensitivity to the inclusion of particular reforms such as those in the 1980s.

What is important is that the eight benchmark reforms still capture a large amount of variation in marginal tax rates. Virtually all of this variation stems from federal income tax changes. Most changes to social security rates are excluded because they fund benefit expansions and/or have long implementation lags. With only one minor exception, the reforms change AMTRs in the same direction for all income groups, but there is also some heterogeneity across reforms in the relationship between income and the size of the change. In particular, the tax changes are usually much larger for higher income taxpayers. There are six cuts in tax rates, three under Democratic and three under Republican presidents. ${ }^{21}$ There are two tax increases, one under a Democratic and the other under a Republican presidency. There is therefore no obvious relation with presidential party affiliation. Reforms lowering income tax rates are generally more frequent, which is not surprising given the lack of indexation in the tax code. Finally, the often lengthy political and legislative processes preceding tax reforms mean that the eventual marginal tax rate changes were certainly to some extent anticipated prior to their enactment. This fact does not violate the identifying assumptions since only contemporaneous exogeneity, but not lag exogeneity, with respect to other macroeconomic shocks is required. As long as there is sufficient randomness in the timing and/or size of the changes, $z_{t}$ remains a useful measure that is correlated with the underlying surprise changes.

\subsubsection{Model Specifications}

In addition to the time series for log net-of-tax rates and log income levels described earlier, the baseline SVAR-IV model includes the following set of control variables in $X_{t}:$ Log real GDP per tax unit, the unemployment rate, the $\log$ real stock market index, inflation and the federal funds rate. These variables generally capture business cycle conditions, interactions with monetary policy, as well as the effects of bracket creep. The controls $X_{t}$ further includes log real government spending per tax unit (purchases and net transfers) and the change in log real federal government debt per tax unit. These variables are included to capture interactions with other current and past fiscal

\footnotetext{
${ }^{21}$ Although the 1948 reform was passed after a Truman veto.
} 
policies, in particular since tax changes are often motivated by concerns about government deficits. ${ }^{22}$ Our baseline SVAR-IV specification is a VAR(2) for the nine endogenous variables estimated using yearly data from 1946-2012. We also include dummy variables for 1949 and 2008 as additional regressors. As mentioned earlier, the baseline LP-IV specification uses exactly the same right-hand-side variables as the SVAR-IV specification, i.e. $W_{t}$ includes two lags of income, net-of tax rates, the variables in $X_{t}$, and the dummy variables. We do not interact the dummy variables with the remaining controls, which implicitly assumes that the slope coefficients of the both the SVAR-IV and the LP-IV model are stable across the sample.

Our choice of macroeconomic controls is motivated by pre-test results indicating that the (recent) history of these variables, income and tax rates contain the most relevant information to isolate the unanticipated short run innovations in tax rates and income. Based on these variables, the VAR model is for instance quite successful in capturing many of the known pre-announced tax rate changes. ${ }^{23}$ Appendix B.2 verifies robustness to a variety of changes in the baseline specification. First, we discuss the lag structure. Standard lag selection criteria recommend one to three lags. However, inspection of the residuals indicates a minimum of two lags is required to eliminate evidence of residual autocorrelation. We use two lags in our baseline specifications, but we note that the point estimator for the short run ETI obtained under either the SVAR-IV or the LP-IV model with three lags is very similar (in both cases the confidence interval is wider, but the ETI remains significant at the 5\% level).

Second, we discuss our selection of dummy variables. The inclusion of the 1949 and 2008 dummies, both recession years, is not innocuous for the SVAR-IV results, but has virtually no impact on the LP-IV results (see the first panel of Figure B.3). The first and last few years in the sample are periods of relative macroeconomic turbulence and unusual policy variation associated with the end of WWII and the 2007-2009 financial crisis. Rather than dropping these periods from the sample, as is common practice, the dummy approach yields results that are more stable across subsamples while preserving the major 1948 tax reform as a source of identifying variation. ${ }^{24}$ We note

\footnotetext{
${ }^{22}$ Appendix A provides precise variable definitions and sources.

${ }^{23}$ Results are available on request.

${ }^{24}$ Romer and Romer (2010) and Barro and Redlick (2011) report the sensitivity to inclusion of the 1948 tax reform and use samples starting in 1950 for their main analysis. We found the results to be much more sensitive to a dummy for the 1949 recession than including the 1948 reform. See Appendix B.2 for more discussion. Mertens and Ravn (2013) also focus on the 1950-2006 sample. Saez (2004) and Saez et al. (2012) use data for 1960-2000 and 1960-2006 respectively. Our choice of including dummy variables only allows for 'breaks' in the model intercept. A more general specification would allow also for breaks in the slope parameters by interacting the dummy variable with each of the controls. This is, however, not feasible given the size of our sample.
} 
that with or without dummies, both the SVAR-IV and LP-IV estimators remain statistically significant at the 5\% level.

Finally, Appendix B.2 also discusses sensitivity to the sample choice and to alternative versions of $z_{t}$. We note that the estimated responses of log-income based on an SVAR-IV model for the 1950-2006 sample are almost identical to the results obtained in our benchmark specification. The LP-IV estimated over the same period generates different estimates, but these are larger than the benchmark at every horizon beyond impact.

\subsection{The Response of Aggregate Income to Marginal Tax Rates}

\subsubsection{Weak Instrument Concerns and Inference}

Unfortunately, the requirement of contemporaneous exogeneity of the series for $z_{t}$ is not testable since there are no overidentifying restrictions. The relevance of $z_{t}$ as proxies or instruments, on the other hand, is testable. Before turning to the main estimation results, we present formal statistical tests of the conditions in (7) and (11). Verifying these relevance assumptions is important to assess whether weak instrument problems may bias our conclusions.

In the LP-IV framework, the relevance condition in (11) is the standard one for linear IV models. In our baseline LP-IV specification with aggregate income and net-of-tax rates, the value for the first-stage F (using a Newey and West (1987) HAC-robust residual covariance matrix with 8 lags) is 229.25 for the Barro and Redlick (2011) netof-tax rate, and 62.24 for the Piketty and Saez (2003) net-of-tax rate. Both these values are well above the threshold value of 10 proposed by Stock and Yogo (2005), as well as the more stringent cutoff suggested by Montiel-Olea and Pflueger (2013), indicating that $z_{t}$ is a highly relevant instrument for marginal tax rates. Based on these results, we follow the standard 2SLS inference procedures in the LP-IV model, with Newey and West (1987) HAC-robust standard errors.

The SVAR-IV relevance condition in equation (7) is subtly different from the one in a traditional linear IV model, and we follow the inference procedures proposed in Montiel-Olea, Stock and Watson (2017). The relevant F-statistic in the SVAR-IV model, which is provided in Appendix B.1, is 11.09 for the Barro and Redlick (2011) net-of-tax rate, and 8.90 for the Piketty and Saez (2003) net-of-tax rate. The former value exceeds the Stock and Yogo (2005) thresh- 
old, while the latter is just below. ${ }^{25}$ Both values exceed the $5 \%$-level critical value of 3.84 for the null hypothesis of zero covariance between $z_{t}$ and innovations to the AMTR series. Based on these first-stage test results, we conduct inference in the SVAR-IV model using standard Delta-method confidence intervals as suggested by Montiel-Olea et al. (2017), with a Newey and West (1987) HAC-robust residual covariance matrix.

Appendix B.1 discusses a number of alternative inference procedures for both the SVAR-IV and LP-IV models, including weak-IV robust and bootstrap methods. The results show that virtually all alternative intervals for the SVAR-IV/LP-IV estimates are close to the standard confidence intervals reported in the next section, and none lead to any substantively different conclusions.

\subsubsection{Estimation Results}

The first set of results is based on models that include aggregate reported income and the Barro and Redlick (2011) aggregate net-of-tax rate. Figure 5 depicts the SVAR-IV impulse responses to a one percent increase in the aggregate net-of-tax rate identified by imposing the conditions in (6) and (7) with non-zero observations in $z_{t}$ taking on the values in column [5] of Table 3. Figure 6 shows the LP-IV impulse responses obtained using the same series as an instrumental variable. All figures also display $68 \%$ and $95 \%$ confidence intervals. The income responses are on a scale that is directly comparable to those of the time series regressions reported earlier in Table 2.

The SVAR-IV estimates in Figure 5 (top left panel) show that an unanticipated decrease in taxes has transitory effects on the average marginal tax rate. The initial decrease in the tax rate persists almost perfectly in the following year. From then onwards, the tax rate gradually reverts to the level expected prior to the shock. Although statutory changes in federal tax rates are usually legislated as permanent, the estimates imply that in expectation policy shocks are fully reversed by sunsets, subsequent reforms or bracket creep after five to six years. The estimated dynamic adjustment of tax rates has two important implications for the interpretation of the results. First, since the tax rate decrease persists almost perfectly in the following year, the one-period-after-the-shock income response provides a plausible estimate of the short run ETI associated with a full year of lower tax rates. Second, the transitory nature of changes in tax rates implies a potentially important role for timing and intertemporal substitution effects.

\footnotetext{
${ }^{25}$ We note that both values are substantially lower than those from the conventional first-stage F-test for linear IV models. This can arise because the validity of SVAR-IV and LP-IV inference relies on different high-level assumptions, see Appendix B.1 for more explanation.
} 
Reported income per tax unit (bottom left panel) reacts positively to the unanticipated decrease in the AMTR. Income rises on average by $0.71 \%$ in the year of the tax cut and by $1.37 \%$ in the following year. Both estimates are highly statistically significant, and contrast sharply with the low and insignificant estimates for the aggregate elasticities in the univariate regressions in the first column of panels A-C in Table 2. The income response remains significant at the $5 \%$ level for a full three years after the year of impact and peaks at almost $1.50 \%$ in the second. From then onwards, incomes gradually decrease to levels expected prior to the shock, although the effects appear more persistent than the decline in the AMTR. A cut in the marginal tax rate also leads to a significant increase in real GDP per capita (top right panel) and a persistent and significant decline in the unemployment rate (bottom right panel). Real GDP rises by $0.44 \%$ in the year of the cut, and by up to $0.78 \%$ two years after. The unemployment rate initially falls by 0.23 percentage points, and is 0.39 percentage points lower in the next year. Similar to the response of income reported on tax returns, the output and unemployment responses are hump-shaped and more persistent than the change in tax rates. Measured by the impulse response coefficient for the following year, the SVAR model yields a short run ETI estimate for all tax units of 1.37 , with a $95 \%$ confidence range of 0.80 to 1.94 . Importantly, the responses of GDP and unemployment indicate that the positive response of income reported to tax authorities coincides with important real effects on economic activity.

Figure 6 shows the responses from the LP-IV regressions. For comparison, the figure also depicts the SVAR point estimates as thinner lines. Because the LP-IV controls in $W_{t}$ coincide exactly with the VAR right-hand-side variables, the impact responses in the SVAR-IV and LP-IV models are numerically identical for all outcome variables. For horizons beyond zero, the estimates are different. However, the main conclusion from Figure 6 is that the LP-IV responses nevertheless remain very close to those from the SVAR-IV. The income response is hump-shaped with a similar peak of $1.54 \%$ at the same horizon, and is again highly statistically significant for three full years after the year of impact. The LP-IV estimates also confirm the finding of important real effects on economic activity. Both the GDP and unemployment responses are very similar in size and shape as those obtained in the SVAR-IV framework, and they are statistically significant for the same horizon. Again, the tax rate decrease persists almost perfectly the following year and then gradually reverts to the levels expected before the cut. The AMTR decrease is somewhat more persistent when using local projections. Measured by the impulse response coefficient in the following year, 
the LP-IV approach yields a short run ETI for all tax units of 1.19, with a 95\% confidence range of 0.45 to 1.93 .

Appendix B.2 conducts a large number of checks to assess the robustness to various specification and sample choices, and shows that the ETI estimates are not very sensitive to the inclusion of any particular tax act in the proxy/instrument, including the larger 1948, 1964 or 1980s reforms. The inclusion of the dummies is more consequential for the SVAR-IV estimates: the point estimate declines from 1.37 to 1.15 when the 2008 dummy is omitted and to 0.96 when the 1949 dummy is dropped, although the estimates remain highly significant. The dummies are less influential for the LP-IV estimates: the point estimate declines to 1.01 when the 2008 dummy is omitted, but remains 1.19 when the 1949 dummy is dropped. Restricting the sample to 1950-2012, 1950-2006 or 1960-2000 raises the SVAR-based ETIs to $1.41,1.50$ and 1.40 respectively, and the LP-IV estimates to $1.54,1.80$ and 1.57 , respectively. In all these cases, the estimates remain highly significant. Using the AMTR series based on the Piketty and Saez (2003) income concept, or the series that only captures the federal income taxes, also yields somewhat larger ETI estimates. Appendix B.2 also documents similar results for two alternative series for $z_{t}$ based on official estimates of the tax liability impact of the full set of 15 tax reforms. One source of concern is that the selected tax reforms are systematically correlated with other policy changes. There is little historical or empirical evidence of correlation with spending changes, see Romer and Romer (2010) or Mertens and Ravn (2013), but changes in personal tax rates occasionally coincide with changes to corporate taxes in the same direction. An extended SVAR model that controls for simultaneous changes in corporate taxes using the methodology of Mertens and Ravn (2013) results in a similar ETI estimate of 1.35. Various additions to the set of control variables also have no major impact and all SVAR/LP-IV point estimates remain similar in size and highly statistically significant.

\subsection{The Response to Marginal Tax Rates: Different Income Groups and Income Sources}

According to the evidence in the previous sections, aggregate reported income and real GDP rise significantly following persistent but transitory cuts in marginal tax rates, and unemployment falls. We now provide additional evidence on the sensitivity of income to marginal tax rates by income groups and income source.

One way of assessing how ETIs differ across income groups is by estimating separate SVAR/LP-IV models for each income group. The results are shown in Figure 7. The methodology for estimating the SVAR-IV responses 
in the left panel of Figure 7 is the same as for the aggregate SVAR in the previous section, but the net-of-tax rate and income series for all tax units are replaced with the corresponding series for each income group. The impulse responses are identified by imposing the conditions in (6) and (7) using the corresponding income specific series for $z_{t}$ based on the values in columns [6] to [12] in Table 3. The LP-IV estimates in the right panel are obtained analogously using conditions (10) and (11). Both approaches identify ETIs associated with unanticipated changes in group specific tax rates. Given the high correlation between tax rate changes implemented by the reforms, it is important to keep in mind that the resulting estimates will also reflect effects from correlated tax rate changes for other income groups. It is possible to identify the effects of income group specific tax shocks in isolation, and we will pursue this avenue in Section 5.2 below. $^{26}$

As can be seen in Figure 7, the estimated ETIs for the individual subgroups are positive at all horizons considered. The income responses are very similarly hump-shaped across income groups, peaking at values ranging from around 0.8 for the top $10-5 \%$ bracket up to 1.5 for the top $1 \%$ bracket. The top $1 \%$ elasticities are consistently the highest, but the elasticities are also large for all other income groups. Panel A in Table 4 reports the first two SVAR-IV impulse responses coefficients for each income group, corresponding to the same and following year tax elasticities, together with the confidence intervals. The top $1 \%$ elasticities are highly statistically significant, with a following year estimate of 1.35. In sharp contrast to the results of the initial regressions in panels A-C of Table 2, the SVAR-IV identified elasticities are also large and statistically significant at income levels outside of the top $1 \%$. The following year elasticities for the top 5-1\% and top 10-5\% are 0.91 and 0.79 , while the bottom $99 \%$ and $90 \%$ elasticities are 1.01 and 0.98 , respectively. ${ }^{27}$ Panel A in Table 5 reports the LP-IV estimates. Just as for the aggregate results, the ETIs for the bottom 90\%-99\% are slightly below those obtained from the SVAR-IV model, while those for the top 1, 5 and $10 \%$ are about the same. The confidence intervals are wider, and the evidence for statistical significance in the bottom groups is weaker. If the VAR model is indeed correctly specified, this is not surprising as the LP-IV estimators are in that case less efficient. Both Tables 4 and 5 also report the F-statistics associated with tests for the relevance assumptions, see Section 4.4.1. Because in a few cases the test results indicate possible weak

\footnotetext{
${ }^{26}$ Another strategy would be to study income shares or income differences between groups. Such a strategy, however, does not produce meaningful results if indeed the ETIs vary with income or if there are spill over effects, evidence for which we find in Section 5.2.

${ }^{27}$ Note that in Table 4 the ETIs by income group are all below and therefore seemingly inconsistent with the estimates for all tax units in the first two columns. This, however, is because the distribution of the cuts across income groups, as well as the associated change in the AMTR for all tax units, will differ for every estimate. The implied decline in aggregate net-of-tax-rate is not equal to a one-percent decrease in the aggregate net-of-tax rate as in the first two columns of Table 4.
} 
IV problems, Appendix B.1 provides alternative weak-instrument robust confidence intervals, without substantive changes in the conclusions.

Taken together, the income-specific SVAR/LP-IV estimates contradict the conclusions in Saez (2004) or Saez et al. (2012), and provide clear evidence for responses to tax rates that extend well beyond the highest incomes alone. Consistent with the existing evidence, however, the estimated ETIs do remain larger for top incomes. Besides possible heterogeneity in real substitution behavior, one possibility is that the smaller tax rate changes for lower incomes do not always incur sufficient utility losses to induce changes in behavior, see Chetty (2012). Another explanation is that taxpayers with higher incomes have greater access to avoidance opportunities. If this is the case, than the finding of more broad-based income responses is a further indication of real economic effects of tax changes. We verified that our conclusions regarding the income group-specific ETI estimates are not sensitive to the inclusion of any specific tax reforms in the $z_{t}$ variables. ${ }^{28}$

To gain further insight into the nature of the income response and the role of avoidance, Figure 8 shows the responses of different sources of income based on the data provided by Piketty and Saez (2003). The income measure studied so far is real market income per tax unit excluding realized capital gains. Figure 8 shows the SVAR/LP-IV responses of the wage and non-wage subcomponents of this measure. Non-wage income includes entrepreneurial income (S-corporation, partnership and sole proprietorship profits), rents, dividends and interest, and accounts for about $15 \%$ of reported income on average. The figure additionally shows the responses of broader measures of total market and non-wage income that also include the realized capital gains reported on tax returns. Capital gains in the US, on average around $5 \%$ of income, are taxed at a different rate, and the response of incomes that include capital gains provides insight into the potential shifting of income between capital gains and other income as an avoidance strategy. The SVAR-IV responses of the new income measures are obtained from separate SVAR models that are the same as before, but add the new income variable of interest as an additional endogenous variable. The LP-IV responses are obtained analogously, adding two lags of the additional income variable to the controls.

Figure 8 shows that both wage and non-wage sources of income react positively to the transitory but persistent

\footnotetext{
${ }^{28}$ One exception is the 1964 reform. When omitted, the bottom $99 \%$ and $90 \%$ ETIs are reduced to 0.71 and 0.51 , respectively. The ETI estimates for all tax units and for top tax units, on the other hand, remain very similar. Results are available on request.
} 
decrease in marginal tax rates. There are, however, some notable differences in the size and shape of the income responses. Wage income, which reacts in a hump-shaped fashion with peaks of 1.19\% (SVAR-IV) and 1.29\% (LPIV) in the third full year after the year of impact, is less elastic than non-wage income (excluding capital gains), which shows a peak increase of $3.29 \%$ in the following year using SVAR-IV, and of $2.76 \%$ one year later using LP-IV. The rise in reported non-wage sources of income is more transitory than the reaction of wage income, which is more delayed and persistent. Once marginal tax rates have returned to previous levels in the fifth year after the tax cut (see Figure 5), the increase in non-wage income has dissipated entirely. The first column in Panels B and C of Tables 4 and 5 reports the first two impulse responses coefficients for wage and non-wage income for all tax units. The short-run aggregate wage and non-wage income responses are each highly statistically significant. Based on the following year impact, the short run SVAR-IV elasticity of wage income is 0.94 , which is significant at the $1 \%$ level. The second-year SVAR-IV elasticity of non-wage income for all tax units is 3.29 and is also significant at the $1 \%$ level. The corresponding LP-IV estimates are 0.81 and 2.93, respectively. The former is significant at the $10 \%$ level, the latter at the $1 \%$ level.

The results in Figure 8 clearly show that reported aggregate non-wage income is especially responsive to taxes. This may be due to real substitution effects, but potentially also to the fact that non-wage sources of income are generally easier to time or conceal. To the extent it is less prone to avoidance effects, the significant rise in wage income provides a stronger indication for a real economic response to tax rates. Nevertheless, certain taxpayers with high incomes may still have considerable scope to shift labor income without any associated real change in income generating activities, see e.g. Slemrod $(1995,1996)$. The remaining columns in Panels B and C of Tables 4 and 5 report the elasticities of wage and non-wage income for different income groups. ${ }^{29}$ As before, these are obtained from separate SVAR/LP-IVs in which the series for all tax units are replaced with the corresponding series for each income group. Interestingly, the elasticities of wage income are the largest for the top $1 \%$ and bottom $90 \%$ brackets, and equal 0.96 and 0.90 in the SVAR-IV model, respectively. The sensitivity of bottom $90 \%$ wage income is probably the least likely to be due to avoidance effects. Moreover, the statistically significant response of bottom 90\% wage income is also consistent with the impact on unemployment in Figures 5 and 6. The following-year wage

\footnotetext{
${ }^{29}$ The wage share is decreasing in income, and is on average $44 \%$ for the Top $1 \%$, $73 \%$ for the Top 5-1\%, $86 \%$ for the Top $10-5 \%$, and $0.87 \%$ for the Bottom $90 \%$ (as a fraction of total market income including capital gains). The realized capital gains share is increasing in income, and is on average $13 \%$ for the Top 1\%, $5 \%$ for the Top 5-1\%, 2\% for the Top 10-5\%, and 3\% for the Bottom $90 \%$ (as a fraction of total market income including capital gains).
} 
income SVAR-IV elasticities are considerably smaller for the brackets in between, with values for the top 5-1\% and top $10-5 \%$ of 0.14 and 0.63 , respectively. Moreover, only the latter is statistically significant. For every income group except the bottom $90 \%$, the elasticity of non-wage income is much larger than the elasticity of wage income. Interestingly, whereas wage income in the top $5-1 \%$ is essentially unresponsive, non-wage income in this group is the most sensitive to taxes of all income groups. The short-run SVAR-IV elasticities of non-wage income are statistically significant for all income groups within the top 5\%, but insignificant outside of the top 5\%. Once again, the corresponding LP-IV estimates in Table 5 display very similar patterns. The confidence bands are generally wider, and sometimes considerably so. In sum, there appears to be considerable heterogeneity in the type of income that is sensitive to tax rates: exclusively wage income for the bottom $90 \%$, and exclusively non-wage income for the top $5-1 \%$. For the other income groups, it is a combination of both.

Finally, we discuss the role of income shifting between capital gains and other income. Figure 8 shows that total income and non-wage income both increase regardless of whether realized capital gains are included. The impact responses become somewhat smaller, which provides some evidence for income shifting in the initial year of the tax cut. However, in subsequent years the income responses become larger. Overall, including realized capital gains has no major implications for the aggregate ETI estimates, which remain similar in size and highly statistically significant. Looking at individual income groups, however, there are more substantial differences that are suggestive of income shifting by high income tax payers. Panels D and E of Tables 4 and 5 report the elasticities of total income and non-wage income after including realized capital gains. For the top income groups, the inclusion of capital gains reduces the ETI estimates, while the opposite is the case for the bottom 90\% group. For the non-wage income elasticities, similar results hold. Drawing firm conclusions is complicated by the fact that including the highly volatile capital gains data often widens the confidence intervals considerably. Whereas the implications for aggregates appear to be minor, including capital gains does flatten the ETI-income profile to the point where the ETIs become more similar in size across income groups.

\subsection{Discussion and Comparison with Earlier Evidence}

The evidence for large ETIs and real economic responses to taxes is not an artifact of the use of VAR or LP techniques widely used in macroeconomics. Instead, the main reason for the discrepancy with the time series evidence from 
public finance is the IV step based on the selection of tax reforms by Romer and Romer $(2009,2010)$ to address the endogeneity of tax policy. To make this unambiguous, panel D in Table 2 reports additional 2SLS estimates for the original regressions of income growth on net-of-tax rate changes, but using only the Romer and Romer (2009, 2010) selection of exogenous reforms as a instrument. The regressions, which are conceptually similar to those in Barro and Redlick (2011), include exactly the same controls as in panels B and C of the same table, and also as in panel A of Tables 4 and 5. The only difference with the previous regressions with controls in Table 2 is the instrument used for changes in tax rates, which are now the same $z_{t}$ variables as in the SVAR/LP-IV models.

The 2SLS estimates in panel D of Table 2 confirm the large ETIs and establish the importance of accounting for the endogeneity of tax policy. The estimates are, in fact, numerically identical to those from the LP-IV regressions that use the levels of income and net-of-tax rates (panel Table A of Table 5). This equivalence is due to the fact that the controls in the difference regressions are the same and include the levels of these variables. Comparing the various panels in Tables 2, it is clear that each of the steps undertaken to control for confounding factors has the largest effects for the lower income groups. For the bottom 90\%, adding the predetermined variables raises the elasticity from -0.52 to zero. Instrumenting with all statutory changes increases the ETI to 0.36, while instrumenting with the exogenous tax rate changes brings the estimate up to 0.79 . The same steps raise the top $1 \%$ elasticity by a smaller amount, from 0.84 into the $1.30-1.40$ range. The likely explanation is simply that the fraction of endogenous variation in tax rates is decreasing in income. Federal income tax policy interventions, in practice the dominant source of useful identifying variation, explain a larger fraction of the tax rate variation at the top, see Table 1, and the same is true for the exogenous measures in Table 3. Measured by the $R^{2}$ coefficient, the $z_{t}$ series in columns [5] to [12] in Table 3 explain $48 \%$ of the variation in all statutory changes for the top $1 \%$ but this decreases with income to $25 \%$ for the bottom $90 \%$. This indicates that cyclical and spending motivated policy changes are relatively more important for lower incomes. Another contributing factor is that top marginal rates are much more insulated from bracket creep.

The size of the real economic responses estimated in the SVAR/LP-IV models is in a range consistent with many previous findings in the macro and labor supply literatures. The GDP impact is roughly consistent with those in Romer and Romer (2010) and Mertens and Ravn (2013) after rescaling from net-of-marginal rates to the average rate measures used in these papers. The GDP response is about twice as large as the one found by Barro and Redlick 
(2011), but this may be due to any of several differences in specification or because their estimate omits the same year growth impact. Following Barro and Redlick (2011) and assuming a labor elasticity of output of one, the second year GDP response suggests a value for the elasticity of aggregate hours of 0.78 . Evaluated at the mean unemployment rate in the sample, the unemployment response suggest an extensive labor supply elasticity of 0.41 . Taking the difference yields an intensive labor supply elasticity of 0.37 . Based on the summary of the quasi-experimental evidence on the labor supply response to taxes, Chetty, Guren, Manoli and Weber (2013) consider values of 0.3 to 0.5 for the intensive margin and a value of 0.25 for the extensive margin as plausible. Our estimates are therefore consistent with the labor supply evidence on the intensive margin elasticity, while the extensive elasticity is perhaps moderately higher.

Taking a simple average of the SVAR/LP-IV estimates of the (following year) ETIs and each of the aggregate AMTR measures yields a value of approximately 1.2 for all tax units. Since the estimates from numerous variations in specification reported in Appendix B.2 also average to a similar value, we take 1.2 as our baseline estimate of the aggregate ETI. This number should be interpreted as the short-run macro elasticity associated with a persistent but transitory change in average marginal tax rates that incorporates general equilibrium effects, as well as intertemporal substitution effects. There obviously remains considerable uncertainty associated with the estimate, as the confidence intervals still cover a relatively wide range of values. This is unavoidable given the sample size and the extent of the postwar variation in marginal tax rates that can plausibly be classified as exogenous.

\section{Additional Evidence for Real Responses to Marginal Tax Rates}

The evidence for real economic effects of taxes remains open to several interpretations. Innovations in marginal tax rates simultaneously induce changes in after tax incomes. The stimulative effects on income and employment may therefore operate primarily through demand-side multiplier effects rather than direct effects on individual incentives. The disaggregated ETI estimates show significant responses across income groups, but these incorporate the effects of correlated tax rate changes among a large fraction of tax payers. It is therefore for instance not clear whether a tax reform targeting top incomes alone would also have important real economic effects. This section presents additional evidence for more specific counterfactual tax experiments to answer these questions. 


\subsection{Average versus Marginal Tax Rates}

The Romer and Romer (2009, 2010) classification of postwar tax changes yields, after eliminating those with delayed implementation, a total of fifteen plausible instances of tax policy 'shocks', see Table 3. The results so far are based on a subset of eight of those instances corresponding to tax reforms with a direct impact on AMTRs through changes in statutory rate schedules. The other seven tax policy changes had nontrivial effects on average tax rates but did not alter the basic marginal rate schedules relative to prior law. Through modifications to tax credits, exemptions, deductions or coverage, the impact on average marginal tax rates of these policy changes is either zero or smaller and more indirect. This section extends the SVAR-IV model to make use of these additional policy shocks for identification. In addition to the series $z_{t}$ for shocks to the AMTR for all tax units used in Section 4.4, the identification strategy relies on an additional time series for shocks to average tax rates. The approach exploits the historical variation in the impact on average and marginal rates across tax reforms to isolate the effects of average and marginal tax rate changes. The results provide insights into the importance of traditional multiplier effects for explaining the income response to tax rate changes.

The SVAR specification is identical to Section 4.4, but now also includes the (log) average tax rate, or ATR, as an additional endogenous variable, defined as total revenue and contributions as a ratio of the Piketty and Saez (2003) measure of aggregate market income. ${ }^{30}$ Consider a vector containing the exogenous structural innovations to the AMTR and the ATR, $\bar{v}_{t}^{\tau}=\left[v_{t}^{A M T R}, v_{t}^{A T R}\right]^{\prime}$ with $\mathbb{E}\left[\bar{v}_{t}^{\tau}\right]=\mathbf{0}$. Let $v_{t}^{o}$ be the vector containing all other structural shocks that affect the economy, which we now assume has a dimension equal to the number of variables less the two tax policy shocks. Denoting the vector of marginal and average tax rate proxies by $\bar{z}_{t}$, the identifying assumptions are:

$$
\begin{aligned}
& \mathbb{E}\left[\bar{z}_{t} v_{t}^{O \prime}\right]=\mathbf{0} \\
& \mathbb{E}\left[\bar{z}_{t} \bar{v}_{t}^{\tau \prime}\right]=\Phi
\end{aligned}
$$

where $\Phi$ is an unknown nonsingular $2 \times 2$ matrix. As before, the first condition imposes contemporaneous exogeneity of the tax policy changes and is motivated by Romer and Romer (2009)'s narrative analysis. The second condition

\footnotetext{
${ }^{30}$ See appendix A for the precise definition.
} 
states that the two measures of shocks to average and marginal rates (collected in $\bar{z}_{t}$ ) are contemporaneously correlated with the true exogenous surprise innovations. Conditions (12) and (13) do not suffice to identify the dynamic responses to AMTR and ATR exogenous shocks separately. However, as shown in Mertens and Ravn (2014), it is possible to introduce an additional restriction on the responses of AMTR or ATR to identify the causal effects of meaningful counterfactual tax experiments.

Using equations (3) and (4) and adding the ATR as an additional endogenous variable, we can express the tax rates residuals $u_{t}^{A M T R}$ and $u_{t}^{A T R}$ in the VAR(2) of Section 4 as the bivariate system of simultaneous equations:

$$
C\left[\begin{array}{c}
u_{t}^{A M T R} \\
u_{t}^{A T R}
\end{array}\right]=D\left[\begin{array}{c}
u_{t}^{\text {income }} \\
u_{t}^{x}
\end{array}\right]+\left[\begin{array}{c}
v_{t}^{A M T R} \\
v_{t}^{A T R}
\end{array}\right]
$$

where $C$ is a $2 \times 2$ nonsingular matrix and $D$ is $2 \times\left(d_{x}+1\right)$ matrix. The conditions (12) and (13) identify $C^{\prime} C$ and $C^{-1} D$, which is one condition too few to pin down $C$ and $D$. However, there are two additional restrictions on the AMTR and ATR responses that can be imposed consecutively and that are particularly meaningful.

Consider first the zero restriction $C_{2,1}=0$. This upper triangular restriction on $C$ yields the response to an unanticipated counterfactual tax reform that, after controlling for current and lagged values of $i_{\text {come }}, X_{t}$, as well as for lags of the tax rate variables, affects marginal rates but has no impact on statutory average tax rates. The associated income response is therefore due to a change in marginal rates, since any direct effect of marginal tax rates on average tax rates in equation (14) is restricted to be zero on impact. The Tax Reform Act of 1986, with large marginal rate reductions accompanied by various revenue enhancing provisions, is probably the closest historical equivalent of this type of tax experiment. The upper triangular restriction $C_{2,1}=0$ also identifies that response to an unexpected change in the average tax rate, but allowing for impact on the statutory marginal rates.

Consider next the zero restriction $C_{1,2}=0$. This lower triangular restriction on $C$ corresponds to a counterfactual tax reform that changes average tax rates but leaves statutory marginal rates unchanged. The associated income response is likely to be predominantly generated by changes in disposable income and multiplier effects rather than direct incentive effects, since at least on impact the statutory effect on marginal tax rates is imposed to be zero. Many 
of the postwar tax policy interventions are of this type. The lower triangular restriction $C_{1,2}=0$ also identifies that response to an unexpected change in the marginal tax rate, but allowing for impact on the statutory average rate.

The additional proxy for average tax rates used for identification is the sum of columns [1] to [4] in Table 3 as a ratio of total reported market income in the previous year, which yields an annual version of the quarterly narrative measures of legislative changes in federal individual income and payroll taxes described in Mertens and Ravn (2013). Similar to Romer and Romer (2010), innovations to average tax rates are measured by dividing the ex ante estimated impact of the selected tax reforms on tax liabilities by (previous year) total income. The tax liability impact estimates are obtained from official contemporaneous government sources such as the Joint Committee on Taxation or the Congressional Budget Office. Appendix A provides the numbers and source documents, and Figure 9 presents a scatter plot of the ATR and AMTR proxies. Unsurprisingly, the correlation between the average and marginal tax rate impact of the tax reforms is high, and equals 0.90 . In fact, the ATR changes from the 15 reforms can be successfully used as an alternative relevant instrument for identifying impulse responses as in the previous Section. ${ }^{31}$ It is important to emphasize that the identification approach in this Section does not require both proxies to be uncorrelated, i.e. we do not impose that the matrix $\Phi$ in the condition (12) is diagonal. The identification scheme instead exploits the variation in the ATR/AMTR impacts across the reforms, as well as the presence of reforms without direct adjustments to the rate schedule (labeled as 'without AMTR impact'). The regression line in Figure 9 is steeper than the 45 degree line, which means that tax reforms making adjustments to the rate schedule (labeled as 'with AMTR impact') typically induce larger changes in AMTRs than in ATRs. As mentioned before, the Tax Reform Act of 1986 is the most notable case of a reform with a large AMTR impact relative to the ATR impact.

Figure 10 depicts the dynamic responses to the counterfactual tax experiments, together with $68 \%$ and $95 \%$ Deltamethod confidence bands. For a clear comparison, Panel A first reports the case of a marginal tax rate shock that does allow for impact on the statutory average tax rate $\left(C_{1,2}=0\right)$. Panel A establishes that including the average tax rate in the VAR system, and using all fifteen exogenous reforms listed in Table 3, does not substantively alter the earlier results. The income response to an increase in the net-of-tax rate of one percent is very similar in size to Figure 5 and remains significant. Including the exogenous reforms without direct marginal rate provisions does not lead to tighter estimates and, partly because of the larger system, the confidence bands are slightly wider than in the

\footnotetext{
${ }^{31}$ Columns [23] in Tables B.3 and B.4 of the Appendix show this yields very similar ETI estimates.
} 
benchmark model. Not surprisingly, the average tax rate declines following a marginal rate cut.

Panel B in Figure 10 depicts the response to a marginal tax rate cut of the same size but now without any statutory change in the average tax rate $\left(C_{2,1}=0\right)$. The associated response of income is very similar to Panel A and the benchmark estimates, and is highly significant. The average tax rate still declines as a result of the estimated net feedback from incomes and the variables in $X_{t}$, but the decline is much smaller and, in contrast to Panel A, not statistically significant.

Finally, Panel $\mathrm{C}$ shows the response to a one percent average tax rate cut imposing no statutory impact on the AMTR $\left(C_{1,2}=0\right)$. Even after allowing for indirect endogenous feedback, the response of the AMTR remains close to zero throughout. The main finding is that, in sharp contrast to the results for marginal tax rate changes after controlling for average tax rates, there is no evidence that income responds strongly to average tax rate changes once marginal rate changes are controlled for. The point estimates are in fact slightly negative, although they are not statistically significant at any horizon.

The findings in panel $\mathrm{B}$ and $\mathrm{C}$ of Figure 10 indicate that the large tax elasticities of income are not explained by strong multiplier effects due to changes in after tax incomes. The results are instead much more consistent with theoretical models that include direct incentive effects and forward looking substitution behavior. Based on a comparison of the regression coefficients on AMTR changes and the Romer and Romer (2009, 2010) series, Barro and Redlick (2011) arrive at the same conclusion. The methodology above, which is the same as used by Mertens and Ravn (2013) to separate the impacts of personal and corporate taxes, is in principle better suited for isolating the causal effects of average and marginal tax rates. The results in Figure 10 also reveal that it is the subset of Romer and Romer (2009) reforms with direct AMTR impact that is responsible for the finding of real economic effects of tax policy shocks in the macro studies. Another implication is that measures of marginal tax rates are more relevant and informative indicators of tax policy than the average tax rate measures that are more frequently used in macroeconometric studies. In terms of policy implications, an important qualification is, however, in order. Because many lower income households face no federal income tax liabilities, the results may not be that informative about policies that more strongly affect disposable incomes of those lower in the income distribution. Nonetheless, the results in 
Figure 10 clearly emphasize the importance of marginal tax rates in explaining the evidence for the real economic effects of tax reforms.

\subsection{The Effects of Cutting Top or Bottom Marginal Tax Rates}

Many of the postwar tax reforms have made particularly large changes in top marginal tax rates, and these changes also account for an important fraction of the AMTR changes for all tax units. This section exploits the idiosyncratic variation in tax rates for different income groups to estimate the effects of hypothetical tax reforms that only alters marginal tax rates for a subgroup of taxpayers. The associated responses thus differ from those reported in Section 4.5, which did not control for simultaneous tax changes outside of the own income group. Isolating the causal effects of more targeted marginal rate changes is potentially informative about general equilibrium and spill-over effects. It is for instance less likely that top marginal rate changes directly generate a large demand stimulus. Focusing on top rate changes in isolation also fits into recent policy discussions on optimal tax rates at the top, see e.g. Diamond and Saez (2011), and provides insight into possible explanations for the correlation between top marginal tax rates and top $1 \%$ income shares documented by Piketty et al. (2014) for the US and other OECD countries.

The key empirical challenge is to control for simultaneous exogenous changes in tax rates across income groups, while at the same time preserving all endogenous feedback that arises because of changes in relative incomes, bracket creep, etc. We address this challenge in exactly the same fashion as in the previous section isolating the separate effects of average and marginal tax rates. The results are derived from an SVAR-IV model identical to Section 4.4 but with two modifications. First, the aggregate AMTR and income series are replaced with the corresponding separate series for the top $1 \%$ and bottom 99\%. Second, following Saez (2004) and Saez et al. (2012), we include linear and quadratic time trends to capture longer run trends in income inequality. ${ }^{32}$ The identification strategy relies on the joint use of the proxies for shocks to the top 1\% and bottom 99\% AMTRs given in columns [6] and [11] of Table 3.

\footnotetext{
${ }^{32}$ Appendix B.2 shows that including the same time trends in the SVAR/LP-IV model for aggregate income of Section 4.4 does not have any important effects.
} 
The conditions in (12) and (13) and an additional zero restriction identify the coefficients in

$$
C\left[\begin{array}{c}
u_{t}^{\text {top } 1 \% \text { AMTR }} \\
u_{t}^{b t m} 99 \% \text { AMTR }
\end{array}\right]=D\left[\begin{array}{c}
u_{t}^{\text {top } 1 \% \text { income }} \\
u_{t}^{\text {btm } 99 \% \text { income }} \\
u_{t}^{x}
\end{array}\right]+\left[\begin{array}{c}
v_{t}^{\text {top } 1 \%} \\
v_{t}^{b t m} 99 \%
\end{array}\right]
$$

where the $u_{t}$ 's denotes the tax rate and income residuals. Imposing the upper triangular restriction $C_{2,1}=0$ identifies the response to an unanticipated counterfactual tax reform for the top $1 \%$ without any statutory change in rates for the bottom $99 \%$. Imposing $C_{1,2}=0$ identifies the response to a shock to bottom $99 \%$ rates without any statutory change for the top $1 \%$.

Figure 10 displays the dynamic response to a targeted one percent rise in the net-of-tax rate of the top $1 \%$, as well as the associated $68 \%$ and $95 \%$ confidence bands. The upper left panel shows that the top marginal rate shock causes a persistent but transitory decrease in the top $1 \%$ tax rate. The increase is more persistent than in the case of an aggregate tax shock, which not only appears consistent with postwar policy decisions regarding top rates but may also partly reflects that bracket creep is less relevant at the top of the income distribution. The upper right panel shows that, after allowing for endogenous feedback, the response of the bottom 99\% AMTR remains close to zero at all horizons. This justifies interpreting the results beyond the impact period as also originating exclusively with top marginal rate changes.

The panels in the second row of Figure 11 provide the responses of average incomes of both groups. The left panel in the first row shows that the targeted tax cut leads to a significant increase in top $1 \%$ incomes, which rises by $1.51 \%$ on impact and by $1.57 \%$ in the following year, after which there is a gradual decline. The response is significant at the $5 \%$ level on impact, as well as for the two subsequent years. The following-year response is similar and even slightly larger than those estimated earlier in Section 4.5. The rise in top 1\% incomes is, however, more transitory than in Section 4.5, and also more transitory than the aggregate income response in Section 4.4. Short run ETIs for top incomes as large as 1.5 are similar to those initially found by Lindsey (1987) and Feldstein (1995) for the 1980s reforms, which made the largest changes to top statutory rates. Romer and Romer (2014) also focus on top rate changes and control for tax rate changes for lower income groups by focusing on the interwar period, during which 
only households with the highest incomes effectively paid income taxes. In diff-in-diff regressions using thin slices at the top of the income distribution, Romer and Romer (2014) find much smaller short run elasticities of around 0.2. Whether this is due to differences between the pre- and postwar federal tax codes, the diff-in-diff strategy, the persistence of the tax rate changes, data quality, or other factors is not clear.

According to the right panel in the second row of Figure 11, a cut in top rates has a positive effect on lower incomes. Average incomes of the bottom $99 \%$ rise by $0.23 \%$ on impact and by up to $0.44 \%$ in the following year. The positive spill over effect is significant at the $5 \%$ level in the first and second year after the year of the tax cut. Nonetheless, the top marginal rate cut unambiguously leads to greater inequality in pre-tax incomes. The results are therefore consistent with the correlation between top statutory rates and top income shares observed in the US and internationally. Piketty, Saez and Stantcheva (2014) propose a causal explanation for this correlation beyond classical incentive or avoidance effects: lower top marginal tax rates lead to more aggressive rent-seeking efforts by agents with the highest incomes. Avoidance or rent-seeking channels alone would imply zero or negative spill overs from a top rate cut onto incomes outside the top. The positive impact on lower incomes does not invalidate these channels, but suggests a dominant role for classical incentive effects. At least at this level of aggregation, the finding of spill over effects also raises concerns with the interpretation of ETI estimates obtained using income shares or income differences.

The bottom row of Figure 11 presents the response of GDP and the unemployment rate. The cut in the top $1 \%$ AMTR leads to an increase in real GDP of $0.26 \%$ on impact and of $0.30 \%$ in the following year. Although the rise in GDP is only marginally statistically significant, it nonetheless suggests that the positive top income response does not result exclusively from avoidance or rent-seeking behavior. The finding that a top marginal rate cut leads to increases in aggregate economic activity is corroborated by the unemployment response in the bottom right panel of Figure 11, which shows that the unemployment rate is persistently lower by up to 17 basis points in the following years. This decline is significant at the $5 \%$ level for the following year and the next. The positive spill over effects on lower incomes may therefore be to an important extent driven by net job creation.

Figure 12 depicts the estimated effects of the reverse experiment of a targeted cut in marginal tax rates for the 
bottom 99\%. The right panel in the first row shows that the tax cut leads to a persistent but transitory decrease in the bottom 99\% AMTR. The top 1\% AMTR is higher on impact and from the third period onwards, but its response is very imprecisely estimated. The right panel in the second row of Figure 12 shows that bottom $99 \%$ incomes respond positively to the targeted tax cut, rising by up to $2.1 \%$ in the third and fourth year after impact. There is, however, a sharp difference in timing compared to the top 1\% income response to its own AMTR in Figure 11. Bottom 99\% incomes show approximately no response in the short run, but increase only from the second year after the tax cut onwards. In contrast, the top $1 \%$ income response in Figure 11 is immediate and more transitory. The effect of a bottom $99 \%$ tax cut on top $1 \%$ incomes is ambiguous, negative in the first two years and positive afterwards, and has very wide confidence bands. The eventual increase in income is highly statistically significant for the bottom $99 \%$, but insignificant for the top $1 \%$. The impact decrease in top $1 \%$ incomes is marginally significant at the $5 \%$ level.

Finally, the bottom row of Figure 12 shows the response of GDP and the unemployment rate after a targeted tax cut for taxpayers outside of the top 1\%. The cut in bottom $99 \%$ tax rates leads to an increase in real GDP of up to $1.63 \%$ in the third year after impact, while the unemployment rate declines by up to 0.53 percentage points in the same period. The timing of these responses is similar to the reaction of bottom $99 \%$ incomes, and shows a substantial delay relative to the more immediate real effects estimated for a top $1 \%$ tax cut in Figure 12 . Unsurprisingly, the aggregate GDP and unemployment responses to a one percent cut in the net-of-tax rate for the bottom $99 \%$ are much larger than to a narrower cut for only the top $1 \%$. They are also considerably larger than to a one percent cut in the net-of-tax rate for all tax units, see Figure 5, which reflects the larger and more idiosyncratic variability in top tax rates in the postwar period. The difference in timing suggest that are important differences in the transmission mechanisms of cuts in top or bottom tax rates. As documented above, the typical unanticipated US tax reform changes the entire rate schedule in the same direction. The real economic effects appear to be mostly driven by responses to changes in top rates in the short run, while the effects of broader changes occur with a delay of several years. The delayed response may also help explain why reactions to tax rates of incomes outside of the top have been harder to detect empirically. 


\section{Concluding Remarks}

Using a narrative identification strategy to obtain measures of exogenous variation in marginal tax rates, this study finds significant and broad based effects on reported income. This is consistent with recent macro studies detecting substantial effects of tax changes on real economic variables in the US and other countries using similar identification approaches. However, it conflicts with existing evidence in the public finance literature that uses aggregate time series constructed from tax returns data. We show that the difference can be explained by the efforts to resolve the endogeneity of marginal tax rates due to tax policy being responsive to spending and the business cycle, bracket creep, anticipation effects, etc. One may always question whether these efforts truly circumvent all endogeneity problems. However, this paper demonstrates the important consequences of taking elementary steps to mitigate the influence of confounding factors. As in any time series study, it is necessary to assume that the economic environment at some level is stable across the sample. It is therefore always risky to draw strong conclusions about the impact of particular historical or contemplated future tax reforms. With these caveats in mind, our findings are relevant for assessing the role of income taxation for macroeconomic stabilization and the impact of austerity programs, for understanding the empirical relationship between income taxes and inequality, and for optimal tax policy. The results also add more indirectly to the growing evidence that hours and employment decisions are influenced by taxes, see e.g. Blundell, Duncan and Meghir (1998), Keane (2011), Chetty (2012) and Chetty et al. (2013).

There are several ways for future research to verify and extend the analysis. The identification of exogenous variation in marginal tax rates ultimately relies on a limited number of postwar tax reforms in the US. Tax returns data and narrative datasets become increasingly available for other countries, e.g. Piketty et al. (2014), Cloyne (2013), Hayo and Uhl (2014) and Leigh et al. (2014), which allows for replication of the results. Second, measuring the long run effects of marginal tax rate changes in US data alone is extremely challenging. However, separating the effects of temporary and permanent tax changes at least for top incomes may be feasible by incorporating prewar data. Third, the empirical models in this paper are linear. There may be important nonlinearities in the relationship between marginal tax rates and economic activity, both in the short and long run, see Auerbach and Gorodnichenko (2012) or Jaimovich and Rebelo (2014). Finally, the results in this paper are based on reduced form models and should be combined with realistic structural models to gain greater insight into the tax transmission mechanism. We leave these and other extensions for future work. 


\section{References}

Anderson, T. W., and H. Rubin, 1949, "Estimation of the Parameters of a Single Equation in a Complete System of Stochastic Equations", Annals of Mathematical Statistics 20, pp. 46-63.

Auerbach, Alan J. and Yuriy Gorodnichenko, 2012, "Measuring the Output Responses to Fiscal Policy", American Economic Journal: Economic Policy Vol. 4(2), pp. 1-27.

Auten, Gerald and Robert Carroll, 1995, "Behavior of the Affluent and the 1986 Tax Reform Act", Proceedings of the Annual Conference on Taxation Held under the Auspices of the National Tax Association-Tax Institute of America Vol. 87, pp. 70-76.

Auten, Gerald and Robert Carroll, 1999, “The Effect Of Income Taxes On Household Income”, Review of Economics and Statistics Vol. 81(4), pp. 681-693.

Badel, Alejandro and Mark Huggett, 2015, "The Sufficient Statistic Approach: Predicting the Top of the Laffer Curve", manuscript, Georgetown University.

Barro, Robert J. and Charles J. Redlick, 2011, "The Macroeconomic Effects of Government Purchases and Taxes”, Quarterly Journal of Economics Vol. 126(1), pp. 51-102.

Barro, Robert J., and Chaipat Sahasakul, 1983, "Measuring the Average Marginal Tax Rate from the Individual Income Tax", Journal of Business Vol. 56(4), pp. 419-452.

Barro, Robert J., and Chaipat Sahasakul, 1986, "Average Marginal Tax Rates from Social Security and the Individual Income Tax”, Journal of Business Vol. 59(4), pp. 555-566.

Blundell, Richard, Alan Duncan and Costas Meghir, 1998, "Estimating Labor Supply Responses Using Tax Reforms", Econometrica, Vol. 66 (4), pp. 827-861.

Blundell, Richard, Monica Costa Dias, Costas Meghir and Jonathan M. Shaw, 2013, "Female Labor Supply, Human Capital and Welfare Reform", NBER Working Paper No. 19007.

Caplan, Benjamin, 1956, “A Case Study: The 1948-1949 Recession", in: "Policies to Combat Depression", National Bureau of Economic Research, pp. 27-58.

Carroll, Robert, 1998, "Do Taxpayers Really Respond to Changes in Tax Rates: Evidence from the 1993 Tax Act”, U.S. Department of the Treasury Working Paper 79.

Chetty, Raj, 2009, "Is the Taxable Income Elasticity Sufficient to Calculate Deadweight Loss? The Implications of Evasion and Avoidance”, American Economic Journal: Economic Policy Vol. 1(2), pp. 31-52.

Chetty, Raj, 2012, "Bounds on Elasticities with Optimization Frictions Avoidance: A Synthesis of Micro and Macro Evidence on Labor Supply”, Econometrica Vol. 80(3), pp. 969-1018.

Chetty, Raj, Adam Guren, Day Manoli and Andrea Weber, 2013, "Does Indivisible Labor Explain the Difference between Micro and Macro Elasticities? A Meta-Analysis of Extensive Margin Elasticities", NBER Macroeconomics Annual, University of Chicago Press Vol. 27(1), pp. 1- 56.

Cloyne, James, 2013, "What Are the Effects of Tax Changes in the United Kingdom? New Evidence from a Narrative Evaluation”, American Economic Review Vol. 103(4), pp. 1507-1528.

Diamond, Peter and Emmanuel Saez, "The Case for a Progressive Tax: From Basic Research to Policy Recommendations", Journal of Economic Perspectives Vol. 25(4), pp. 165-190.

Feenberg, Daniel R. and James M. Poterba, 1993, "Income Inequality and the Incomes of Very High-Income Tax payers: Evidence from Tax Returns", Tax Policy and the Economy 7, pp. 145-177.

Feldstein, Martin, 1969, "The Effects of Taxation on Risk Taking”, Journal of Political Economy Vol. 77(5), pp. 755-764.

Feldstein, Martin, 1995, "The Effect of Marginal Tax Rates on Taxable Income: A Panel Study of the 1986 Tax Reform Act", Journal of Political Economy Vol. 103(3), pp. 551-572.

Feldstein, Martin, 1999, "Tax Avoidance and the Deadweight Loss of the Income Tax", The Review of Economics 
and Statistics Vol. 81(4), pp. 674-680.

Giertz, Seth H., 2010, “The Elasticity of Taxable Income during the 1990s: New Estimates and Sensitivity Analyses", Southern Economic Journal Vol. 77(2), pp. 406-433.

Gonçalves, Silvia and Lutz Kilian, 2004, "Bootstrapping Autoregressions with Conditional Heteroskedasticity of Unknown Form”, Journal of Econometrics Vol. 123(1), pp. 89-120.

Goolsbee, Austen, 1999, "Evidence on the High-Income Laffer Curve from Six Decades of Tax Reform", Brookings Papers on Economic Activity No. 2

Gruber, Jon and Emmanuel Saez, 2002, “The Elasticity of Taxable Income: Evidence and Implications”, Journal of Public Economics Vol. 84, pp. 1-32.

Hayo, Bernd and Matthias Uhl, 2014, "The Macroeconomic Effects of Legislated Tax Changes in Germany", Oxford Economic Papers Vol. 66(2), pp. 397-418.

House,Christopher L. and Matthew D. Shapiro, 2006, "Phased-In Tax Cuts and Economic Activity", American Economic Review Vol. 96(5), pp. 1835-1849.

Jaimovich, Nir and Sergio Rebelo, 2014, "Non-linear Effects of Taxation on Growth", manuscript, USC Marshall School of Business.

Jentsch, Carsen and Kurt G. Lunsford, 2016, "Proxy SVARs: Asymptotic Theory, Bootstrap Inference, and the Effects of Income Tax Changes in the United States", Federal Reserve Bank of Cleveland Working Paper No. 1619.

Jorda, Oscar, 2005, "Estimation and Inference of Impulse Responses by Local Projections", American Economic Review Vol. 95(1), pp. 161-182.

Jorda, Oscar, Schularick, Moritz, and Alan M Taylor, 2015, "Betting the house, Journal of International Economics Vol. 96, pp. S2-S18.

Lindsey, Lawrence B., 1987, "Individual Tax Payer Response to Tax Cuts 1982-1984: With Implications for the Revenue Maximizing Tax Rates”, Journal of Public Economic Vol. 33(2), pp. 173-206.

Keane, Michael P., 2011, "Labor Supply and Taxes: A Survey", Journal of Economic Literature Vol. 49(4), pp. 961-1075.

Keane, Michael P. and Richard Rogerson, 2012, "Micro and Macro Labor Supply Elasticities: A Reassessment of Conventional Wisdom", Journal of Economic Literature Vol. 50(2), pp. 464-476.

Kueng, Lorenz, 2014, "Identifying the Household Consumption Response to Tax Expectations using Bond Prices", NBER Working Paper No. 20437.

Leeper, Eric M., Todd B. Walker and Shu-Chun Susan Yang, 2013, "Foresight and Information Flows", Econometrica Vol. 81(3), pp. 1115-1145.

Leigh, Daniel, Andrea Pescatori and Jaime Guajardo, 2014, "Expansionary Austerity New International Evidence", Journal of the European Economic Association Vol. 12(4), pp. 949-968.

Lütkepohl, Helmut, 1990, “Asymptotic Distributions of Impulse Response Functions and Forecast Error Variance Decompositions of Vector Autoregressive Models", The Review of Economics and Statistics, pp. 116-125.

McGrattan, Ellen R., "The Macroeconomic Effects of Distortionary Taxation", Quarterly Journal of Economics Vol. 127(3), pp. 1515-1550.

Mertens, Karel and Morten Ravn, 2012, "Empirical Evidence on the Aggregate Effects of Anticipated and Unanticipated US Tax Policy Shocks", American Economic Journal: Economic Policy Vol. 4(2), pp. 145-181.

Mertens, Karel and Morten Ravn, 2013, "The Dynamic Effects of Personal and Corporate Income Tax Changes in the United States", American Economic Review Vol. 103(4), pp. 1212-1247.

Mertens, Karel and Morten Ravn, 2014, "A Reconciliation of SVAR and Narrative Estimates of Tax Multipliers", Journal of Monetary Economics Vol. 68 supplement, pp. S1-S19.

Montiel Olea, José L., and Carolin Pflueger, 2013, “A robust test for weak instruments”, Journal of Business \& Economic Statistics Vol. 31(3), pp. 358-369.

Montiel Olea, José L., James H. Stock and Mark W. Watson, 2017, "Inference in SVARs Identified with External 
Instruments.", Working Paper Columbia University.

Newey, Whitney K. and Kenneth D. West, 1987, "A Simple, Positive Semi-definite, Heteroskedasticity and Autocorrelation Consistent Covariance Matrix", Econometrica 55(3), pp. 703-708.

Parker, Jonathan A. and Annette Vissing-Jørgensen, "The Increase in Income Cyclicality of High-Income Households and Its Relation to the Rise in Top Income Shares," Brookings Papers on Economic Activity Vol. 41(2), pp. $1-70$.

Pechman, Joseph A., 1987, "Federal Tax Policy, Fifth Edition", Brookings Institution, Washington DC.

Piketty, Thomas and Emmanuel Saez, 2003, "Income Inequality in the United States, 1913-1998", Quarterly Journal of Economics Vol. 118(1), pp. 1-39.

Piketty, Thomas and Emmanuel Saez, 2007, "Income Inequality in the United States, 1913-2002”, in Top Incomes Over the Twentieth Century, A.B. Atkinson and T. Piketty eds., Oxford University Press, 2007.

Piketty, Thomas, Emmanuel Saez and Stefanie Stantcheva, 2014, "Optimal taxation of Top Incomes: A Tale of Three Elasticities”, American Economic Journal: Economic Policy Vol. 6(1), pp. 230-271.

Ramey, Valerie A., 2011a, "Identifying Government Spending Shocks: It's All in the Timing", Quarterly Journal of Economics Vol. 126(1), pp. 10-50.

Ramey, Valerie A., 2011b, "Can Government Purchases Stimulate the Economy?", Journal of Economic Literature Vol. 49(3), pp. 673-85.

Ramey, Valerie A., 2016, "Macroeconomic Shocks and Their Propagation”, Handbook of Macroeconomics, forthcoming.

Ramey, Valerie A. and Sarah Zubairy, 2017, Government Spending Multipliers in Good Times and in Bad: Evidence from U.S. Historical Data, Journal of Political Economy, forthcoming.

Romer, Christina D., and David H. Romer, 2009, "A Narrative Analysis of Postwar Tax Changes”, University of California, Berkeley, manuscript.

Romer, Christina D., and David H. Romer, 2010, "The Macroeconomic Effects of Tax Changes: Estimates Based on a New Measure of Fiscal Shocks", American Economic Review Vol. 100(3), pp. 763-801.

Romer, Christina D., and David H. Romer, 2014, "The Incentive Effects of Marginal Tax Rates: Evidence from the Interwar Era", American Economic Journal: Economic Policy Vol. 6(3), pp. 242-281.

Saez, Emmanuel, 2001, "Using Elasticities to Derive Optimal Income Tax Rates", Review of Economic Studies Vol. 68, pp. 205-229.

Saez, Emmanuel, 2003, “The Effect of Marginal Tax Rates on Income: a Panel Study of Bracket Creep”, Journal of Public Economics Vol. 87, pp. 1231-1258.

Saez, Emmanuel, 2004, "Reported Incomes and Marginal Tax Rates, 1960-2000: Evidence and Policy Implications", in: Tax Policy and the Economy Vol. 18, Editor J. Poterba, pp. 117-172.

Saez, Emmanuel, Joel Slemrod and Seth. H. Giertz, 2012, "The Elasticity of Taxable Income with Respect to Marginal Tax Rates: A Critical Review”, Journal of Economic Literature Vol. 50(1), pp. 3-50.

Sammartino, Frank and David Weiner, 1997, "Recent Evidence on Taxpayers' Response to the Rate Increases in the 1990s", National Tax Journal Vol. 50(3), pp. 683-705.

Sims, Christopher, 1980, "Macroeconomics and Reality", Econometrica Vol. 48(1), pp. 1-48.

Shiller, Robert J., 2000, "Irrational Exuberance”, Princeton University Press.

Slemrod, Joel, 1995, "Income Creation or Income Shifting? Behavioral Responses to the Tax Reform Act of 1986", American Economic Review Vol. 85(2), pp. 175-180.

Slemrod, Joel, 1996, "High-Income Families and the Tax Changes of the 1980s: The Anatomy of Behavioral Response" in: Empirical Foundations of Household Taxation, edited by Martin Feldstein and James M. Poterba, Chicago and London: University of Chicago Press, pp. 169-189.

Slemrod, Joel, 1998, "Methodological Issues in Measuring And Interpreting Taxable Income Elasticities", National Tax Journal 51(4), pp. 773-788.

Stock, James H. and Motohiro Yogo, 2005, "IV Regression, Identification and Inference for Econometric Models: 
Essays in Honor of Thomas Rothenberg", edited by D.W. Andrews and J.H. Stock, pp. 80-108.

Stock, James H. and Mark W. Watson, 2008, "What's New in Econometrics - Time Series", NBER Summer Institute, Lecture 7.

Stock, James H. and Mark W. Watson, 2012, "Disentangling the Channels of the 2007-2009 Recession”, Brookings Papers on Economic Activity Spring 2012, pp. 81-135.

Stock, James H. and Mark W. Watson, 2017, "Identification and Estimation of Dynamic Causal Effects in Macroeconomics", Working Paper Harvard University.

Triest, Robert K., 1998, "Econometric Issues in Estimating the Behavioral Response to Taxation: A Nontechnical Introduction", National Tax Journal Vol. 51(4) pp. 761-772.

Yang, Shu-Chun Susan, 2005, “Quantifying Tax Effects under Policy Foresight”, Journal of Monetary Economics Vol. 52(8), pp. 1557-1568. 
All Tax Units

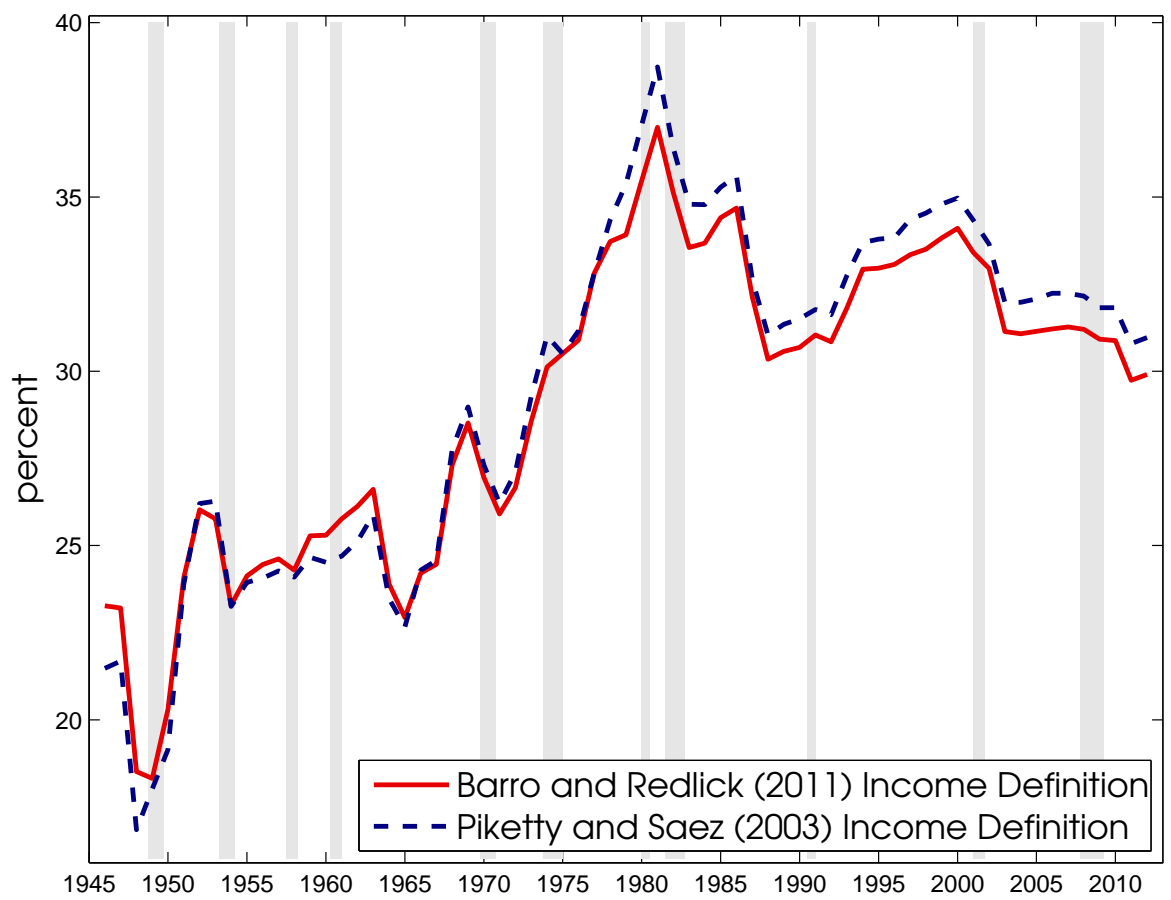

Top and Bottom Tax Units

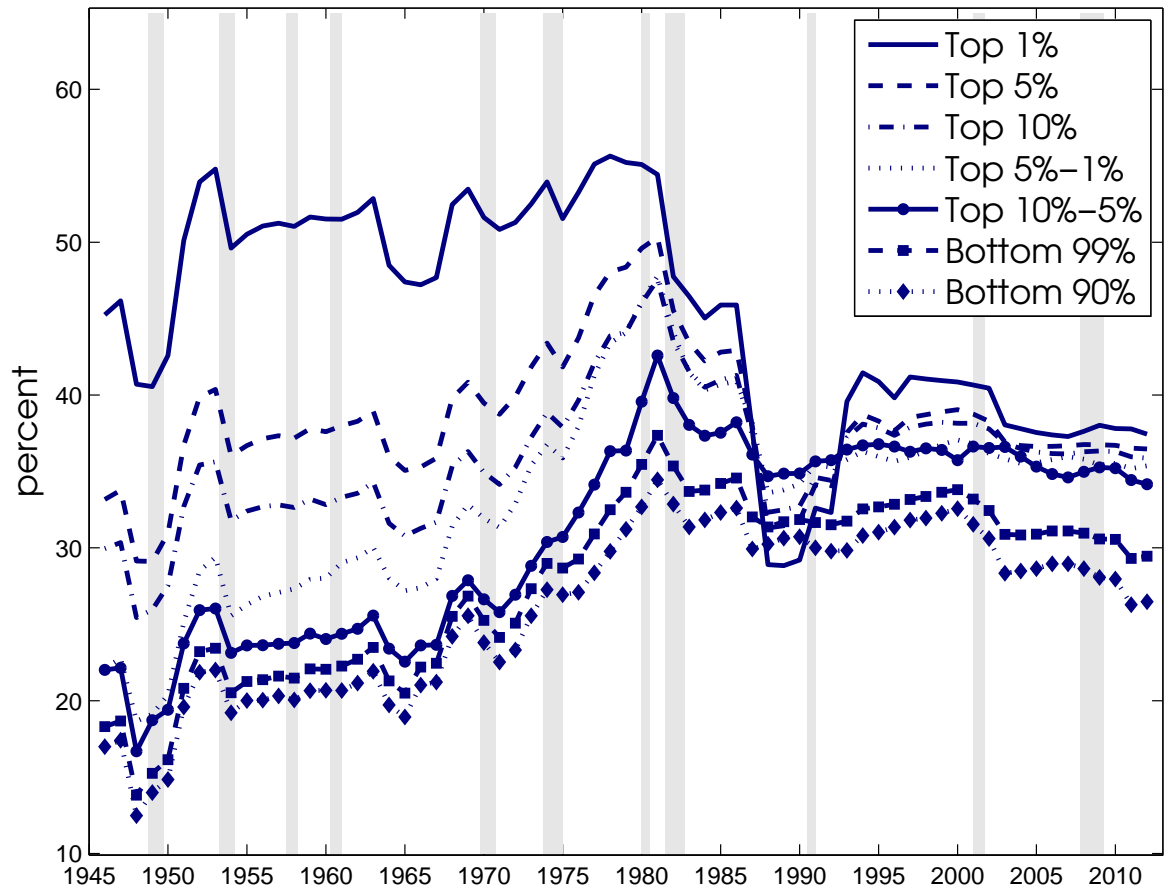

Figure 1 Average Marginal Tax Rates 1946-2012: Individual Income and Social Security.

The series are income weighted averages of marginal federal individual income tax rates and social security (OASDI and HI) contribution rates. Top and bottom tax percentiles are based on the distribution of income over potential tax units as in Piketty and Saez (2003). Sources and data construction are detailed in the appendix. Shaded areas denote NBER-dated recessions. 


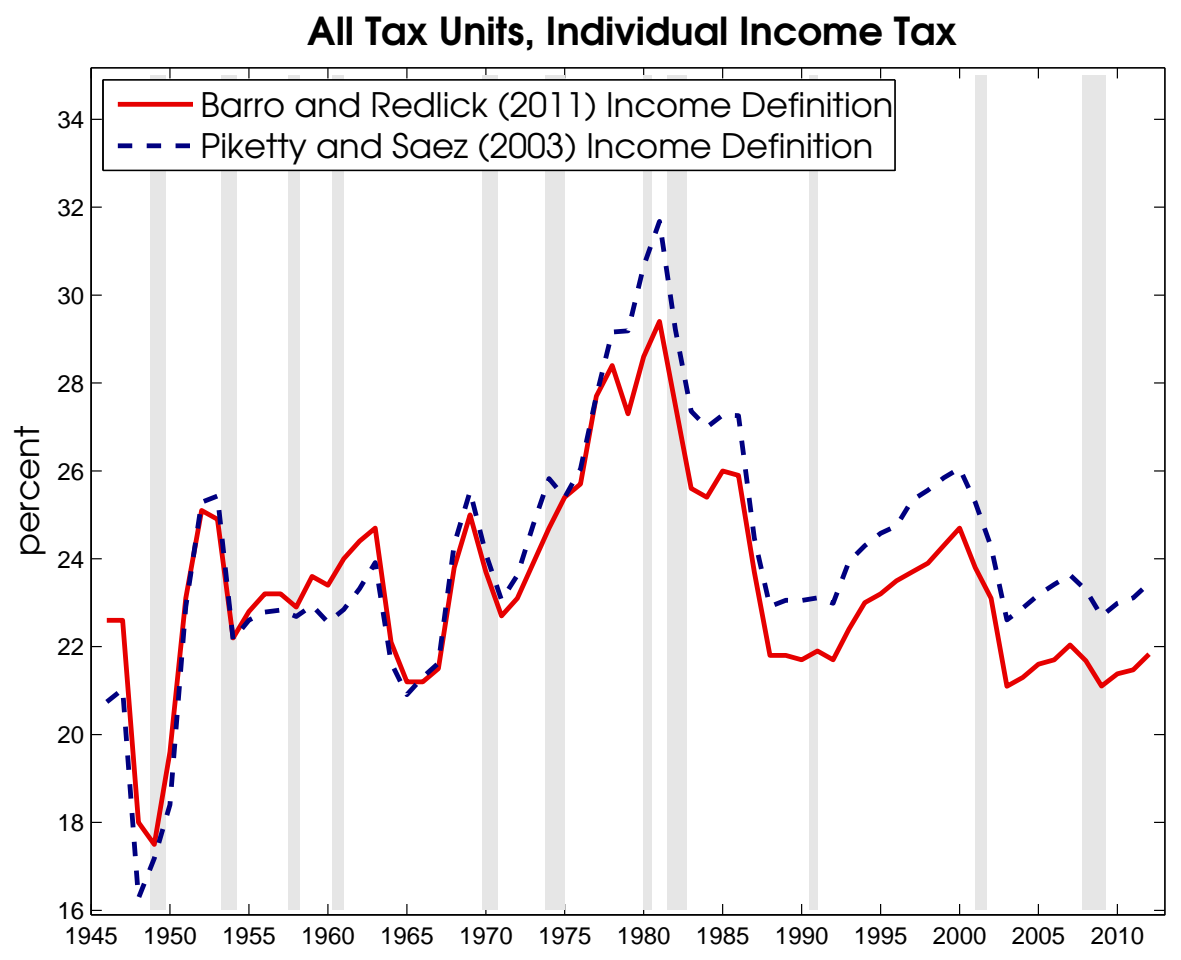

Top and Bottom Tax Units, Individual Income Tax

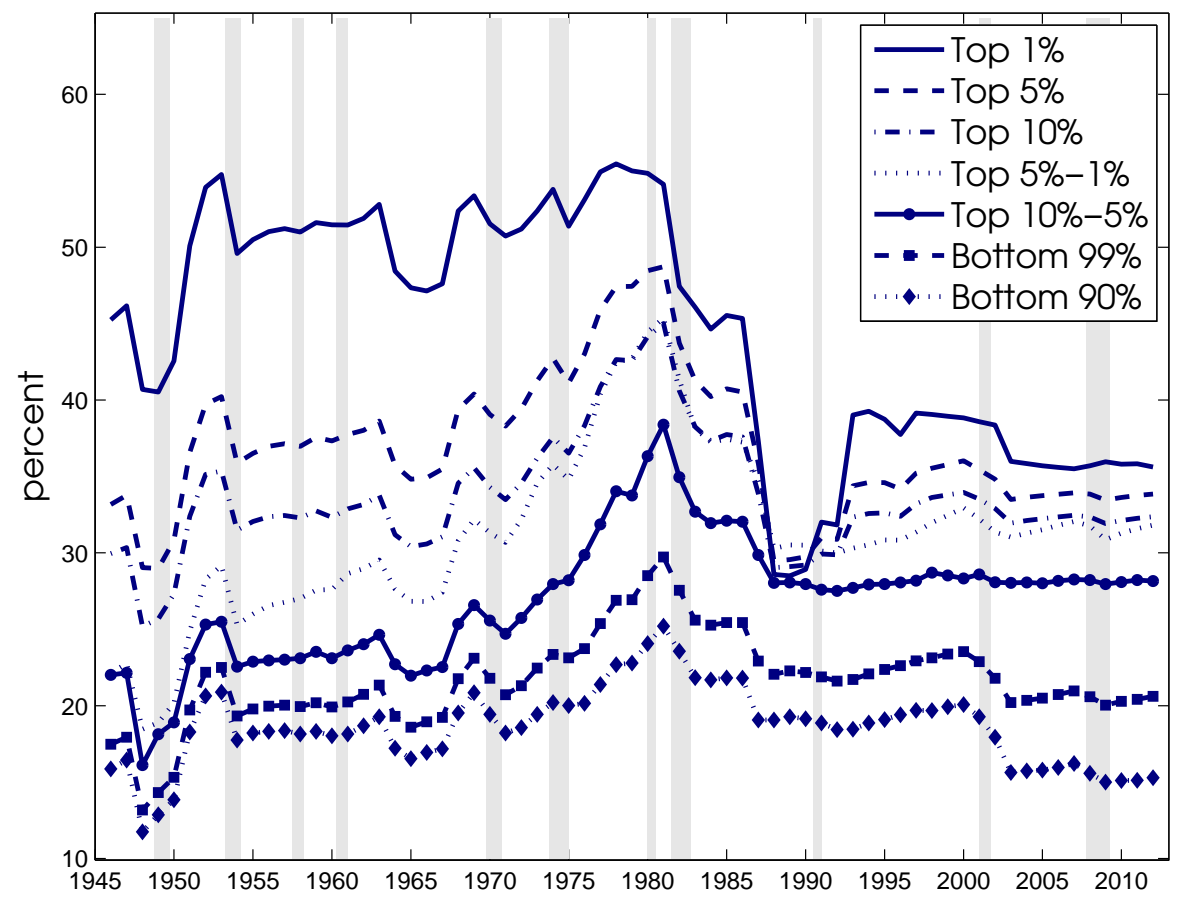

Figure 2 Average Marginal Individual Income Tax Rates 1946-2012.

The series are income weighted averages of marginal federal individual income tax rates. Top and bottom tax percentiles are based on the distribution of income over potential tax units as in Piketty and Saez (2003). Sources and data construction are detailed in the appendix. Shaded areas denote NBER-dated recessions. 


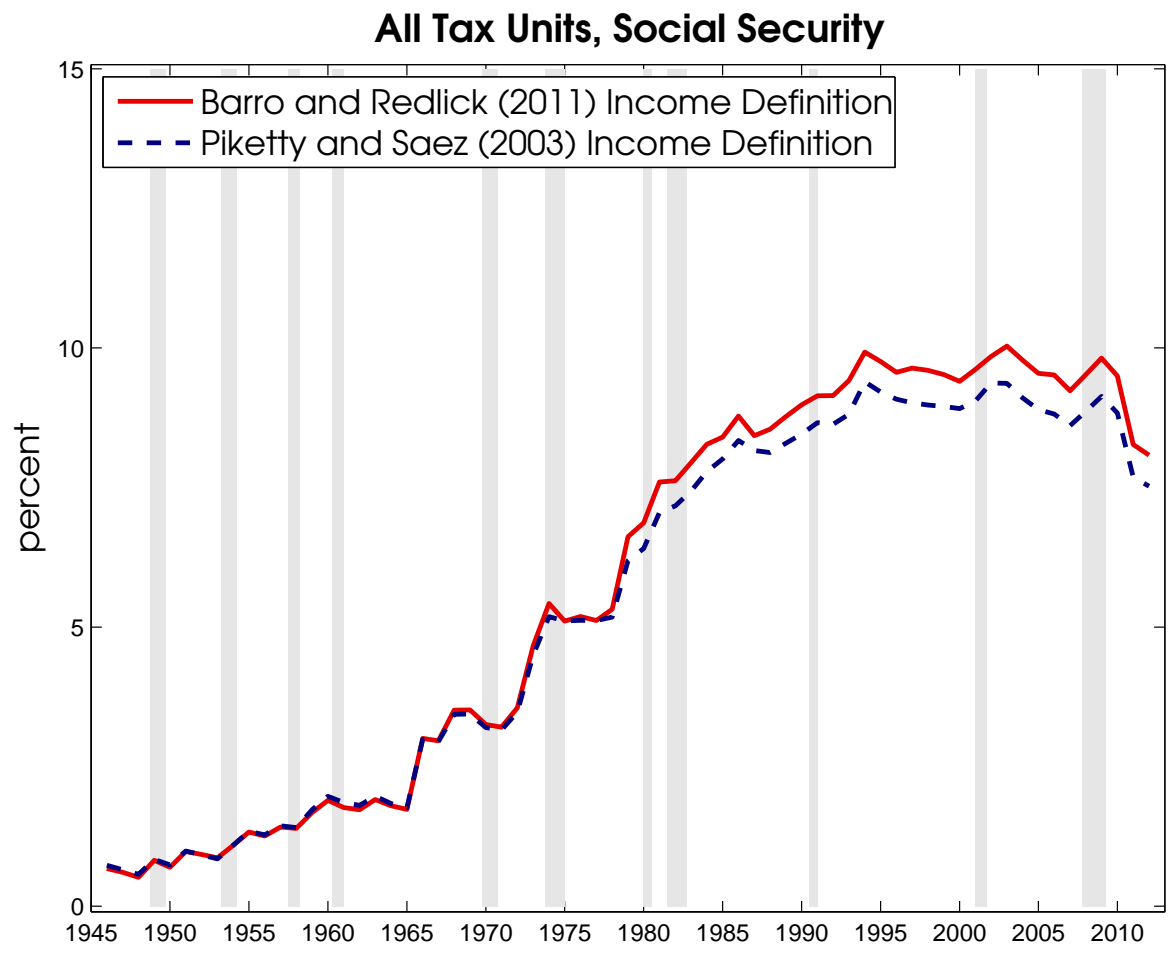

Top and Bottom Tax Units, Social Security

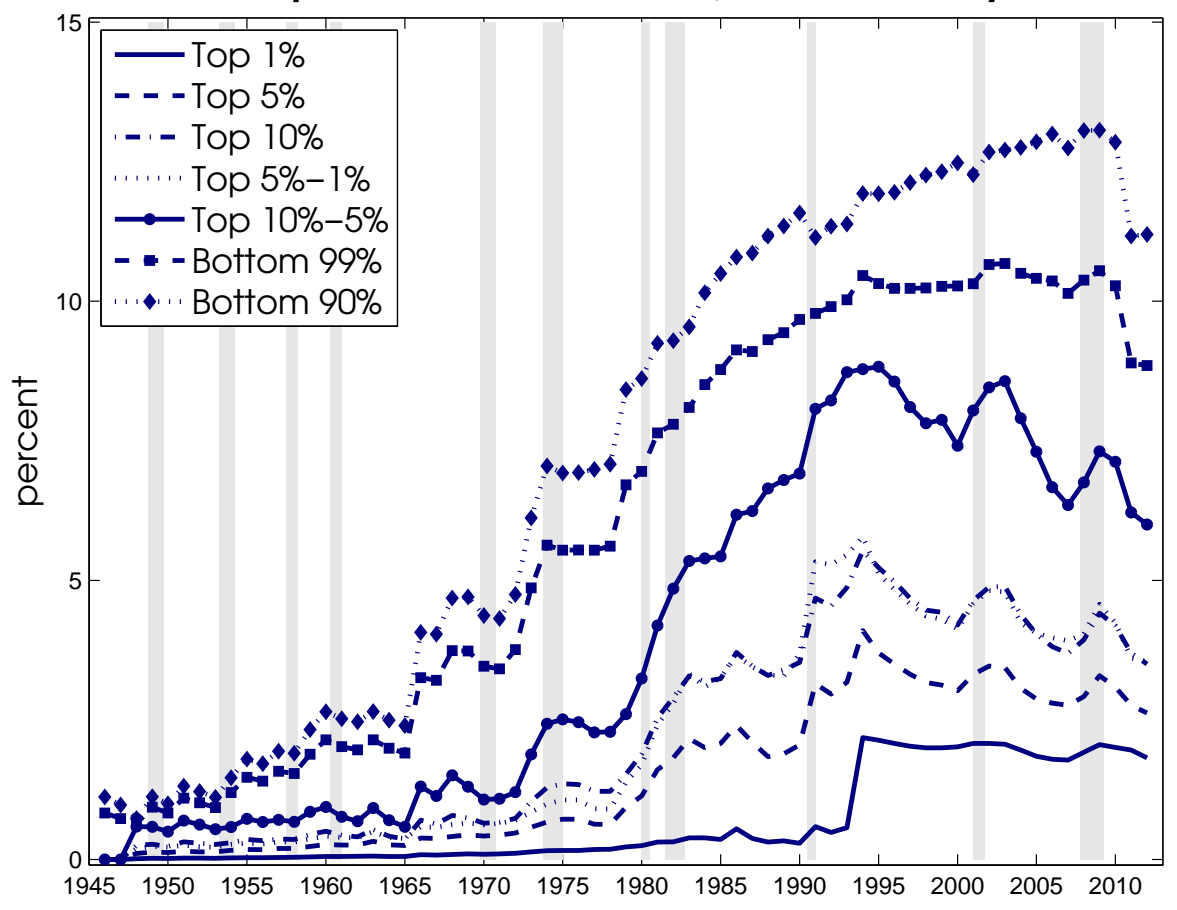

Figure 3 Average Marginal Social Security Tax Rates 1946-2012.

The series are income weighted averages of marginal social security (OASDI and HI) contribution rates. Top and bottom tax percentiles are based on the distribution of income over potential tax units as in Piketty and Saez (2003). Sources and data construction are detailed in the appendix. Shaded areas denote NBER-dated recessions. 

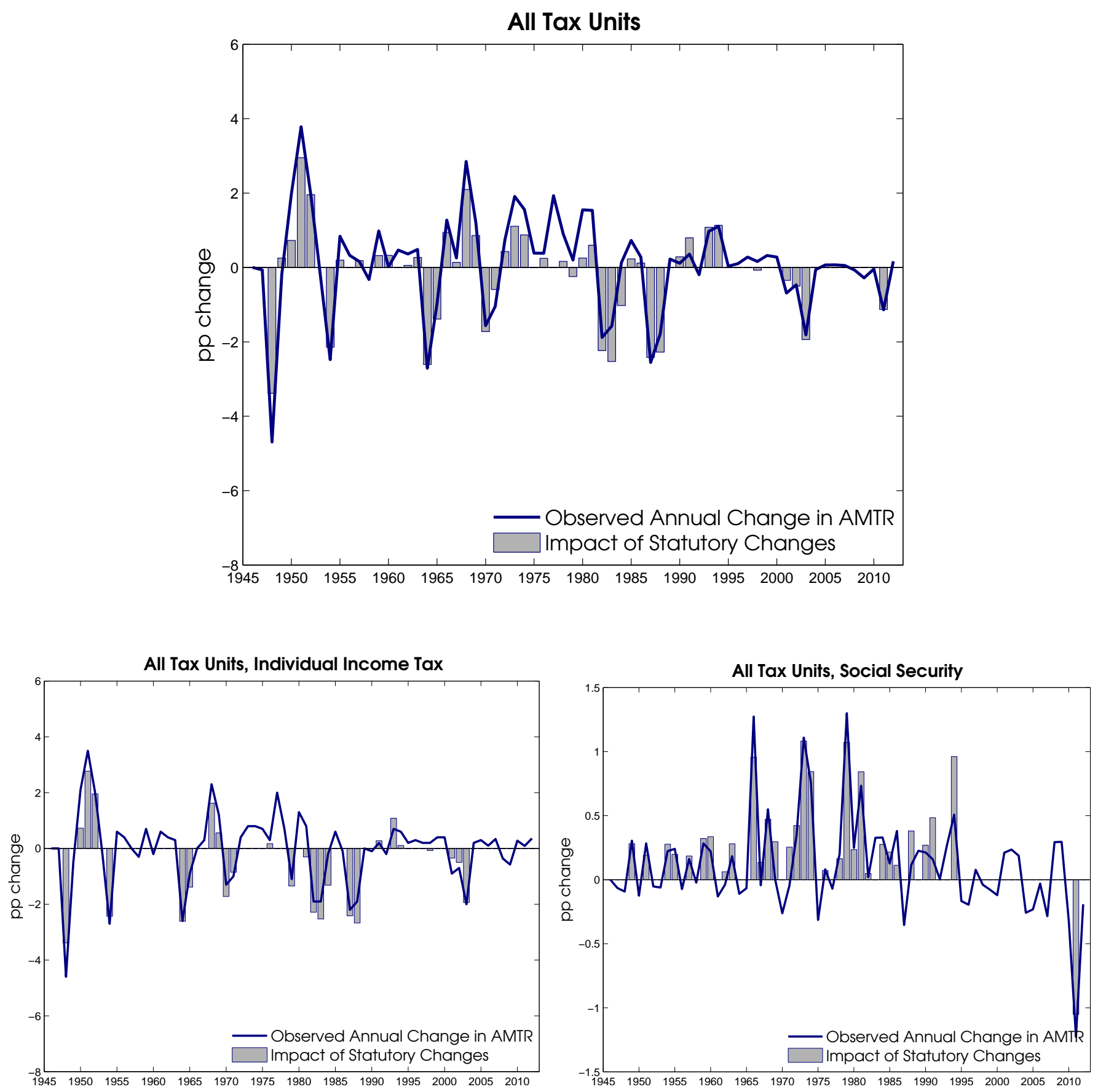

Figure 4 Estimates of the Impact of Statutory Changes on Average Marginal Tax Rates.

Observed annual change in the Barro and Redlick (2011) income concept AMTR for all tax units. The impact of statutory changes in year $t$ is the difference between a counterfactual AMTR constructed using the year $t-1$ income distribution and year $t$ rates and brackets deflated by any automatic adjustments between $t-1$ and $t$, and the observed year $t-1$ average marginal tax rate. 
1/(1-AMTR) All Tax Units

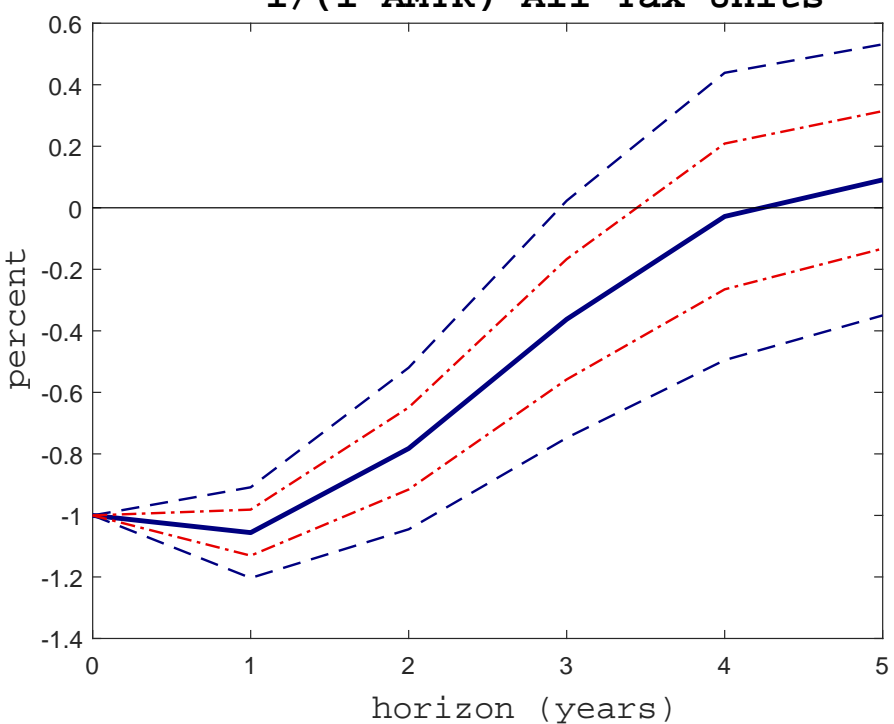

Income (All Tax Units)

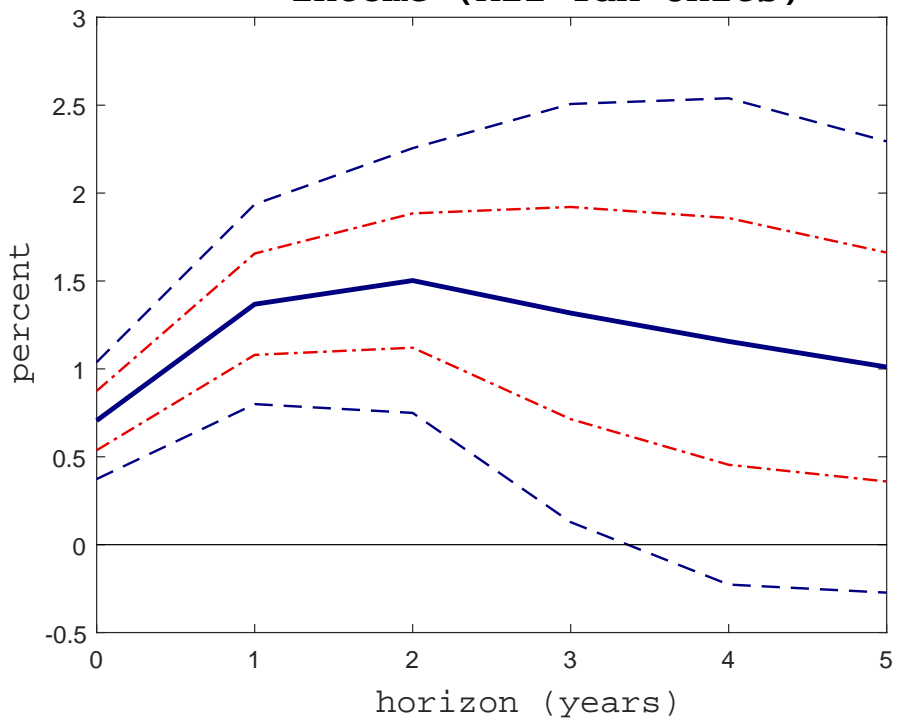

Real GDP

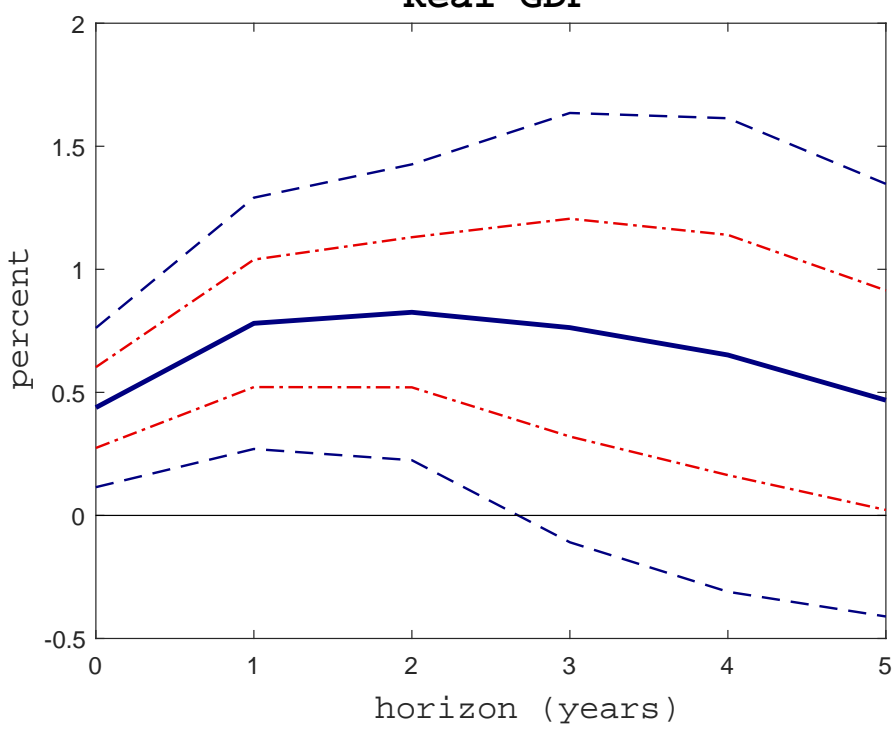

Unemployment Rate

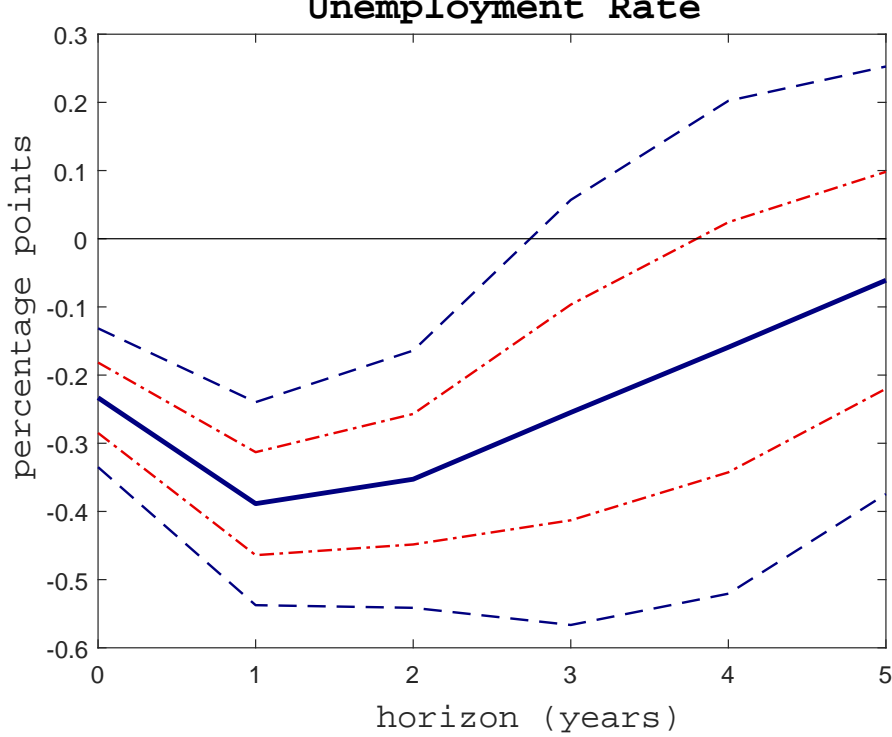

Figure 5 SVAR-IV Aggregate Responses to a One Percent Increase in the Marginal Net-of-Tax Rate.

Impulse responses are based on the SVAR-IV model in equations (3)-(4) with two lags and dummies for 1949 and 2008 as exogenous variables. The sample period is 1948-2012. The endogenous variables are aggregate real income per tax unit from Piketty and Saez (2003), which excludes realized capital gains and government transfers, the log of one minus the AMTR based on the Barro and Redlick (2011) income definition, real GDP, the unemployment rate, government spending, change in federal debt, inflation, real stock prices and the federal funds rate. Identification is based on imposing the conditions in (6) and (7), with observations of $z_{t}$ given in column [5] of Table 3. The upper left panel plots the response of the inverse net-of-tax rate to clarify that the shock induces an AMTR decrease. Broken lines are the 68\% and 95\% standard Delta-method confidence intervals suggested by Montiel-Olea, Stock and Watson (2017) with a Newey and West (1987) HAC-robust residual covariance matrix. 
1/(1-AMTR) All Tax Units

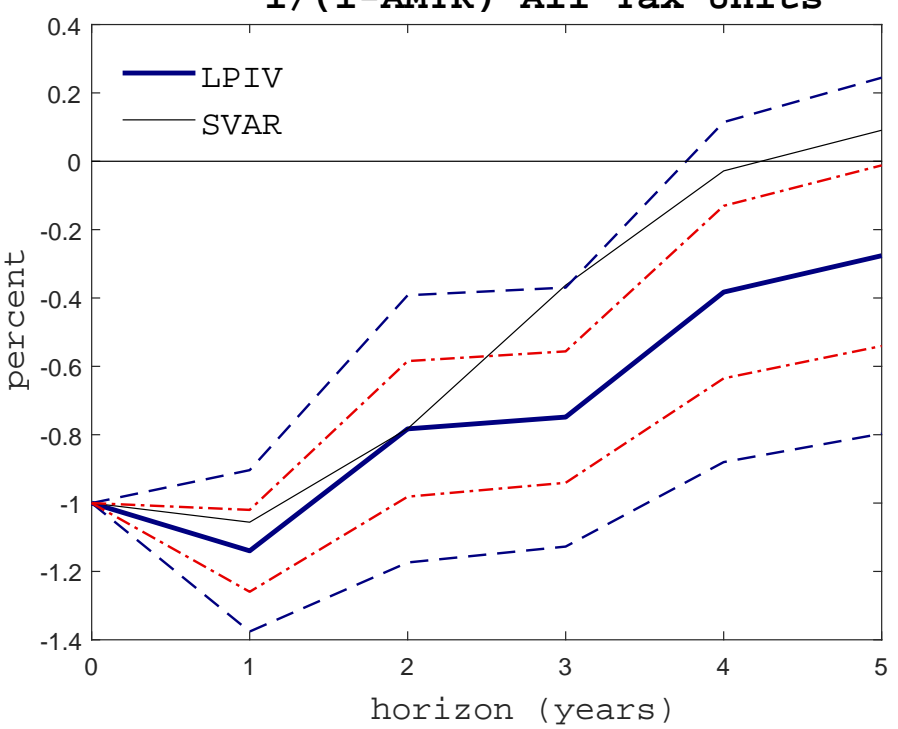

Income (All Tax Units)

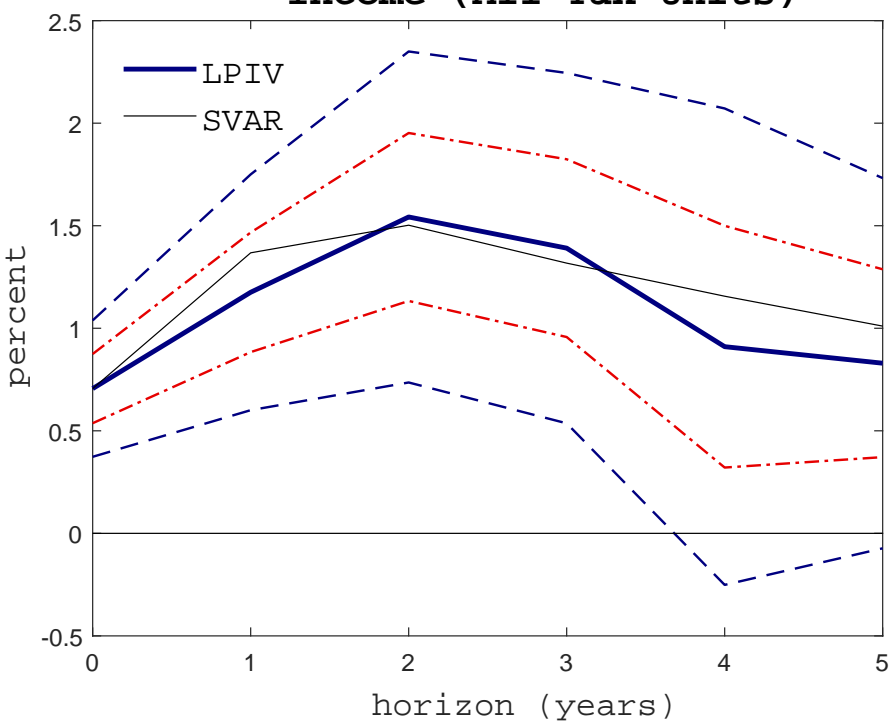

Real GDP

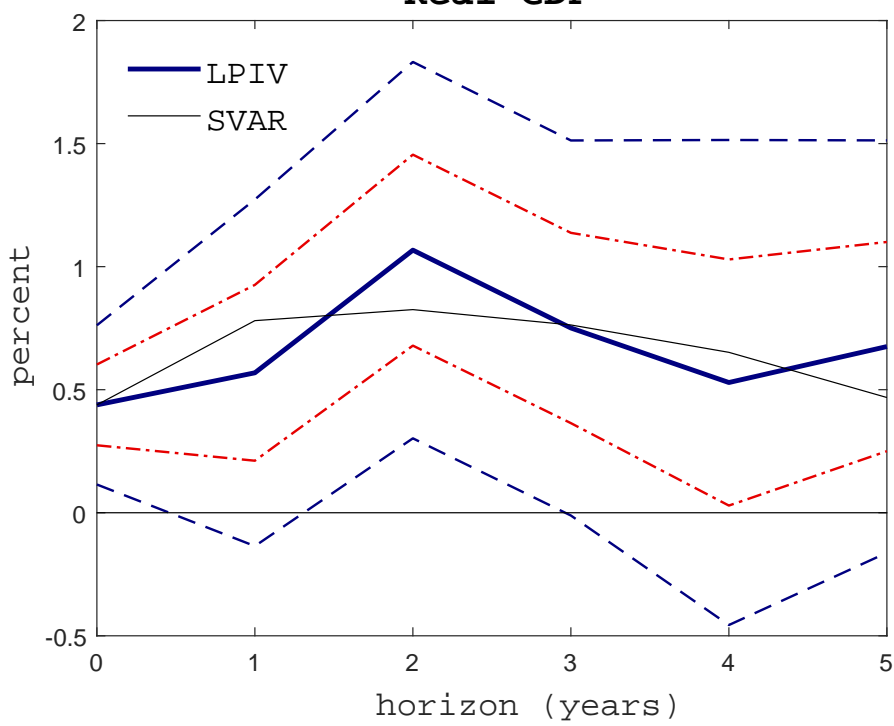

Unemployment Rate

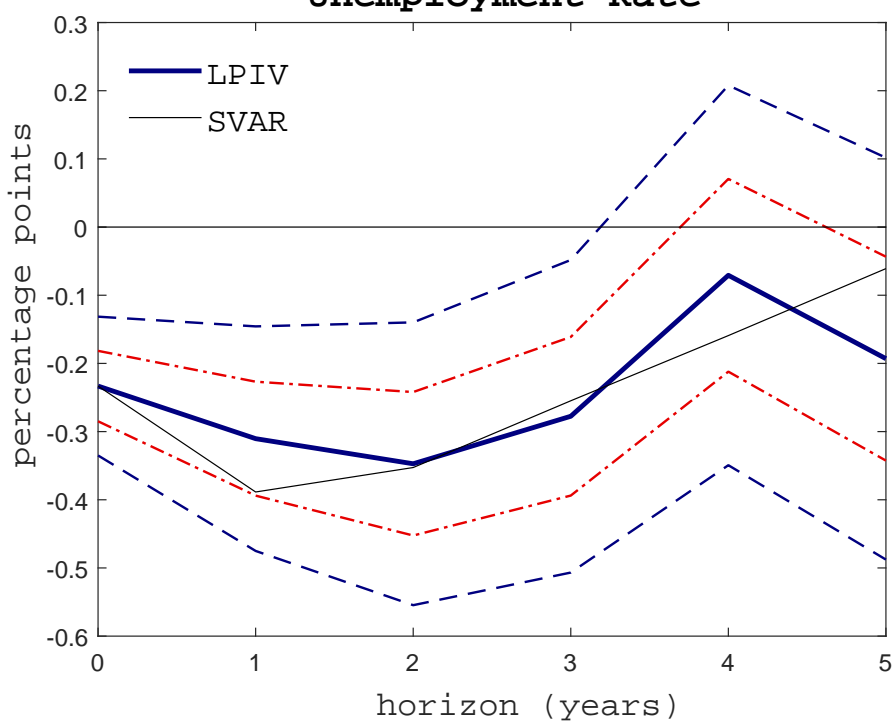

Figure 6 LP-IV Aggregate Responses to a One Percent Increase in the Marginal Net-of-Tax Rate.

Impulse responses are based on the LP-IV regression in equation (9) estimated under assumptions (10)-(11). The control variables are two lags of each of the following variables: aggregate real income per tax unit from Piketty and Saez (2003), which excludes realized capital gains and government transfers; the log of one minus the AMTR based on the Barro and Redlick (2011) income definition; real GDP; the unemployment rate; government spending; change in federal debt; inflation; real stock prices; and the federal funds rate. The regression also include dummies for 1949 and 2008. Estimates are obtained from 2SLS using $z_{t}$ in column [5] of Table 3 as instrument. The upper left panel plots the response of the inverse net-of-tax rate to clarify that the shock induces an AMTR decrease. Broken lines are 68\% and 95\% confidence bands based on Newey and West (1987) HAC-robust standard errors. The fine black line repeats the SVAR-IV estimates from Figure 5 for comparison. 

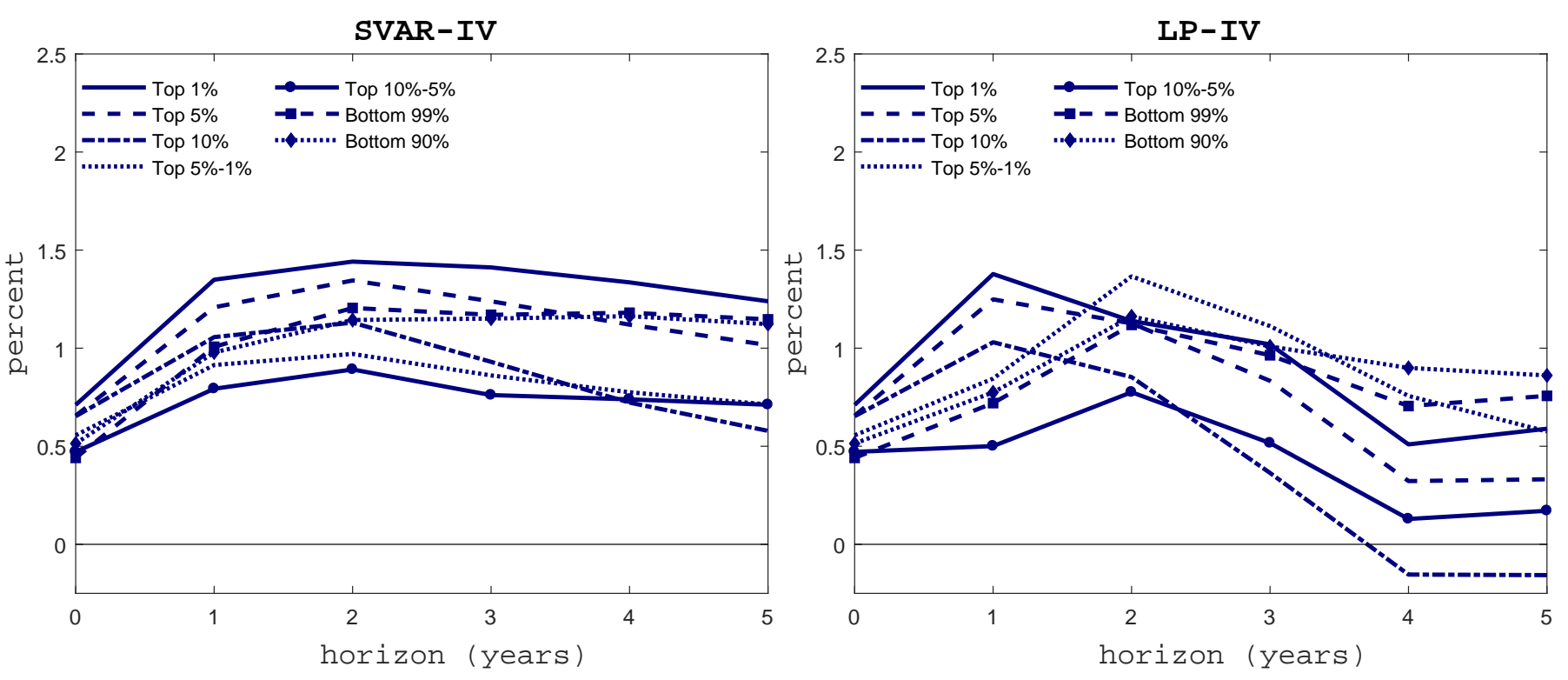

Figure 7 Dynamic Estimates of Tax Elasticities of Income, by Income Group.

Notes: Left panel: Impulse responses are based on separate SVAR-IV models as in equations (3)-(4) and Figure 5, but replacing the aggregate income and tax rate variables with the group-specific variables. Identification is based on imposing the conditions in (6) and (7), with $z_{t}$ given in the column of Table 3 corresponding to the income group. Right panel: Impulse responses are based on the LP-IV model as in equation (9) and Figure 6 estimated under the conditions in (10) and (11). Estimates are obtained from 2SLS, with $z_{t}$ given in the column of Table 3 corresponding to the income group as instrument, and replacing the aggregate income and tax rate variables with the group-specific variables. First stage statistics and confidence intervals for the first two periods are given in Table 4.
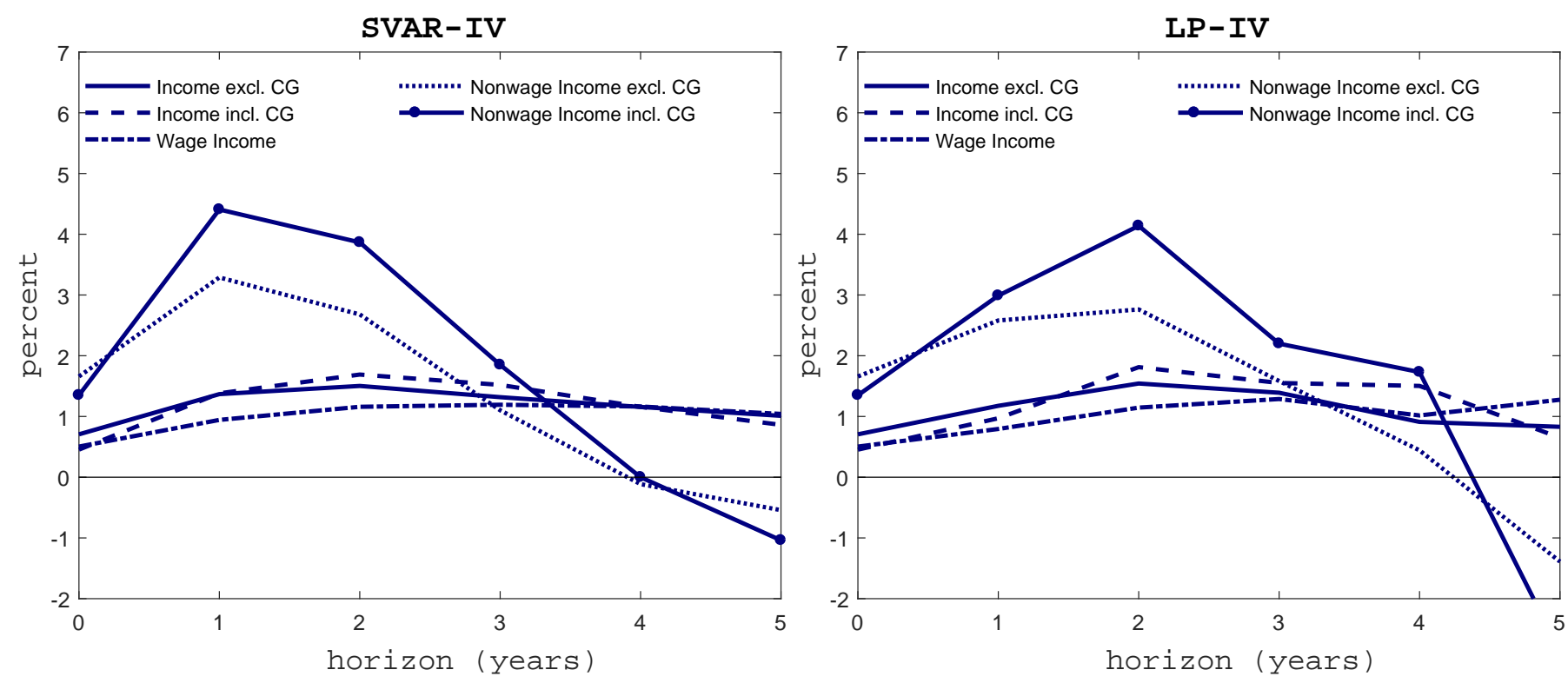

Figure 8 Dynamic Estimates of Tax Elasticities of Income, by Income Source.

Notes: Left panel: Impulse responses are based on separate SVAR-IV models as in equations (3)-(4) and Figure 5, but adding each of the new income measures as an additional endogenous variables. Identification is based on imposing the conditions in (6) and (7), with nonzero observations of $z_{t}$ given in column [5] of Table 3. Right panel: Impulse responses are based on the LP-IV model as in equation (9) and Figure 6, estimated under the conditions in (10) and (11), but adding two lags of the new income variables as additional controls. Estimates are obtained from 2SLS using $z_{t}$ in column [5] of Table 3 as instrument. First stage statistics and confidence intervals for the first two periods are given in Table 4. 


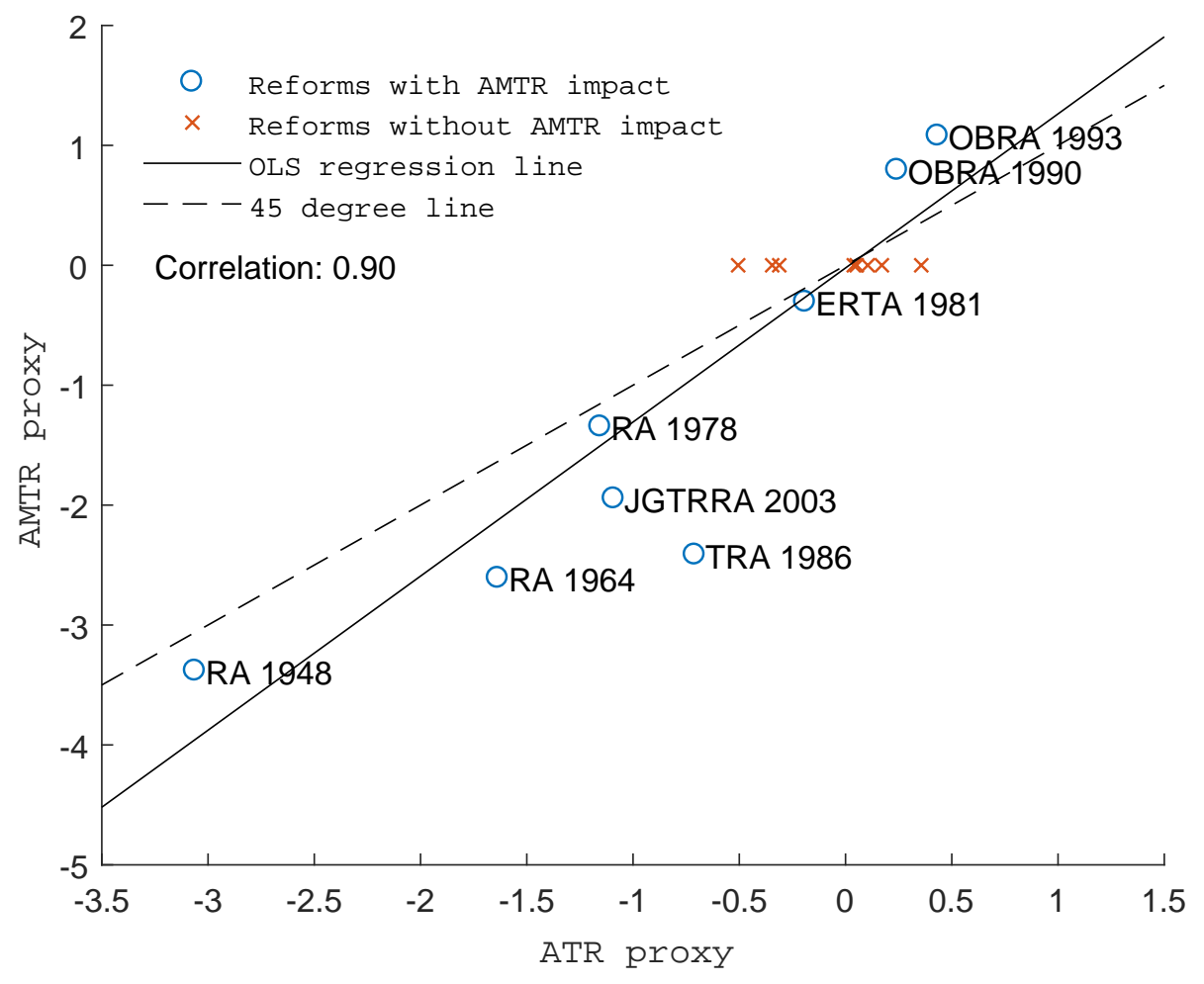

Figure 9 Scatter Plot of the AMTR and ATR Proxies

Notes: The AMTR proxy is given in column [5] of Table 3, and the ATR proxy is the sum of columns [1] to [4] in Table 3, divided by total reported market income from Piketty and Saez (2003) in the previous year. 

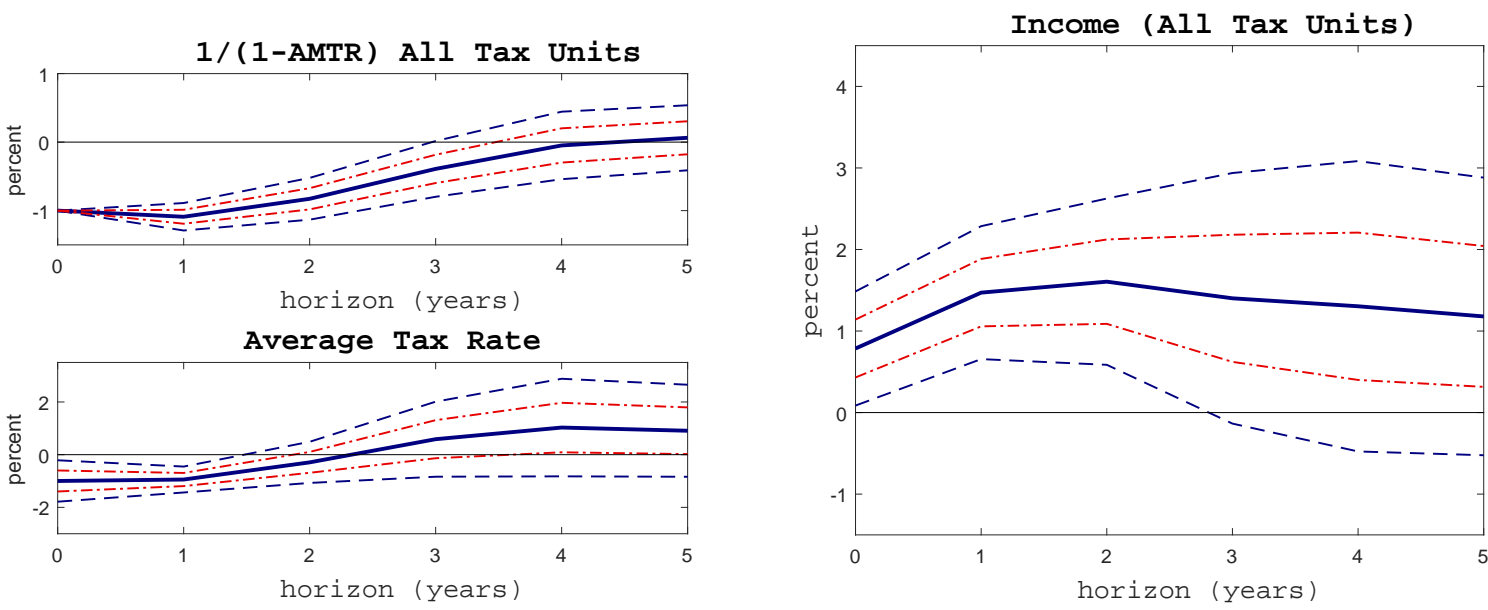

B. Cut in Marginal Tax Rate Without Impact on Statutory Average Tax Rate
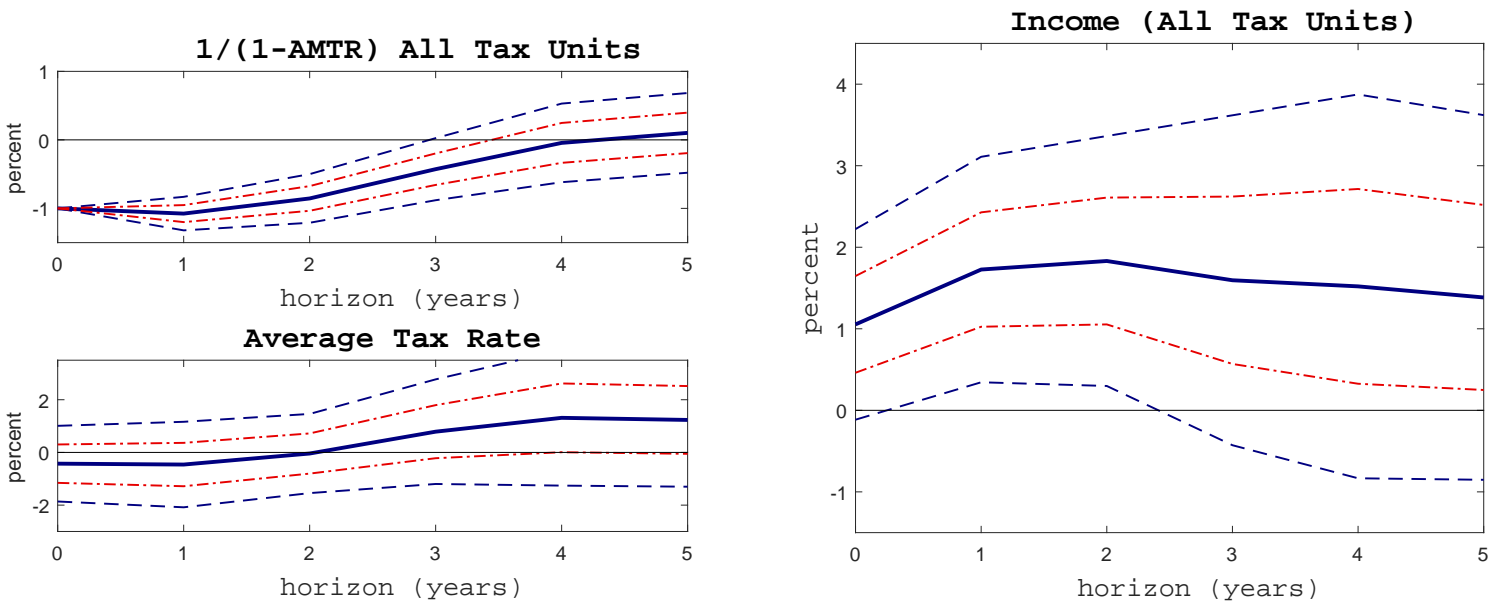

C. Cut in Average Tax Rate Without Impact on Statutory Marginal Tax Rate
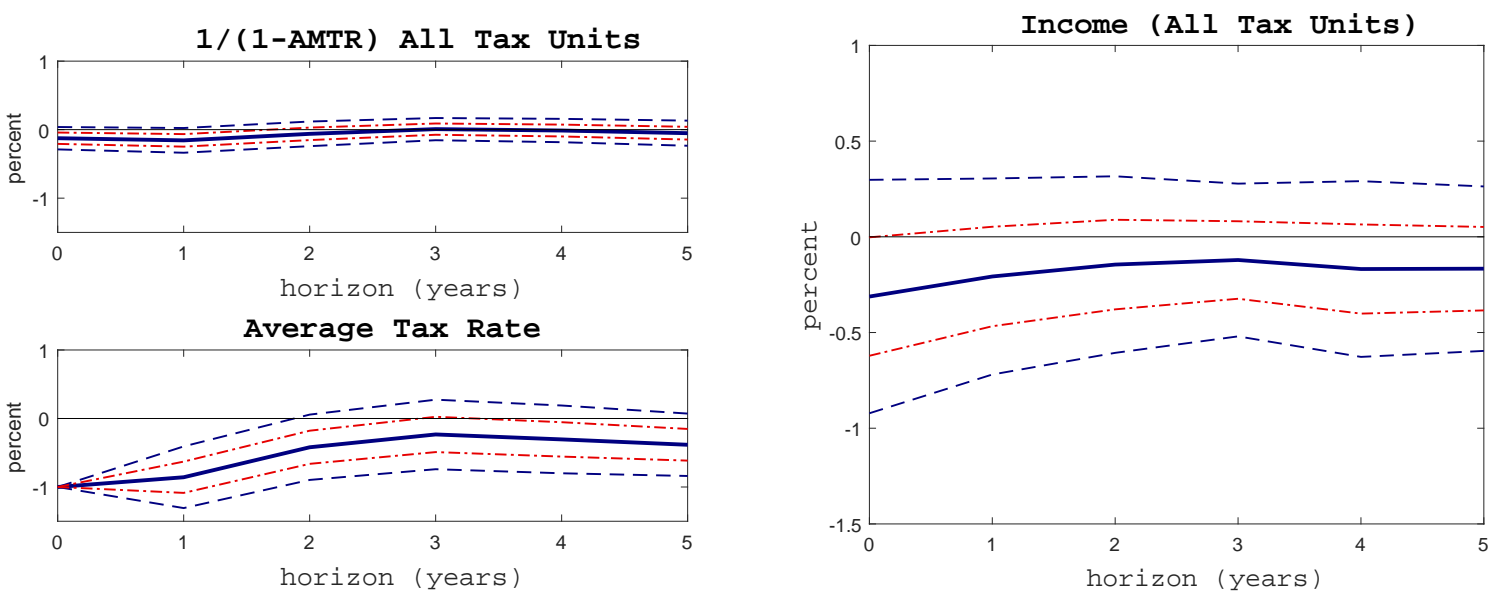

Figure 10 SVAR-IV Dynamic Responses to Shocks to Average and Marginal Rates.

Panels A and B show dynamic responses to a one percent increase in the marginal net-of-tax rate. Panel $\mathrm{C}$ shows the response to a one percent decline in the average tax rate. Estimates are from SVAR-IV model as in Figure 5 but with the log average tax rate as an additional endogenous variable. Identification is based on imposing the conditions in (12) and (13). Panels $\mathrm{A}$ and $\mathrm{C}$ use the restriction $C_{1,2}=0$, and Panel B uses the restriction $C_{2,1}=0$. The proxy for marginal tax rates is given in column [5] of Table 3, the proxy for average tax rates is the sum of columns [1] to [4] in Table 3 , divided by total reported market income from Piketty and Saez (2003) in the previous year. Broken lines are $68 \%$ and $95 \%$ confidence bands based on the Delta method suggested by Montiel-Olea, Stock and Watson (2017), with a Newey and West (1987) HAC-robust residual covariance matrix. 

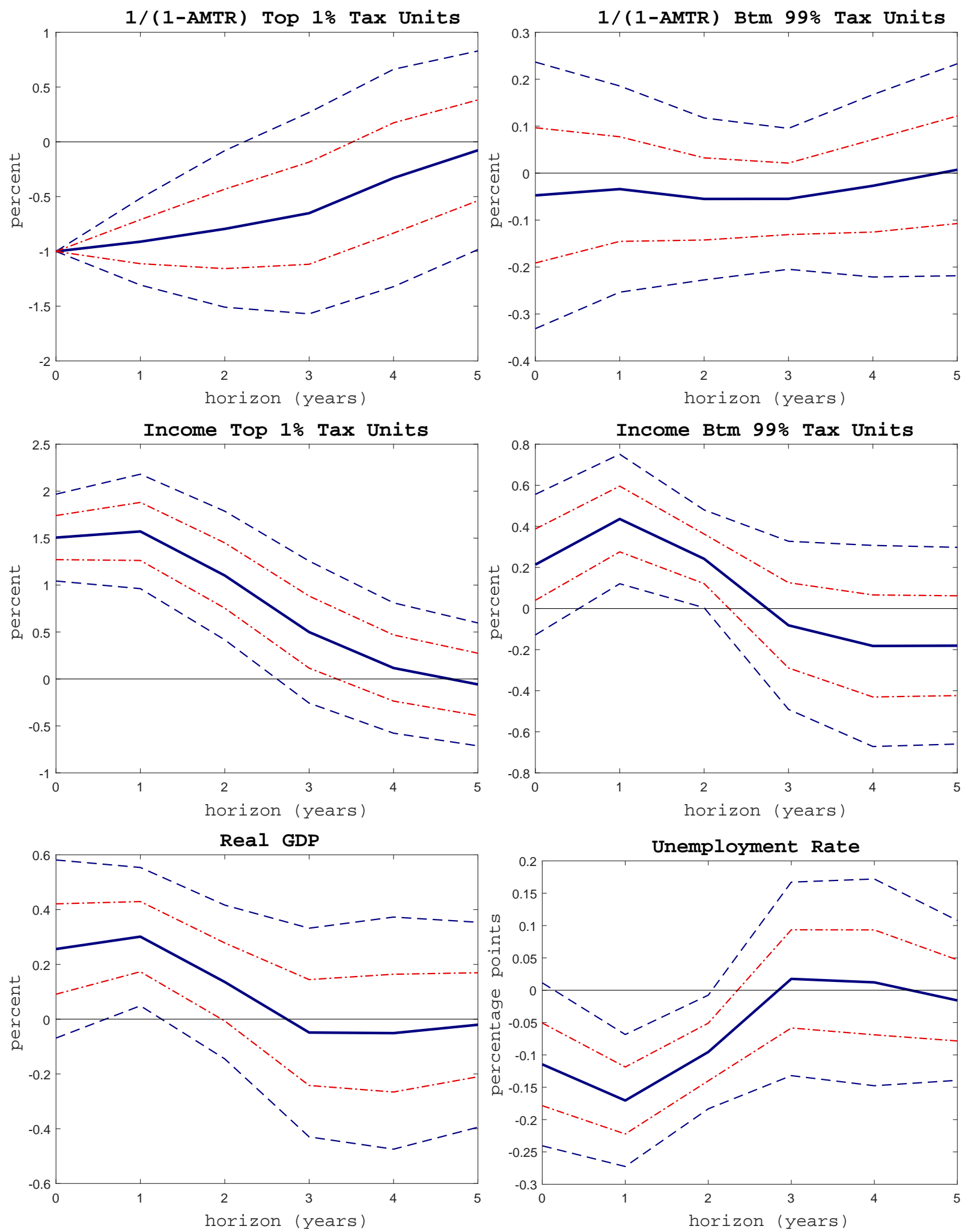

Figure 11 SVAR-IV Responses to a One Percent Increase in the Top 1\% Marginal Net-of-Tax Rate.

Estimates are from a single SVAR-IV model as in Figure 5, but replacing aggregate net-of-tax rates and income with the series for the top 1\% and bottom 99\%, and adding a quadratic time trend. Identification is based on imposing the conditions in (12) and (13) and the restriction $C_{2,1}=0$. The proxies for marginal tax rates are given in columns [6] and [11] of Table 3. Broken lines are $68 \%$ and $95 \%$ confidence bands based on the Delta method suggested by Montiel-Olea, Stock and Watson (2017), with a Newey and West (1987) HAC-robust residual covariance matrix. 

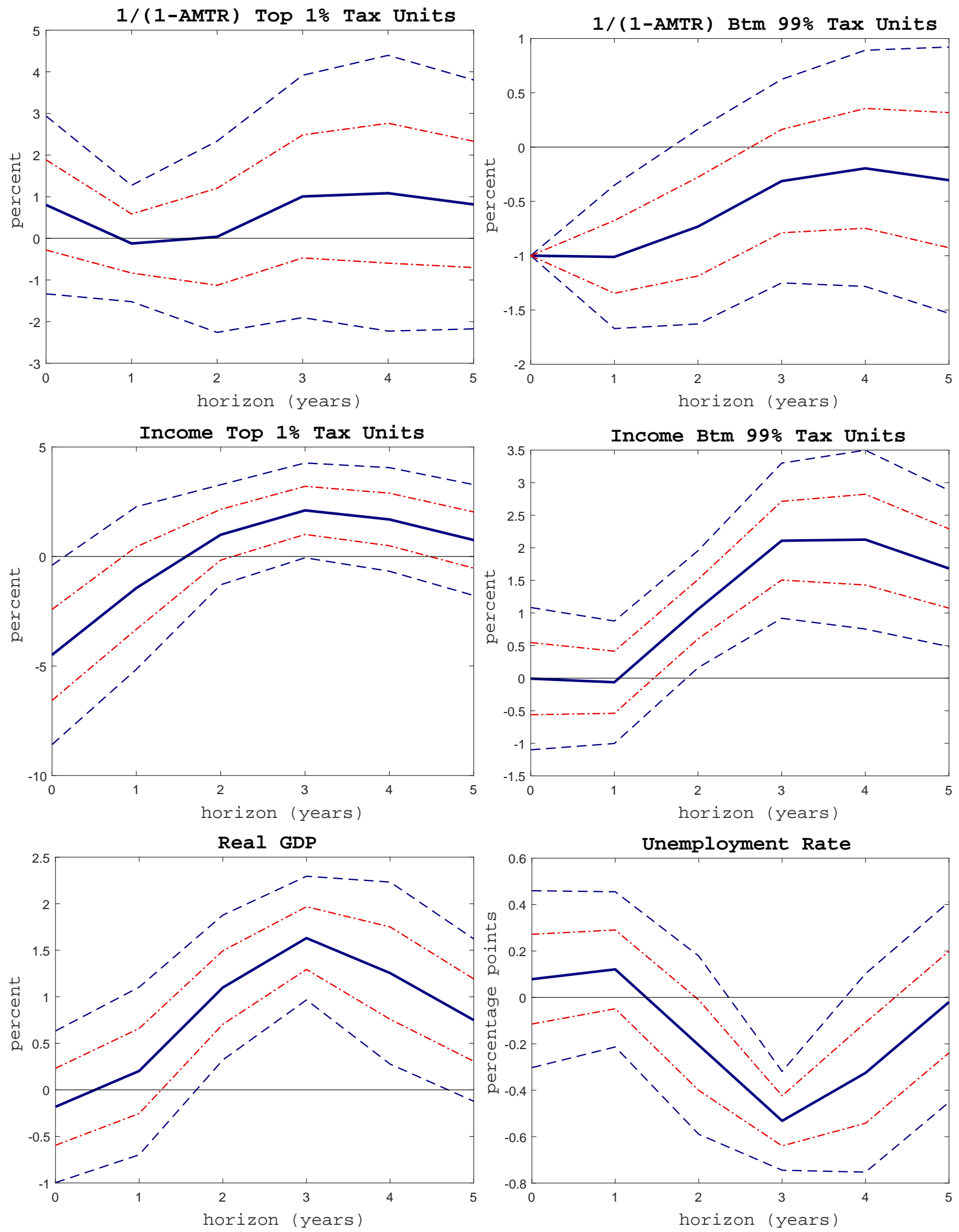

\section{Figure 12 SVAR-IV Responses to a One Percent Increase in the Bottom 99\% Marginal Net-of-Tax Rate.}

Estimates are from a single SVAR-IV model as in Figure 5, but replacing aggregate net-of-tax rates and income with the series for the top 1\% and bottom $99 \%$, and adding a quadratic time trend. Identification is based on imposing the conditions in (12) and (13) and the restriction $C_{1,2}=0$. The proxies for marginal tax rates are given in columns [6] and [11] of Table 3. Broken lines are $68 \%$ and $95 \%$ confidence bands based on the Delta method suggested by Montiel-Olea, Stock and Watson (2017), with a Newey and West (1987) HAC-robust residual covariance matrix. 
Table 1 Average Marginal Tax Rates 1946-2012: Descriptive Statistics

\begin{tabular}{|c|c|c|c|c|c|c|c|c|c|c|c|c|}
\hline & & \multicolumn{2}{|c|}{ AMTR $\times 100$} & \multicolumn{9}{|c|}{$\Delta \ln (1-\mathrm{AMTR}) \times 100$} \\
\hline & & \multirow[t]{2}{*}{ Mean } & \multirow[t]{2}{*}{ St. Dev. } & \multirow[t]{2}{*}{ St. Dev. } & \multicolumn{5}{|c|}{ Correlation with } & \multicolumn{3}{|c|}{$\begin{array}{c}\% \text { of total variation due to } \\
\text { statutory changes in }\end{array}$} \\
\hline & & & & & {$[2]$} & {$[3]$} & {$[5]$} & {$[8]$} & {$[9]$} & Inc Tax & SS Tax & Both \\
\hline [1] & All (BR 2011) & 29.11 & 4.38 & 1.83 & 0.97 & 0.82 & 0.91 & 0.96 & 0.93 & 0.76 & 0.14 & 0.87 \\
\hline [2] & All (PS 2007) & 29.50 & 5.05 & 1.99 & 1.00 & 0.84 & 0.93 & 0.99 & 0.96 & 0.74 & 0.17 & 0.86 \\
\hline [3] & Top $1 \%$ & 45.20 & 7.34 & 4.86 & 0.84 & 1.00 & 0.94 & 0.77 & 0.70 & 0.86 & 0.01 & 0.87 \\
\hline [4] & Top 5\% & 38.38 & 4.42 & 3.29 & 0.90 & 0.97 & 0.99 & 0.83 & 0.75 & 0.82 & 0.02 & 0.83 \\
\hline$[5]$ & Top $10 \%$ & 35.89 & 4.30 & 2.78 & 0.93 & 0.94 & 1.00 & 0.88 & 0.79 & 0.79 & 0.03 & 0.81 \\
\hline [6] & Top 5-1\% & 33.43 & 6.29 & 2.54 & 0.90 & 0.85 & 0.96 & 0.87 & 0.78 & 0.67 & 0.03 & 0.70 \\
\hline [7] & Top 10-5\% & 30.94 & 6.39 & 2.12 & 0.91 & 0.74 & 0.90 & 0.91 & 0.83 & 0.55 & 0.09 & 0.61 \\
\hline [8] & Bottom $99 \%$ & 27.80 & 5.74 & 1.87 & 0.99 & 0.77 & 0.88 & 1.00 & 0.98 & 0.62 & 0.20 & 0.80 \\
\hline [9] & Bottom $90 \%$ & 26.03 & 5.46 & 1.86 & 0.96 & 0.70 & 0.79 & 0.98 & 1.00 & 0.53 & 0.24 & 0.77 \\
\hline
\end{tabular}

Notes: Descriptive statistics for combined federal income and social security tax rates. AMTR is the tax rate in percent and $\Delta \ln (1-$ AMTR $)$ is the annual log change in the net-of-tax rate. Rows [1]-[2] are national averages using Barro and Redlick (2011), resp. Piketty and Saez (2003) income concepts. Rows [3] to [9] are averages within the specified brackets using the income measures of Piketty and Saez (2003). The last three columns report the $R^{2}$ coefficient of regressions of $\Delta \ln (1-$ AMTR $)$ on the estimated impact of statutory changes to income taxes, social security taxes, or both, on the overall tax rates of the specified income bracket. 
Table 2 Univariate Regressions of Income on Net-of-Tax Rates, Sample: 1948-2012

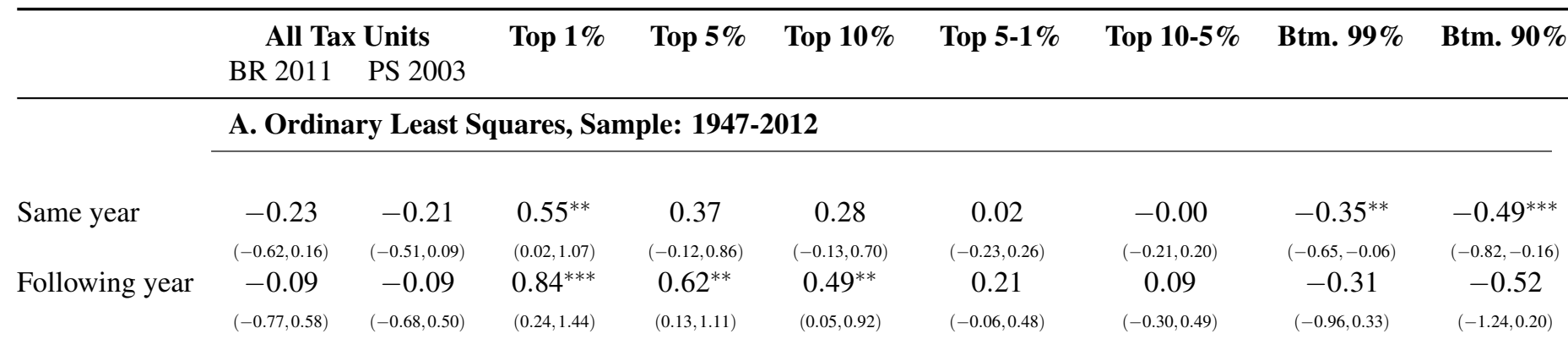

B. Ordinary Least Squares with Controls, Sample: 1948-2012

\begin{tabular}{|c|c|c|c|c|c|c|c|c|c|}
\hline \multirow[t]{2}{*}{ Same year } & -0.05 & -0.07 & $0.61^{* * *}$ & $0.48^{* * *}$ & $0.40^{* * *}$ & 0.01 & -0.03 & -0.19 & -0.28 \\
\hline & $(-0.43,0.33)$ & $(-0.36,0.22)$ & $(0.31,0.91)$ & $(0.25,0.70)$ & $(0.20,0.60)$ & $(-0.16,0.18)$ & $(-0.15,0.10)$ & $(-0.52,0.13)$ & $(-0.69,0.14)$ \\
\hline \multirow[t]{2}{*}{ Following year } & 0.09 & 0.19 & $1.02^{* * *}$ & $0.80^{* * *}$ & $0.64^{* * *}$ & $0.19^{* *}$ & 0.15 & 0.07 & 0.00 \\
\hline & $(-0.44,0.63)$ & $(-0.29,0.67)$ & $(0.70,1.33)$ & $(0.50,1.10)$ & $(0.38,0.90)$ & $(0.04,0.34)$ & $(-0.11,0.41)$ & $(-0.38,0.52)$ & $(-0.56,0.57)$ \\
\hline
\end{tabular}

C. 2SLS with Controls and All Statutory Tax Changes as Instrument, Sample: 1948-2012

$\begin{array}{lccccccccc}\text { Same year } & 0.04 & 0.08 & 0.64^{* * *} & 0.48^{* * *} & 0.39^{* * *} & 0.13 & -0.09 & -0.10 & -0.09 \\ & (-0.33,0.42) & (-0.26,0.43) & (0.33,0.95) & (0.24,0.73) & (0.14,0.63) & (-0.08,0.34) & (-0.37,0.20) & (-0.53,0.33) & (-0.65,0.46) \\ \text { Following year } & 0.33 & 0.40^{*} & 1.07 * * & 0.75^{* * *} & 0.57^{* * *} & 0.22^{*} & 0.03 & 0.20 & 0.36 \\ & (-0.11,0.77) & (-0.05,0.86) & (0.70,1.43) & (0.49,1.01) & (0.33,0.80) & (-0.02,0.46) & (-0.37,0.42) & (-0.41,0.82) & (-0.38,1.10) \\ F_{1 \text { st-Stage }} & 307.68 & 149.49 & 124.82 & 232.03 & 150.80 & 72.87 & 50.84 & 190.72 & 160.56\end{array}$

D. 2SLS with Controls and Exogenous Statutory Tax Changes as Instrument: 1948-2012

\begin{tabular}{|c|c|c|c|c|c|c|c|c|c|}
\hline Same year & $0.71^{* * *}$ & $0.75^{* * *}$ & $0.71^{* * *}$ & $0.66^{* * *}$ & $0.65^{* * *}$ & $0.56^{* *}$ & $0.47^{* * *}$ & $0.44^{*}$ & 0.51 \\
\hline \multirow{3}{*}{ Following year } & $(0.29,1.13)$ & $(0.30,1.19)$ & $(0.30,1.12)$ & $(0.23,1.08)$ & $(0.23,1.07)$ & $(0.12,0.99)$ & $(0.18,0.76)$ & $(-0.06,0.94)$ & $(-0.18,1.21)$ \\
\hline & $1.19^{* * *}$ & $1.24^{* * *}$ & $1.37^{* * *}$ & $1.24^{* * *}$ & $1.03^{* * *}$ & $0.85^{* *}$ & 0.50 & $0.73^{*}$ & 0.79 \\
\hline & $(0.45,1.93)$ & $(0.57,1.91)$ & $(0.60,2.15)$ & $(0.66,1.83)$ & $(0.50,1.56)$ & $(0.20,1.50)$ & $(-0.11,1.12)$ & $(-0.14,1.61)$ & $(-0.38,1.96)$ \\
\hline$F_{1 s t-S t a g e}$ & 229.25 & 62.24 & 51.30 & 33.38 & 34.43 & 17.88 & 14.07 & 29.91 & 16.90 \\
\hline
\end{tabular}

Notes: Same year estimates are based on regressing $\Delta \ln \left(\right.$ income $\left._{t}^{j}\right)$ on $\Delta \ln \left(1-A M T R_{t}^{j}\right)$ and following year estimates are based on regressing $\ln \left(\right.$ income $\left._{t+1}^{j}\right)-\ln \left(\right.$ income $\left._{t-1}^{j}\right)$ on $\Delta \ln \left(1-A M T R_{t}^{j}\right)$ for every income group $j$, see equations (1) and (2). The regressions in Panels B, C and D include two lags of $\ln \left(\right.$ income $\left._{t}^{j}\right)$ and $\ln \left(1-A M T R_{t}^{j}\right)$ as well as two lags of GDP, unemployment rate, government spending, change in federal debt, inflation, real stock prices and the federal funds rate and dummies for 1949 and 2008. Results in the first column are based on the AMTR series for all tax units using the income definition of Barro and Redlick (2011). The other series are based on the income definition of Piketty and Saez (2003). Panel C uses all statutory tax changes as the instrumental variable. Panel D uses the narratively identified tax changes as instruments, with the non-zero observations listed in columns [5] to [12] in Table 3. The first-stage F statistic and 95\% confidence intervals in parentheses are based on Newey and West (1987) HAC adjusted standard errors using 8 lags. Asterisks denote $10 \%, 5 \%$ or $1 \%$ significance. 
Table 3 Estimated Impact of Selected Tax Reforms

\begin{tabular}{|c|c|c|c|c|c|c|c|c|c|c|c|c|c|}
\hline & & \multicolumn{4}{|c|}{$\begin{array}{l}\text { Impact on Tax Liabilities } \\
\text { (billions of current dollars) }\end{array}$} & \multicolumn{8}{|c|}{$\begin{array}{c}\text { Impact on Average Marginal Tax Rate } \\
\text { (percentage points) }\end{array}$} \\
\hline & & \multicolumn{2}{|c|}{$\begin{array}{l}\text { Federal Individual } \\
\text { Income Tax }\end{array}$} & \multicolumn{2}{|c|}{$\begin{array}{l}\text { Social Security } \\
\text { Tax }\end{array}$} & \multirow[b]{2}{*}{$\begin{array}{r}\text { All } \\
\text { Tax } \\
\text { Units }\end{array}$} & \multirow[b]{2}{*}{$\begin{array}{l}\text { Top } \\
1 \%\end{array}$} & \multirow[b]{2}{*}{$\begin{array}{l}\text { Top } \\
5 \%\end{array}$} & \multirow[b]{2}{*}{$\begin{array}{l}\text { Top } \\
10 \%\end{array}$} & \multirow[b]{2}{*}{$\begin{array}{r}\text { Top } \\
5-1 \%\end{array}$} & \multirow[b]{2}{*}{$\begin{array}{r}\text { Top } \\
10-5 \%\end{array}$} & \multirow[b]{2}{*}{$\begin{array}{l}\text { Btm. } \\
99 \%\end{array}$} & \multirow[b]{2}{*}{$\begin{array}{l}\mathrm{Btm} . \\
90 \%\end{array}$} \\
\hline & & $\begin{array}{l}\text { Changes } \\
\text { in rate } \\
\text { schedule }\end{array}$ & $\begin{array}{r}\text { Other } \\
\text { changes }\end{array}$ & $\begin{array}{r}\text { OASDI-HI } \\
\text { changes }\end{array}$ & $\begin{array}{r}\text { Other } \\
\text { changes }\end{array}$ & & & & & & & & \\
\hline & & {$[1]$} & {$[2]$} & {$[3]$} & {$[4]$} & {$[5]$} & {$[6]$} & {$[7]$} & {$[8]$} & {$[9]$} & {$[10]$} & {$[11]$} & {$[12]$} \\
\hline & In year & & & & & & & & & & & & \\
\hline [1] Revenue Act of 1948 & 1948 & -2.4 & -2.2 & 0 & 0 & -3.38 & -9.14 & -7.07 & -6.07 & -5.24 & -3.68 & -2.67 & -2.06 \\
\hline [2] Internal Revenue Code of 1954 & 1954 & 0 & -0.8 & 0 & 0 & 0 & 0 & 0 & 0 & 0 & 0 & 0 & 0 \\
\hline [3] Revenue Act of 1964 & 1964 & -6.3 & 0.2 & 0 & 0 & -2.61 & -6.47 & -4.39 & -3.66 & -3.05 & -2.30 & -2.26 & -2.11 \\
\hline [4] Revenue Act of 1971 & 1971 & 0 & -2.0 & 0 & 0 & 0 & 0 & 0 & 0 & 0 & 0 & 0 & 0 \\
\hline $\begin{array}{l}\text { [5] Tax Reform Act of } 1976 \\
\text { [6] Tax Reduction and }\end{array}$ & 1976 & 1.65 & 0 & 0 & 0 & 0 & 0 & 0 & 0 & 0 & 0 & 0 & 0 \\
\hline Simplification Act of 1977 & 1977 & 0 & -5.4 & 0 & 0 & 0 & 0 & 0 & 0 & 0 & 0 & 0 & 0 \\
\hline $\begin{array}{l}\text { [7] Revenue Act of } 1978 \\
\text { [8] Economic Recovery }\end{array}$ & 1979 & -10.4 & -4.8 & 0 & 0 & -1.35 & -0.76 & -0.96 & -1.36 & -1.09 & -2.06 & -1.40 & -1.34 \\
\hline Tax Act 1981 & 1981 & -3.6 & 0.5 & 0 & 0 & -0.31 & -0.77 & -0.66 & -0.58 & -0.58 & -0.46 & -0.26 & -0.17 \\
\hline [9] Tax Equity and Fiscal & 1982 & 0 & 0.7 & 0 & 0 & 0 & 0 & 0 & 0 & 0 & 0 & 0 & 0 \\
\hline Responsibility Act of 1982 & 1983 & 0.7 & 3.1 & 0.8 & 2.2 & 0 & 0 & 0 & 0 & 0 & 0 & 0 & 0 \\
\hline [10] Deficit Reduction Act of 1984 & 1984 & 0 & 2.1 & 0 & 0 & 0 & 0 & 0 & 0 & 0 & 0 & 0 & 0 \\
\hline $\begin{array}{l}\text { [11] Tax Reform Act of } 1986 \\
\text { [12] Omnibus Budget }\end{array}$ & 1987 & -21.1 & 3.7 & 0 & -0.1 & -2.41 & -10.15 & -6.52 & -5.31 & -4.05 & -3.03 & -1.64 & -0.89 \\
\hline $\begin{array}{l}\text { Reconciliation Act of } 1987 \\
\text { [13] Omnibus Budget }\end{array}$ & 1988 & 0 & -0.2 & 0.5 & 1.2 & 0 & 0 & 0 & 0 & 0 & 0 & 0 & 0 \\
\hline $\begin{array}{l}\text { Reconciliation Act of } 1990 \\
\text { [14] Omnibus Budget }\end{array}$ & 1991 & 1.3 & 1.5 & 4.2 & 1.1 & 0.79 & 2.70 & 1.86 & 1.63 & 1.09 & 1.09 & 0.48 & 0.22 \\
\hline $\begin{array}{l}\text { Reconciliation Act of } 1993 \\
\text { [15] Jobs and Growth Tax Relief }\end{array}$ & 1993 & 15.4 & 0 & 0 & 0 & 1.08 & 7.43 & 3.45 & 2.45 & -0.28 & 0.13 & 0.09 & 0.17 \\
\hline Reconciliation Act of 2003 & 2003 & -43.0 & -20.5 & 0 & 0 & -1.95 & -3.30 & -2.68 & -2.50 & -2.07 & -2.03 & -1.71 & -1.54 \\
\hline
\end{tabular}

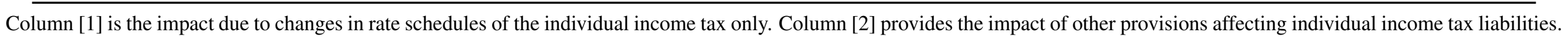

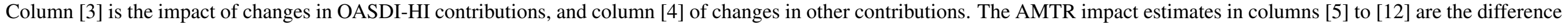

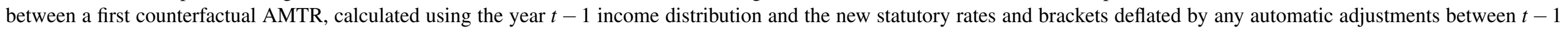
and $t$, and a second counterfactual AMTR based on the year $t-1$ income distribution and rates and brackets under prior law for year $t$. 
Table 4 SVAR-IV Estimates of Short Run Tax Elasticities, Sample: 1948-2012

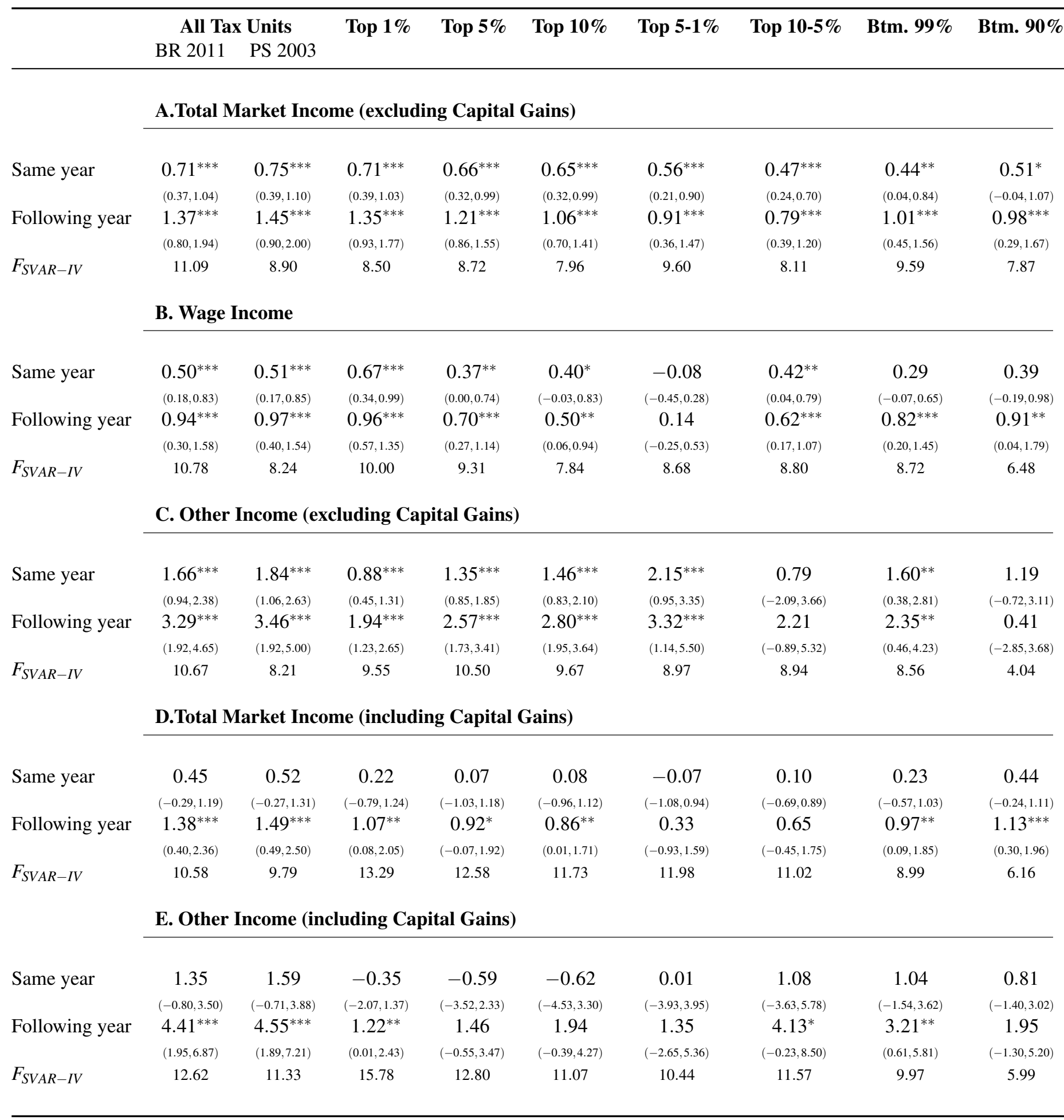

Notes: Elasticities are SVAR-IV estimates based on equations (3)-(4). Identification is based imposing the conditions in (6) and (7), with nonzero observations of $z_{t}$ given in the column of Table 3 corresponding to the income group. The income measures are from Piketty and Saez (2003) and exclude government transfers. PS 2003 and BR 2011 refer to the AMTR series using the income definition of Barro and Redlick (2011) and Piketty and Saez (2003). In parentheses are the 95\% standard confidence intervals based on Delta Method suggested by Montiel-Olea, Stock and Watson (2017) with a Newey and West (1987) HAC-robust residual covariance matrix estimator for the SVAR-IV reduced-form parameters. The $F_{S V A R-I V}$ statistic is defined in equation (B.1). Asterisks denote $10 \%, 5 \%$ or $1 \%$ significance. 
Table 5 LP-IV Estimates of Short Run Tax Elasticities, Sample: 1948-2012

\begin{tabular}{|c|c|c|c|c|c|c|c|c|c|}
\hline & \multicolumn{2}{|c|}{ All Tax Units } & \multirow[t]{2}{*}{ Top 1\% } & \multirow[t]{2}{*}{ Top 5\% } & \multirow[t]{2}{*}{ Top $10 \%$} & \multirow[t]{2}{*}{ Top 5-1\% } & \multirow[t]{2}{*}{ Top 10-5\% } & \multirow[t]{2}{*}{ Btm. 99\% } & \multirow[t]{2}{*}{ Btm. 90\% } \\
\hline & BR 2011 & PS 2003 & & & & & & & \\
\hline & \multicolumn{9}{|c|}{ A.Total Market Income (excluding Capital Gains) } \\
\hline \multirow[t]{2}{*}{ Same year } & $0.71^{* * *}$ & $0.75^{* * *}$ & $0.71^{* * *}$ & $0.66^{* * *}$ & $0.65^{* * *}$ & $0.56^{* *}$ & $0.47^{* * *}$ & $0.44^{*}$ & 0.51 \\
\hline & $(0.29,1.13)$ & $(0.30,1.19)$ & $(0.30,1.12)$ & $(0.23,1.08)$ & $(0.23,1.07)$ & $(0.12,0.99)$ & $(0.18,0.76)$ & $(-0.06,0.94)$ & $(-0.18,1.21)$ \\
\hline \multirow[t]{2}{*}{ Following year } & $1.19^{* * *}$ & $1.24^{* * *}$ & $1.37^{* * *}$ & $1.24^{* * *}$ & $1.03^{* * *}$ & $0.85^{* *}$ & 0.50 & $0.73^{*}$ & 0.79 \\
\hline & $(0.45,1.93)$ & $(0.57,1.91)$ & $(0.60,2.15)$ & $(0.66,1.83)$ & $(0.50,1.56)$ & $(0.20,1.50)$ & $(-0.11,1.12)$ & $(-0.14,1.61)$ & $(-0.38,1.96)$ \\
\hline \multirow[t]{2}{*}{$F_{1 s t-S t a g e}$} & 229.25 & 62.24 & 51.30 & 33.38 & 34.43 & 17.88 & 14.07 & 29.91 & 16.90 \\
\hline & \multicolumn{9}{|c|}{ B. Wage Income } \\
\hline \multirow[t]{2}{*}{ Same year } & $0.50^{* *}$ & $0.51^{* *}$ & $0.67^{* * *}$ & 0.37 & 0.40 & -0.08 & $0.42^{*}$ & 0.29 & 0.39 \\
\hline & $(0.08,0.92)$ & $(0.07,0.95)$ & $(0.24,1.09)$ & $(-0.11,0.85)$ & $(-0.16,0.96)$ & $(-0.55,0.39)$ & $(-0.07,0.90)$ & $(-0.17,0.76)$ & $(-0.36,1.15)$ \\
\hline \multirow[t]{2}{*}{ Following year } & $0.81^{*}$ & $0.79^{*}$ & $1.21^{* * *}$ & $0.79^{* *}$ & 0.45 & -0.01 & 0.04 & 0.51 & 0.71 \\
\hline & $(-0.14,1.76)$ & $(-0.10,1.68)$ & $(0.41,2.00)$ & $(0.15,1.43)$ & $(-0.32,1.22)$ & $(-0.61,0.58)$ & $(-0.88,0.95)$ & $(-0.54,1.56)$ & $(-0.96,2.37)$ \\
\hline \multirow[t]{2}{*}{$F_{1 s t-S t a g e}$} & 206.89 & 50.97 & 39.62 & 35.60 & 42.07 & 11.13 & 14.18 & 25.98 & 15.87 \\
\hline & \multicolumn{9}{|c|}{ C. Other Income (excluding Capital Gains) } \\
\hline \multirow[t]{2}{*}{ Same year } & $1.66^{* * *}$ & $1.84^{* * *}$ & $0.88^{* * *}$ & $1.35^{* * *}$ & $1.46^{* * *}$ & $2.15^{* * *}$ & 0.79 & $1.60^{* *}$ & 1.19 \\
\hline & $(0.73,2.59)$ & $(0.82,2.86)$ & $(0.32,1.44)$ & $(0.71,2.00)$ & $(0.64,2.29)$ & $(0.59,3.71)$ & $(-2.95,4.52)$ & $(0.01,3.18)$ & $(-1.29,3.68)$ \\
\hline \multirow[t]{2}{*}{ Following year } & $2.63^{* * *}$ & $2.78^{* * *}$ & $1.86^{* * *}$ & $2.58^{* * *}$ & $3.01^{* * *}$ & $3.07^{* *}$ & 4.12 & $1.80^{* * *}$ & 0.12 \\
\hline & $(0.97,4.29)$ & $(1.48,4.07)$ & $(0.69,3.03)$ & $(1.24,3.93)$ & $(1.61,4.41)$ & $(0.40,5.74)$ & $(-1.20,9.45)$ & $(0.62,2.99)$ & $(-2.30,2.55)$ \\
\hline \multirow[t]{2}{*}{$F_{1 s t-S t a g e}$} & 200.07 & 50.65 & 34.62 & 29.16 & 26.31 & 18.60 & 15.37 & 25.50 & 10.84 \\
\hline & \multicolumn{9}{|c|}{ D.Total Market Income (including Capital Gains) } \\
\hline \multirow[t]{2}{*}{ Same year } & 0.45 & 0.52 & 0.22 & 0.07 & 0.08 & -0.07 & 0.10 & 0.23 & 0.44 \\
\hline & $(-0.51,1.41)$ & $(-0.51,1.54)$ & $(-1.09,1.54)$ & $(-1.36,1.50)$ & $(-1.27,1.43)$ & $(-1.39,1.24)$ & $(-0.92,1.12)$ & $(-0.81,1.27)$ & $(-0.44,1.32)$ \\
\hline \multirow[t]{2}{*}{ Following year } & 0.98 & $1.14^{*}$ & $1.11^{*}$ & 1.03 & 0.88 & 0.55 & 0.46 & 0.62 & 0.82 \\
\hline & $(-0.24,2.20)$ & $(-0.09,2.36)$ & $(-0.10,2.32)$ & $(-0.21,2.26)$ & $(-0.20,1.97)$ & $(-0.68,1.77)$ & $(-0.78,1.70)$ & $(-0.74,1.97)$ & $(-0.60,2.24)$ \\
\hline \multirow[t]{2}{*}{$F_{1 \text { st-Stage }}$} & 63.14 & 44.17 & 41.80 & 27.89 & 30.42 & 25.30 & 13.72 & 28.02 & 18.76 \\
\hline & \multicolumn{9}{|c|}{ E. Other Income (including Capital Gains) } \\
\hline Same year & 1.35 & 1.59 & -0.35 & -0.59 & -0.62 & 0.01 & 1.08 & 1.04 & 0.81 \\
\hline & $(-1.44,4.14)$ & $(-1.39,4.57)$ & $(-2.58,1.89)$ & $(-4.39,3.20)$ & $(-5.70,4.46)$ & $(-5.10,5.12)$ & $(-5.03,7.18)$ & $(-2.31,4.38)$ & $(-2.06,3.68)$ \\
\hline Following year & $3.03^{* *}$ & $3.41^{* * *}$ & 1.12 & 1.45 & 1.93 & 1.94 & 5.40 & 2.04 & 0.51 \\
\hline & $(0.75,5.32)$ & $(1.15,5.67)$ & $(-0.33,2.57)$ & $(-0.96,3.85)$ & $(-1.55,5.40)$ & $(-1.70,5.57)$ & $(-2.46,13.26)$ & $(-0.51,4.58)$ & $(-1.42,2.45)$ \\
\hline$F_{1 s t-S t a g e}$ & 64.93 & 37.06 & 59.81 & 30.23 & 45.66 & 28.64 & 19.23 & 21.88 & 14.18 \\
\hline
\end{tabular}

Notes: Elasticities are LP-IV estimates based on equation (9) estimated under assumptions (10) and (11). The instrument $z_{t}$ is given by the column of Table 3 corresponding to the income group. The income measures are from Piketty and Saez (2003) and exclude government transfers. PS 2003 and BR 2011 refer to the AMTR series using the income definition of Barro and Redlick (2011) and Piketty and Saez (2003). The first-stage F statistic and 95\% confidence intervals in parentheses are based on Newey and West (1987) HAC adjusted standard errors using 8 lags. Asterisks denote $10 \%, 5 \%$ or $1 \%$ significance. 


\section{A Data Appendix}

\section{A.1 Average Marginal Tax Rates}

This section details the construction of the average marginal tax rates (AMTR) measures for 1946-2012. The series are the sum of the Average Marginal Individual Income Tax Rate (AMIITR) and Average Marginal Payroll Tax Rate (AMPTR):

$$
\mathrm{AMTR}=\mathrm{AMIITR}+\mathrm{AMPTR}
$$

\section{Average Marginal Individual Income Tax Rate (AMIITR)}

The analysis is based on two AMIITR series that differ in income concepts. The first aggregate series simply extends the measure of Barro and Redlick (2011) from 2006 to 2012. The other series (aggregate as well as for different income groups) extend the measures provided by Saez (2004) to include the following years: 1946-1959, 1961/1963/1965 and 2001-2012. From 1966 onwards, the AMIITR series are based on a large sample of tax returns and the NBER's TAXSIM program to calculate the marginal tax rate for each return. In case of Barro and Redlick (2011), the income weights are based on a concept of labor income that includes wages as well as self-employment, partnership and S-corporation income. Saez (2004) uses a broader income concept based on adjusted gross income (AGI) before adjustments but excluding government transfers and capital gains. His series reflects different assumptions on the income of non-filers and also includes TAXSIM-based observations for 1960, 1962 and 1964. Unfortunately, TAXSIM is not consistently available prior to 1966. The series are therefore extended based on data in the annual Statistics of Income (SOI) from the IRS, available at http: / www.irs.gov/uac/SOI-Tax-Stats-Archive, using a methodology analogous to Barro and Sahasakul (1983) and using adjusted gross income for weighting.

The SOI contain tables with information on the number of returns, total AGI, and taxable income for different ranges of AGI per return. In most years, these data are available separately for each filing status (married filing jointly/separately, single person, head of household or surviving spouse). For each year and filing status, I fit a probability distribution function $D(y)$ for adjusted gross income per return $y$,

$$
\begin{aligned}
D(y) & =\sum_{i=1}^{n} w(i) \int_{b(i)}^{\min \{y, b(i+1)\}} f_{i}(x) d x \\
f_{i}(x) & = \begin{cases}\operatorname{Beta}(a(i), 1) & \text { if } m(i) \geq(b(i)+b(i+1)) / 2 \text { and } i<n \\
\operatorname{Beta}(1, a(i)) & \text { if }(b(i)+b(i+1)) /(2+c) \leq m(i)<(b(i)+b(i+1)) / 2 \text { and } i<n \\
\operatorname{BoundPar}(a(i)) & \text { if } m(i)<(b(i)+b(i+1)) /(2+c) \text { or } i=n\end{cases}
\end{aligned}
$$

where $n$ is the total number of brackets, $b(i)$ is the bracket floor and $b(n+1)=\infty, w(i)$ is the fraction of returns in bracket $i$ and $m(i)$ is the mean AGI within bracket $i . D(y)$ approximates the AGI distributions by piecewise combinations of Beta (power function) distributions switching to (Bounded) Pareto distributions in the right tail. For each bracket the parameter $a(i)$ is set to match $m(i)$. Many brackets have $a(i) \approx 1$ such that the distribution is locally approximately uniform. The scalar $c$ determines the location of the switch from a positively-skewed Beta to a Pareto distribution and is set to 0.25 . Computing floors on various percentiles for all returns with positive AGI yields numbers that with few exceptions are well within 1\% of those reported for 1986-2009 by the IRS. The percentiles used for the calculations of tax rates are for all potential tax units as defined by Piketty and Saez (2003, 2007), see Section A.2. Nonfilers' AGI is assumed to equal $20 \%$ of average reported AGI per return.

Method 1 for computing AMIITRs is based on SOI tables that for each filing status report the total AGI and number of returns for which a given statutory rate is the highest marginal rate. The distributions $D(y)$ are used to interpolate for each filing status the total AGI taxed at each statutory rate applicable to returns exceeding the percentile floor. 
This method only considers returns with a regular tax rate as the highest marginal rate, which comprise the vast majority of returns, and does not reflect that certain types of income have a lower marginal rate. ${ }^{33}$ Nonfilers and untaxed returns carry a zero marginal rate. Method 2 for computing AMIITRs uses the data on taxable income in combination with the statutory tax rates and brackets, including surcharges and reductions, to calculate the marginal rate for each AGI level and filing status. The AMIITRs are subsequently computed using numerical integration based on the distributions $D(y)$. This method is again an approximation because all taxable income is assumed to be taxed at the regular rates.

The SOI statistics are not reported consistently over time and missing observations reflect absent or inadequate data. For instance, the tables listing statutory rates and AGI taxed which are required for Method 1 are only available for since 1961-1973 with 1974 and 1978 missing. AGI distributions disaggregated by filing status are to varying degrees incomplete for 1979-2002. In the overlapping years, both methods yield AMIITRs that are very highly correlated with the original series of Saez (2004) and Barro and Redlick (2011). The missing values in their series are interpolated by OLS regressions on the Method 1 series when available, and else on the Method 2 series. This method was used to obtain the overall AMIITR and the AMIITRs for the top 1\%, 5\% and 10\%. The remaining AMIITRs are calculated residually using the income shares in Piketty and Saez (2007).

\section{Average Marginal Payroll Tax Rate (AMPTR)}

The marginal payroll tax series capture the taxation of labor and self employment earnings under the federal OldAge, Survivors and Disability Insurance (OASDI) and Hospital Insurance (HI) programs of Social Security. The tax rates are calculated as

$$
A M P T R=w_{1} \frac{s_{f}+s_{w}}{1+s_{f}}+w_{2} s_{e}
$$

where $s_{f}, s_{w}$ and $s_{e}$ are the contribution rates paid by firms, workers and the self employed respectively, and $w_{1}$ and $w_{2}$ are the total taxable earnings of those with earnings below the annual maximum taxable as a ratio of total income. The contribution rates and taxable ceilings are available from the Social Security Annual Statistical Supplement (http://www.ssa.gov/policy/docs/statcomps/supplement/). The calculation of the aggregate series follows Barro and Sahasakul (1986) and employs data reported by the SSA on the number of workers and self employed with maximum earnings as well as total taxable earnings to calculate total taxable earnings of covered workers with earnings below the maximum. For OASDI, this information is available from the SS Annual Statistical Supplement for the entire sample. For HI, the information is from the Supplement since 1997, whereas earlier data is based on various issues of the Annual Report of the Board of Trustees of the Federal Hospital Insurance Trust Fund. The series is similar but different from the aggregate payroll tax series calculated by Barro and Redlick (2011) who use instead earnings data from IRS tax returns to estimate the weights. For the aggregate series, I prefer the SSA measures of taxable earnings because they take into account changes in coverage of both programs over time and do not require any imputations on the division of earnings between joint filers. The series is constructed for both the Barro and Redlick (2011) and Piketty and Saez (2003) income concepts.

The AMPTR series for the different income groups must be calculated using weights obtained from earnings reported on IRS tax returns within the income group. For the available years (1962, 1964 and 1966-2008), following Barro and Redlick (2011) I use the US Individual Income Tax Public Use Sample available at the NBER. For most years (1974 and 1979-2008), these files include an earnings split between spouses filing jointly which with a few exceptions is based on imputations rather than direct data. For the other years $(1962,1964,1966-1973$ and 1975-

\footnotetext{
${ }^{33}$ Method 1 omits returns for which the capital gains rate is the highest marginal rate and returns with alternative tax computations.
} 
1978) the earnings split on joint returns is imputed by interpolating between two counterfactual tax rates that assume earnings splits that maximize, resp. minimize the payroll tax rate. The interpolation assumes that the true tax rate is a weighted average of these lower and upper bounds with weights that are the same is in the closest subsequent year for which the earnings split is available. For years where the micro data is not available, I use more aggregated data from the IRS SOI on the number of returns with earnings and the total amount of earnings within the top 1\%, 5\% and 10\% income percentiles. Given the longer run trends in female labor force participation and the number of two-earner joint filers, I pursue different strategies for imputing the earnings split before 1966 and after 2008. For 1946-1961, 1963 and 1965, I make the following assumptions about joint filers in the top 1\%, 5\% and 10\% percentiles that report earnings: (a) the proportion of dual earners is the same as in the aggregate (b) primary earnings on returns in the top $10 \%$ are above the maximum taxable amount (c) secondary earnings are log normally distributed with means of resp. $230 \%, 140 \%$ and $115 \%$ of average wages and a standard deviation of $25 \%$ and (d) there are no self employment earnings below the maximum amount. These assumptions seem roughly plausible when compared to data for adjacent years. Moreover, given the relatively low ceilings and contribution rates prior to 1966, even relatively large perturbations of these assumptions have little impact on the resulting tax rates for the top income tax units for that period. The assumptions are applied to 1946-1976 and the resulting series are merged with the series based on micro data using OLS regressions for the overlapping years. For 2009-2012, the tax rate series for top income units are based on weights estimated by the predicted values from regressions on wage and self employment income and the maximum ceiling amounts for 1993-2008. These regressions have a very good fit over that period. The above methodology was used to obtain the AMPTRs for the top 1\%,5\% and 10\%. The remaining AMPTRs are calculated residually using the income shares in Piketty and Saez (2007).

\section{A.2 Other Time Series}

The income series and its subcomponents are from updates of the data provided in Piketty and Saez (2003, 2007). Potential Tax Units is all married men and singles aged 20 or over, obtained from Piketty and Saez (2003); Real GDP per tax unit is NIPA 1.1.3 line 1 divided by potential tax units; Inflation is the log change in the Bureau of Labor Statistics' CPI Research Series Using Current Methods (CPI-U-RS), obtained from Piketty and Saez (2003). The Federal Funds Rate after 1953 is the annual average effective federal funds rate from the Board of Governors. I use the secondary 3 month Tbill rate for 1946-1949 and observations from Romer and Romer (2010) for 19501953. Government Debt per Tax Unit is federal debt held by the public, measured by Table L.106 line 19 (federal government, liabilities, credit market instruments) in the US Financial Accounts (release Z.1 of the Federal Reserve Board), divided by the CPI-U-RS and potential tax units. Government Spending per Tax Unit is the sum of federal government purchases, net interest rate expenditures and net transfers (NIPA 3.2 line 46 less lines 3,4,7,10 and 11 plus NIPA 3.12U line 25), divided by the CPI-U-RS and potential tax units. The Real Stock Price is the S\&P composite index from updates of Shiller (2000), divided by the CPI-U-RS. The Unemployment Rate and Female Participation Rate are for the civilian noninstitutional population aged 16 or more are from the Bureau of Labor Statistics. The Average Tax Rate is the sum of federal personal current taxes and contributions for social insurance (NIPA 3.2 line 3 plus NIPA 3.7 lines 3 and 21) divided by total market income from Piketty and Saez (2003). The Average Capital Gains per Tax Unit is from Piketty and Saez (2003). Ramey News is the measure of news about defense spending (annual totals) constructed by Ramey (2011a). The Moody's Corporate BAA Rate is from the H.15 release of the Federal Reserve Board. Education is the percent of people 25 years or over which completed 4 years of college or more from the Current Population Survey (Table A.2 historical tables on educational attainment). Missing values prior to 1964 are linearly interpolated. The Top 10\% Income Share is in logs and based on data from Piketty and Saez (2003). Wage inequality is the log difference between average wage income of the top $10 \%$ and bottom 90\%. The Gini Coefficient for families is from the Current Population Survey (series F4 of historical tables on income inequality). The average Corporate Tax Rate is federal taxes on corporate income excluding Federal Reserve banks (NIPA Table 3.2 line 9) divided by corporate profits (NIPA Table 1.12 line 13 less Federal Reserve 
Bank Profits in NIPA Tables 6.16 B-C-D). The narrative Corporate Tax Changes series is from Mertens and Ravn (2013).

\section{A.3 Narrative Measures of the Tax Liability Impact of Tax Reforms}

Columns [1] to [4] in Table 3 provide the data on the tax liability impact of the selected tax reforms. The series for the total tax liability impact that is used as the additional proxy in Section 5.1 is the sum of the first four columns in the table as a percentage of total market income in the previous year. In the robustness section, column [22] of Table B.3 uses the same series, whereas column [21] of Table B.3 is the sum of columns [1] and [3] in Table 3 as a percentage of total income in the previous year. In each case the series have zero values an all other years.

\section{Background and sources:}

1. Revenue Act of 1948 Signed: 4/2/48; The 1948 act reduced marginal tax rates on individual income for all taxpayers, with the percentage reduction in rates being largest for low-income taxpayers. It also increased the personal exemption and the standard deduction amounts and permitted income splitting by married couples. A Senate report (No. 1013 March 1948, Table XIV) contains the Joint Committee of Internal Revenue Taxation estimate of the impact on calendar 1949 income tax liabilities of $\$ 4.6$ billion, of which $\$ 1.8$ billion is directly attributed to the rate reductions. I add the effects of income splitting ( $\$ 0.6$ billion) to obtain the total effect of direct marginal rate provisions. The same Senate report also contains the prior law rate schedule.

2. Internal Revenue Code of $\mathbf{1 9 5 4}$ Signed: 8/16/54; This law was a comprehensive reform of the individual income tax system: it combined the 3 percent normal tax and the reduced surtax into a single comprehensive rate schedule, permitted three new tax credits (retirement income, dividends and tax exempt interest), introduced new concepts of taxable income and adjusted gross income, altered or introduced tax deductions (medical expenses, dependent care) and changed filing requirements. (SOI 1954, page 8 -9). In 1954 marginal tax rate decreased as legislated under the Revenue Act of 1951. These changes are treated as fully anticipated (see existing law schedules in Joint Committee on the Economic Report, 1952, Federal Tax Changes and Estimated Revenue Loss under Present Law). The 1954 Treasury Annual Report (p. 44) provides an estimate of the structural changes of the income tax and states the bill reduced taxes on individuals by $\$ 0.8$ billion in fiscal year 1955. I use the full amount for calendar 1954 classified as non marginal tax rate provisions.

3. Revenue Act of 1964 Signed: 2/26/64; The Revenue act of 1964 substantially reduced statutory marginal tax rates across the board. It also changed the adjustments made to gross income (excluding sick pay, allowing higher dividend exclusion), created a new deduction (employee moving expenses), introduced income averaging and the minimum standard deduction and made various other changes (SOI 1964). Taxes on individual were reduced in two stages (1964 and 1965). The 1965 Economic Report (p.65) reports the effect on individual income tax liabilities of the first round of cuts, made retroactive to January 1964, as $\$ 6.7$ billion in calendar 1964. I use similar numbers from the Joint Committee on Internal Revenue Taxation in its report on the 1964 Revenue Bill (February 1964, p.2-3). This report estimates a total individual income tax revenue impact for calendar 1964 of $-\$ 6.1$ billion with an impact of the basic rate changes of $-\$ 6.3$ billion. A 1982 Report to the Subcommittee on Monetary and Fiscal Policy ('The Mellon and Kennedy Tax Cuts: A Review and Analysis'), reports the existing law schedule prior to the 1964 Act which is used to calculate the impact on the average marginal tax rates.

4. Revenue Act of 1971 Signed 12/10/71; The Revenue Act of 1971 provided tax relief primarily for lower income individuals by increasing the personal exemption as well as the minimum standard deduction. The act also instated the Job Development Credit and made changes to depreciation guidelines, which also had implications for individual income tax liabilities. These provisions were made in part retroactive to 1971. The 
1973 Budget, the Congressional Records and the Report of the Joint Committee on Taxation (JCT) all provide estimates of the impact on individual tax liabilities that are roughly consistent. The JCT report contains an estimate of the calendar 1971 impact of \$2 billion for the provisions affecting individuals (December 1972).

5. Tax Reform Act of 1976 Signed 10/4/76; The law contained various changes to the individual income tax code, including an increase in the 'additional tax for tax preferences' (minimum tax), a new child care credit, an increase in the general tax credit and various measures to close loopholes (see SOI 1976, p iv.). The 1977 Economic Report contains at an annualized \$2.4 billion total increase in revenues for 1976. The 1978 Budget (p. 60) and the JCT report (October 1976 Appendix A) provide numbers for the separate individual income tax effects of the bill for fiscal 1977 that are very much consistent with the aggregate numbers for 1977 in the Economic Report. The 1978 Budget breaks down the revenue effects of the reform for fiscal 1977. Tax shelter provisions and tax simplification measures canceling each other out with an impact of $\$ 0.4$ billion and $-\$ 0.4$ billion for fiscal 1977, respectively (1978 Budget p. 60). The net effect is zero, therefore only the figures provided for the increase in the minimum tax rate for individuals (\$1.1 billion in fiscal 1977), out of total increase in liabilities of $\$ 1.6$ billion, is included. The same proportions are used to deduce the effect for calendar 1976, i.e. $(1.1 / 1.6) \times 2.4$ or $\$ 1.65$ billion increase in individual tax liabilities due to the expansion of the minimum tax.

6. Tax Reduction and Simplification Act of 1977 Signed 5/23/77; The Tax Reduction and Simplification Act of 1977 established the "zero bracket amount" which was included in the definition of taxable income, a simplified single deduction amount based-on marital status and a new jobs credit. The Act also extended several temporary provisions of the Tax Reform Act of 1976 (see SOI 1977 p. vi.). The 1978 Economic Report (p.52) provides estimates for individual tax liabilities effects in calendar 1977 of $-\$ 3.3$ billion for calendar 1977. I subtract another $\$ 2.1$ billion in individual income tax revenues to account for the withholding effect on individual taxpayers (see 1979 Budget (p. 50) and Romer and Romer (2009)). The Act changed the tax tables to reflect the change in the definition of taxable income, but this did not affect the rate structure. The entire amount is therefore classified as being due to 'other changes'.

7. Revenue Act of $\mathbf{1 9 7 8}$ Signed 11/6/78; The Revenue Act of 1978 lowered individual tax rates. It widened and reduced the number of brackets, increased the personal exemption and the zero bracket amount, expanded the earned income tax credit and made several other changes (see SOI 1979 p. viii, CBO 1998 Projecting Federal Tax Revenues and the Effect of Changes in the Law, p.11). The 1979 Economic Report (p.93) describes the effect of the bill as a $\$ 14.1$ billion cut in personal taxes and a $\$ 0.7$ increase in outlays for the earned income tax credit in calendar 1979. The 1980 Budget (p. 60-62) reports a similar total impact of $\$ 14.5$ billion in calendar 1979 and \$0.7 billion increase in outlays for the EITC, of which \$ 10.4 billion is due to the rate and bracket changes. I adopt these latter numbers. The JCT report on the 1978 Act contains very similar estimates and also provides the marginal rate schedule under prior law (March 1979, p.42).

8. Economic Recovery Tax Act of 1981 Signed 8/13/81; The Economic Recovery Tax Act of 1981 consisted for the main part of permanent, across-the-board reductions in marginal tax rates in several stages and also instituted the indexing of the bracket structure. Effective in 1981 were changes to the minimum tax, the alternative tax and several other changes to the tax code (see SOI 1981 p 6, CBO 1998 Projecting Federal Tax Revenues and the Effect of Changes in the Law, p.14). The 1983 Budget (p.4-9 and 4.10) provides the decomposition of the decline in tax liabilities for 1981 and puts the reduction in individual income tax liabilities at a total of $\$ 4.0$ billion for calendar 1981. The ERTA report of the JCT (December 1981, Table V-4 in Appendix) estimates an impact on personal tax liabilities in calendar 1981 of $\$ 4.1$ billion of which $\$ 3.6$ billion is due the rate cuts effective in 1981 and also describes the rate schedule under prior law. The Act had little or no direct implications for employment taxes. 
9. Tax Equity and Fiscal Responsibility Act of 1982 Signed 9/3/82; The act repealed the add-on minimum tax, added several new tax preferences to the minimum tax, restructured the treatment of itemized deductions in the minimum tax, established a flat rate of 20 percent for the minimum tax, and increased the minimum tax exemption, and made several other changes. The CBO provides an estimated impact on individual income tax liabilities of \$5 billion for fiscal 1983 (CBO 1998 Projecting Federal Tax Revenues and the Effect of Changes in Tax Law p.18-19). The JCT Report (December 1982) indicate a total effect of 3.1 billion for calendar 1983, and another 0.7 billion in each of calendar 1982 and 1983 due the expansion of the taxation of unemployment benefits, The report assigns $\$ 0.7$ billion as due to the expansion of the alternative minimum tax for calendar 1983. The prior law rate schedule for 1983 is the one legislated under ERTA 1981. The Act also increased the FUTA wage base and rate and expanded the Medicare tax to federal government employees. According to the JCT report these measures raised employment tax liabilities by $\$ 3.0$ billion in calendar 1983 , of which $\$ 0.8$ billion is due the increased Medicare coverage.

10. Deficit Reduction Act of 1984 Signed 7/18/84; The Deficit Reduction Act of 1984 postponed or repealed several revenue reducing provisions scheduled to take effect after 1984 (e.g. the net interest exclusion, made changes to thresholds for income averaging and a large number of minor provisions that raised revenues from corporate and individual taxpayers (SOI 1984 p. 3 and CBO 1998 Projecting Federal Tax Revenues and the Effect of Changes in Tax Law p. 16). Calendar year numbers are not available. The 1986 and 1987 Budgets contain fiscal year revenue impact projections of DEFRA on individual taxes, which where $\$ 0.7$ billion for 1984 and $\$ 5.6$ billion for 1985 . I estimate a calendar 1984 year impact of $\$ 0.7+\$ 5.6 \times 0.25=\$ 2.1$ billion and classify the entire amount as due to non MTR provisions. The prior law rate schedule for 1984 is the one legislated under ERTA 1981. The Act had little or no direct implications for employment taxes and the higher social security rates that became effective in 1984 were part of legislation in previous years.

11. Tax Reform Act of 1986 Signed 10/22/86 ; The Tax Reform Act of 1986 significantly reduced individual income tax liabilities, broadened the individual tax base (eliminating the itemized deductions for state sales taxes paid and expanding the alternative minimum tax) and was the first complete revision of the Internal Revenue Code since 1954 (CBO, Projecting Federal Tax Revenues and the Effect of Changes in Tax Law p. 21). The revenue effects of the tax change in 1987 are generally hard to discern, see Romer and Romer (2009). The CBO (Projecting Federal Tax Revenues and the Effect of Changes in Tax Law p. 25) estimates a total projected reduction of $\$ 15$ billion in individual income tax revenues for fiscal 1987, which is similar to a reduction of $\$ 14.0$ billion for fiscal 1987 after adding the provision affecting individuals in the JCT report (May 1987 Appendix Tables) on TRA 1986. The JCT estimates the revenue impact of the rate reductions alone to be $\$ 16.9$ billion for fiscal 1987. The Act provided for rate reductions in two stages, with 1987 as a transitional tax year. I estimate the calendar 1987 revenue impact of the rate reductions as $-\$ 16.9 \times 1.25=$ $-\$ 21.1$ billion and the combined effect of the other provisions as $(-14.0+16.9) \times 1.25=\$ 3.7$ billion. The prior law schedule for 1987 is described in the JCT report on TRA 1986 and corresponds to the tax schedule for 1986 under the inflation adjustment to the tax brackets using the IRS method. The implications of TRA 1986 for payroll tax liabilities are very small ( $-\$ 0.1$ billion).

12. Omnibus Budget Reconciliation Act of 1987 Signed 12/22/87; The act made some minor changes to tax credits and deductions. The Conference Report (100th Congress, 1st Session, House of Representatives Report No. 100-495, 12/21/87) gives a detailed breakdown of the revenue effects for fiscal years 1988 and 1989. Summing the $1988 \mathrm{FY}$ impact and one quarter of the $1989 \mathrm{FY}$ impact yields an estimated change of $-\$ 0.2$ billion in income tax liabilities for calendar 1988. The act also increased employment taxes by expanding the social security wage base and increasing the FUTA rate. Based on numbers in the Conference Report these measures increased payroll tax liabilities by $\$ 1.7$ billion in calendar 1988 of which $\$ 0.5$ billion is due to expansions of the FICA wage base. 
13. Omnibus Budget Reconciliation Act of 1990 Signed 11/5/90; The Omnibus Budget Reconciliation Act of 1990 increased personal income taxes for upper-income taxpayers by three provisions: a higher top tax rate, a revised phaseout of personal exemptions, and a limit on itemized deductions. It also imposed a new statutory rate of 31 percent on certain income of high-income taxpayers and replaced a set of provisions enacted in TRA-86 that had created an implicit 33 percent statutory tax rate over a limited range but that had resulted in a top marginal rate of 28 percent for the highest-income taxpayers. (CBO, Projecting Federal Tax Revenues and the Effect of Changes in Tax Law p. 27,31). The JCT Report (October 1990) provides detailed estimates of the fiscal year impacts of all provisions. The total impact of $\$ 2.9$ billion for calendar 1991 is obtained by summing the FY 1991 amounts and one quarter of the FY 1992 amounts for provisions affecting individual income taxes. Based on the JCT report, the basic, minimum and maximum rate changes account for $\$ 1.3 \mathrm{billion}$. The prior law tax schedule is the 1990 schedule adjusted for inflation using the IRS method. The Act also affected employment taxes by instituting a large increase in the Medicare tax earnings cap, expanding the coverage of social security to State and Local employees not participating in a public employee retirement system and by extending the higher FUTA rate. Based on the JCT report, these measures increased payroll tax liabilities by $\$ 5.3$ billion, of which $\$ 4.2$ billion is due to higher FICA taxes.

14. Omnibus Budget Reconciliation Act of 1993 Signed 8/10/93; The Omnibus Reconciliation Act of 1993 increased income tax rates, mostly for higher earners. The JCT report on OBRA 1993 (August 1993) provides a by-component breakdown of the revenue implications for fiscal 1994 onward, including details on components retroactive to 1/1/93. The revenue effects for the 1993 part of the tax reform are mostly entirely due to the increase in individual tax rates. I adopt the JCT estimate of $\$ 15.4$ billion for the full fiscal 1994 as the estimated impact of the rate changes for calendar 1993. The prior law tax schedule is the 1992 schedule adjusted for inflation using the IRS method. The act also eliminated the earnings cap for the Medicare tax (Hospital Insurance). The removal of the cap (\$2.8 billion in 2004) was only effective in 1994 and is therefore not included.

15. Jobs and Growth Tax Relief Reconciliation Act of 2003 Signed 8/10/03; The Jobs and Growth Tax Relief Reconciliation Act of 2003 included an expansion of the 10 percent tax bracket, an increase in exemptions for the minimum tax, a reduction in rates on married couples, an increase in the child credit, as well as lower a reduction in taxes on dividends and capital gains. The JCT report (May 2003) provides detailed estimated of the fiscal year impacts of all provisions. The total impact of $-\$ 63.5$ billion for calendar 2003 is obtained by summing the FY 1993 amounts and one quarter of the FY 1994 amounts for provisions affecting individual income taxes. Based on the JCT report, the rate reductions account for a decrease of $\$ 43.0$ billion in liabilities. The prior law tax schedule is the one legislated for 2003 by the 2001 Economic Growth and Tax Relief Reconciliation Act of 2001 after inflation adjustments using the IRS method. 


\section{B Additional Analysis}

\section{B.1 First-stage Statistics and Weak Instrument Concerns}

In addition to the SVAR-IV/LP-IV exogeneity conditions, the main requirement on the random variable $z_{t}$ is its relevance. While the former condition is not testable in our framework, the latter is. This section discusses the SVAR-IV/LP-IV 'first-stage' statistics along with potential weak-instrument concerns. Our results show that the weak-instrument robust confidence intervals for SVAR-IV/LP-IV are both very close to the standard confidence intervals reported in the previous sections.

SVAR-IV RELEVANCE: In the SVAR-IV framework, the relevance condition states that the covariance between $z_{t}$ and the scalar shock representing the exogenous innovations in tax rates, $v_{t}^{\tau}$, has to be different from zero $\left(\mathbb{E}\left[z_{t} v_{t}^{\tau}\right]=\alpha \neq 0\right)$. As discussed before, the motivation to exclude tax reforms that were legislated at least one year before becoming effective was to generate a value of $\alpha$ far away from zero.

The relevance and exogeneity assumption, plus the normalization $B_{1,1}=-1$, imply that $\mathbb{E}\left[z_{t} u_{t}^{A M T R}\right]=-\alpha$. Since the reduced-form residual $u_{t}^{A M T R}$ can be estimated by least-squares, we can test the null hypothesis $\alpha=0$ by looking at the standardized sample mean of the random variable $z_{t} \widehat{u}_{t}^{A M T R}$. Under standard regularity conditions, the null hypothesis of $\alpha=0$ can be rejected at the $\gamma \%$ (asymptotic) level whenever:

$$
F_{S V A R-I V} \equiv\left((1 / \sqrt{T}) \sum_{t=1}^{T} z_{t} \widehat{u}_{t}^{A M T R}\right)^{2} / \operatorname{AsyVar}\left((1 / \sqrt{T}) \sum_{t=1}^{T} z_{t} \widehat{u}_{t}^{A M T R}\right)
$$

is larger than the $(1-\gamma)$ quantile of a chi-squared random variable with one-degree of freedom.

There are two interesting features about the statistic in equation (B.1). First, the results in Montiel-Olea, Stock and Watson (2017) imply that the 'center' of the $F_{S V A R-I V}$ statistic is analogous to the so-called concentration parameter in the linear IV model. Second, whenever the data is such that the null hypothesis $\alpha=0$ is rejected at the $\gamma \%$ level using (B.1), the $(1-\gamma) \%$ weak-instrument robust confidence set recommended by Montiel-Olea, Stock and Watson (2017) is guaranteed to be a finite-length interval.

In our baseline SVAR-IV specification, the $F_{S V A R-I V}$ statistic equals 11.09 when using the aggregate AMTR series based on the Barro and Redlick (2011) income concept (Table 4, Panel A, Column [1]). The corresponding value when we use the aggregate AMTR series based on the Piketty and Saez (2003) income concept is 8.90 (Table 4, Panel A, Column [2]). Both these values are larger than 3.84 (the 95\% quantile of a chi-squared with one degree of freedom). The former just exceeds the value of 10 suggested by Stock and Yogo (2005), while the latter is just below.

The top panel of Figure B.1 compares $68 \%$ and $95 \%$ weak-instrument robust confidence intervals for the dynamic responses of income vis-à-vis standard confidence intervals for the Barro and Redlick (2011) AMTR series. The figure shows that the $68 \%$ weak-instrument robust confidence intervals are almost identical to the standard ones. The 95\% confidence intervals exhibit some differences, but most of them concern the upper bound of the weak-instrument robust confidence set. For instance, as reported in column [1] in Panel A of Table 4, the standard confidence interval for the short run ETI measured one period after the shock is $[.80,1.94]$, while the weak instrument robust confidence interval is $[0.77,2.20]$. The bottom panel of Figure B.1 shows that the Delta-method intervals are also similar to those from the bootstrap procedures proposed in Mertens and Ravn (2013), Montiel-Olea, Stock and Watson (2017) and Jentsch and Lunsford (2016). The only exceptions are the 95\% intervals for the moving block bootstrap proposed by Jentsch and Lunsford (2016), which are considerably wider than all of the others. 
LP-IV RELEVANCE: Consider the usual first-stage regression:

$$
\log \left(1-\text { AMTR }_{t}\right)=c+d^{\prime} W_{t}+\pi z_{t}+v_{t}
$$

In the LP-IV framework, the relevance condition is tantamount to the standard relevance assumption for linear IV models: $\pi \neq 0$. Thus, the typical test for the null hypothesis of instrument irrelevance is the $\mathrm{F}$ test for $\pi=0$ (taking into account the potential heteroskedasticity and/or autocorrelation in the residual $v_{t}$ ).

In our baseline LP-IV specification the first-stage F (using a Newey-West HAC-robust residual covariance matrix with 8 lags) is 229.25 when using the aggregate AMTR series based on the Barro and Redlick (2011) income concept (Table 5, Panel A, Column [1]). The corresponding value when we use the aggregate AMTR series based on the Piketty and Saez (2003) income concept is 62.24 (Table 5, Panel A, Column [2]). These values for the firststage $F$-statistics are above the Stock and Yogo (2005) threshold and above the more stringent cutoff suggested by Montiel-Olea and Pflueger (2013). Figure B.2 shows that both the 68\% and 95\% (HAC) Anderson and Rubin (1949) confidence intervals are, for all practical purposes, indistinguishable from the standard IV confidence regions.

We note that the validity of SVAR-IV and LP-IV inference relies on different high-level assumptions. On the one hand, SVAR-IV inference assumes that the reduced-form VAR parameters (slope coefficients of the vector autoregression and the covariance between $z_{t}$ and $u_{t}$ ) are approximately distributed as a multivariate normal. On the other hand, LP-IV inference assumes that the reduced-form IV parameters (the regression coefficients corresponding to the reduced form versions of the equations (9) and (B.2)) are approximately distributed as multivariate normal. Since the reduced-form VAR parameters and the reduced-form IV parameters are different objects, SVAR-IV/LP-IV impose regularity assumptions on different statistics.

As a final exercise, and in order to have a more direct comparison between the SVAR-IV/LP-IV results, we report confidence intervals for LP-IV under the VAR high-level assumptions. To do this, we assume that the true data generating process is a vector autoregression. The results for the short run ETI are reported in B.2. The 68\% confidence level the confidence intervals for the dynamic responses of income-whether based on SVAR-IV or LP-IV assumptions-lie close to each other for the first three horizons. Starting at horizon four (three years after the shock), the VAR based LP-IV confidence intervals become wider and the response of income becomes insignificant for the last two periods. At the $95 \%$ level, the discrepancy between the two types of confidence intervals arises as early as horizon two. For instance, the LP-IV VAR based confidence interval for the short run ETI is $[1.34,1.81]$, whereas the standard LP-IV confidence interval is [.45, 1.93].

To address possible weak instrument concerns for the elasticity estimates by income group and income source, Tables B.1 and B. 2 repeats the estimation results of Tables 4 and 5, but report the weak-instrument robust confidence intervals suggested by Montiel-Olea, Stock and Watson (2017) for the SVAR-IV estimates, and those from inverting the Anderson and Rubin (1949) test for the LP-IV estimates. 
68\% Confidence Level

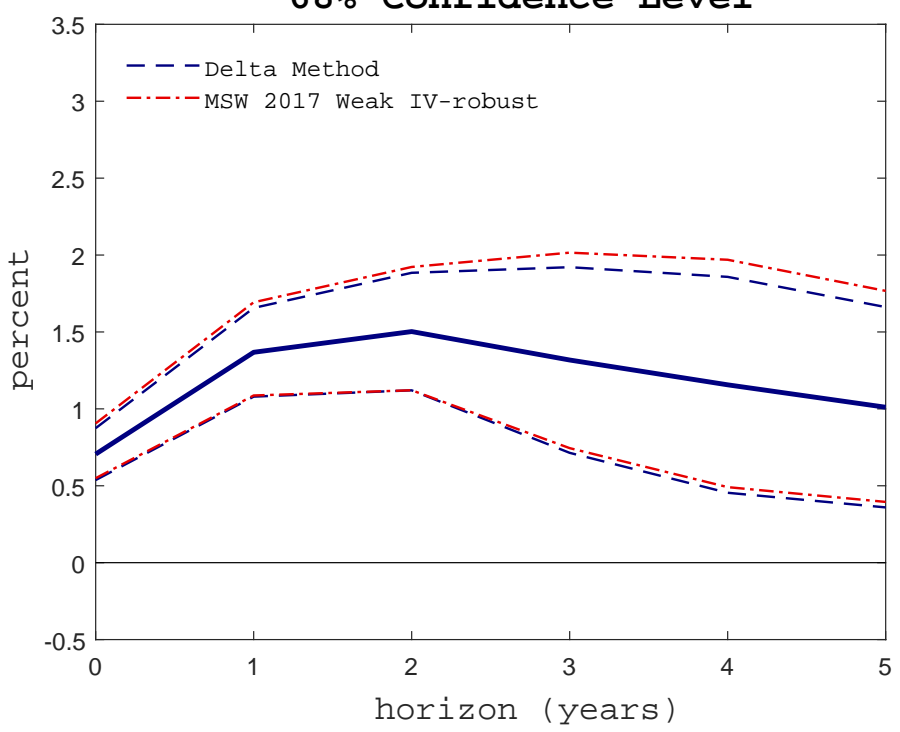

68\% Confidence Level

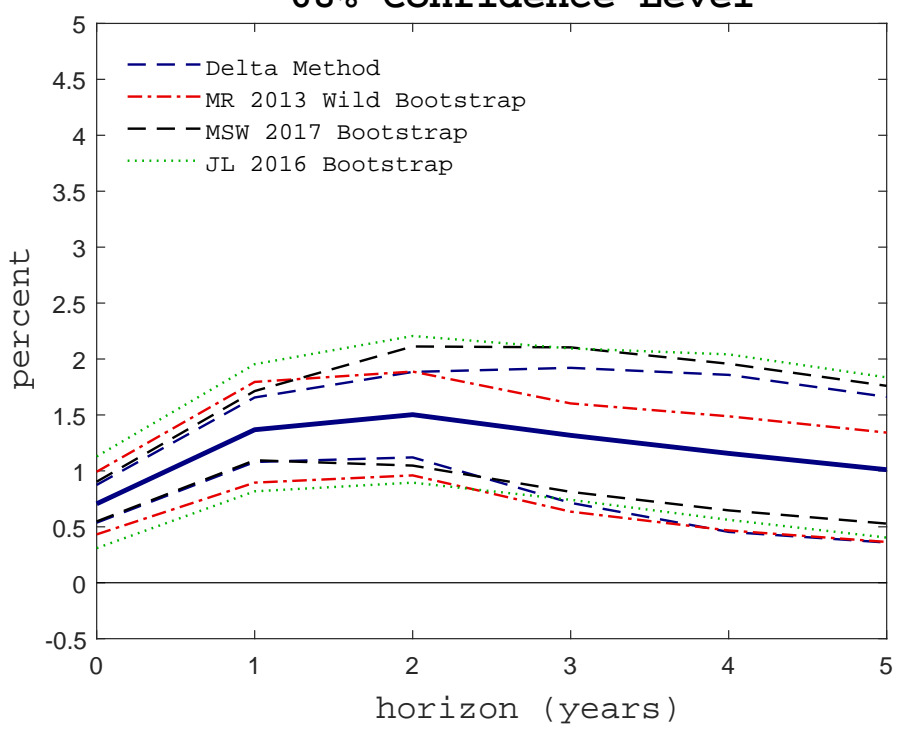

95\% Confidence Level

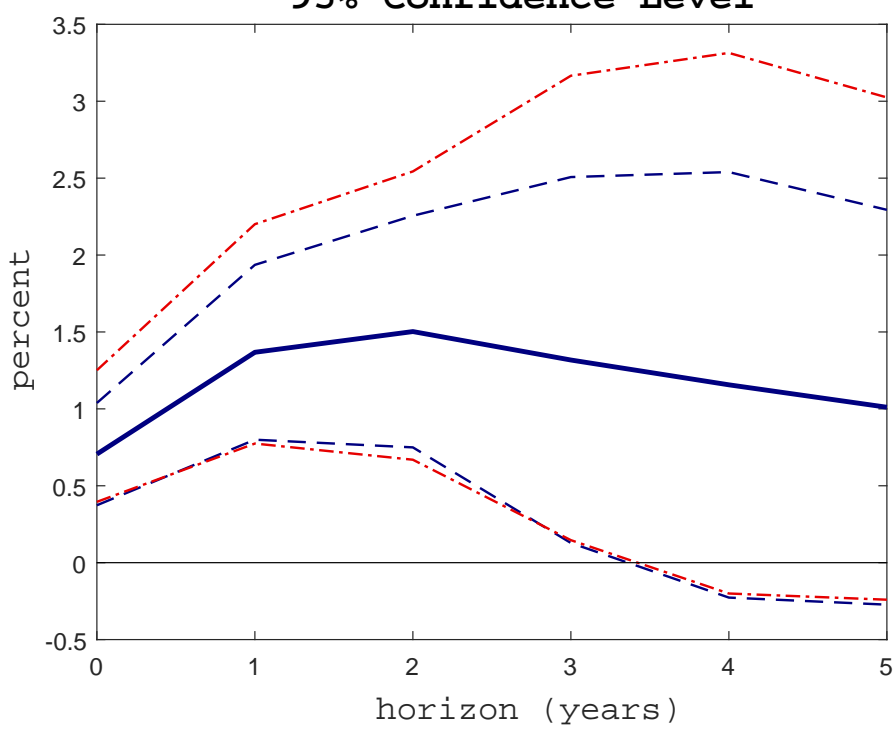

95\% Confidence Level

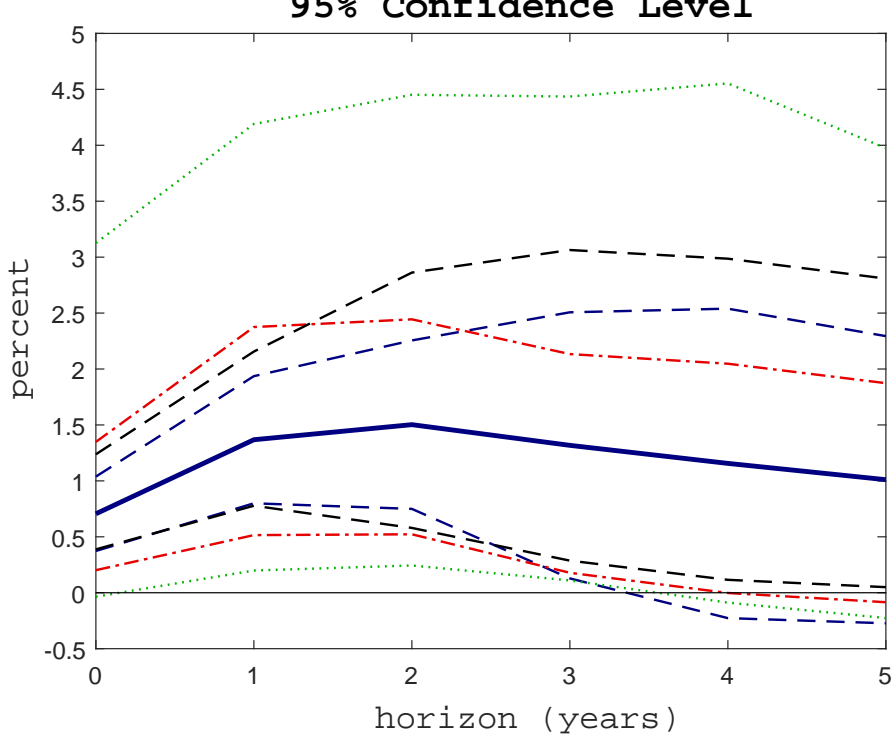

\section{Figure B.1 Confidence Intervals for SVAR-IV Estimates of Aggregate Tax Elasticities of Income}

Point estimates are obtained using the SVAR-IV model as in Figure 5. Top Panel: Broken lines compare the weak-iv robust confidence interval suggested in Montiel-Olea, Stock and Watson (2017) with the standard confidence interval based on the Delta Method. In both cases, the Newey and West (1987) HAC-robust residual covariance matrix with 8 lags is used to estimate asymptotic covariances. Bottom Panel: Broken lines compare the bootstrap intervals suggested in Mertens and Ravn (2013), Montiel-Olea, Stock and Watson (2017) and Jentsch and Lunsford (2016), respectively, with the standard confidence interval based on the Delta Method. 

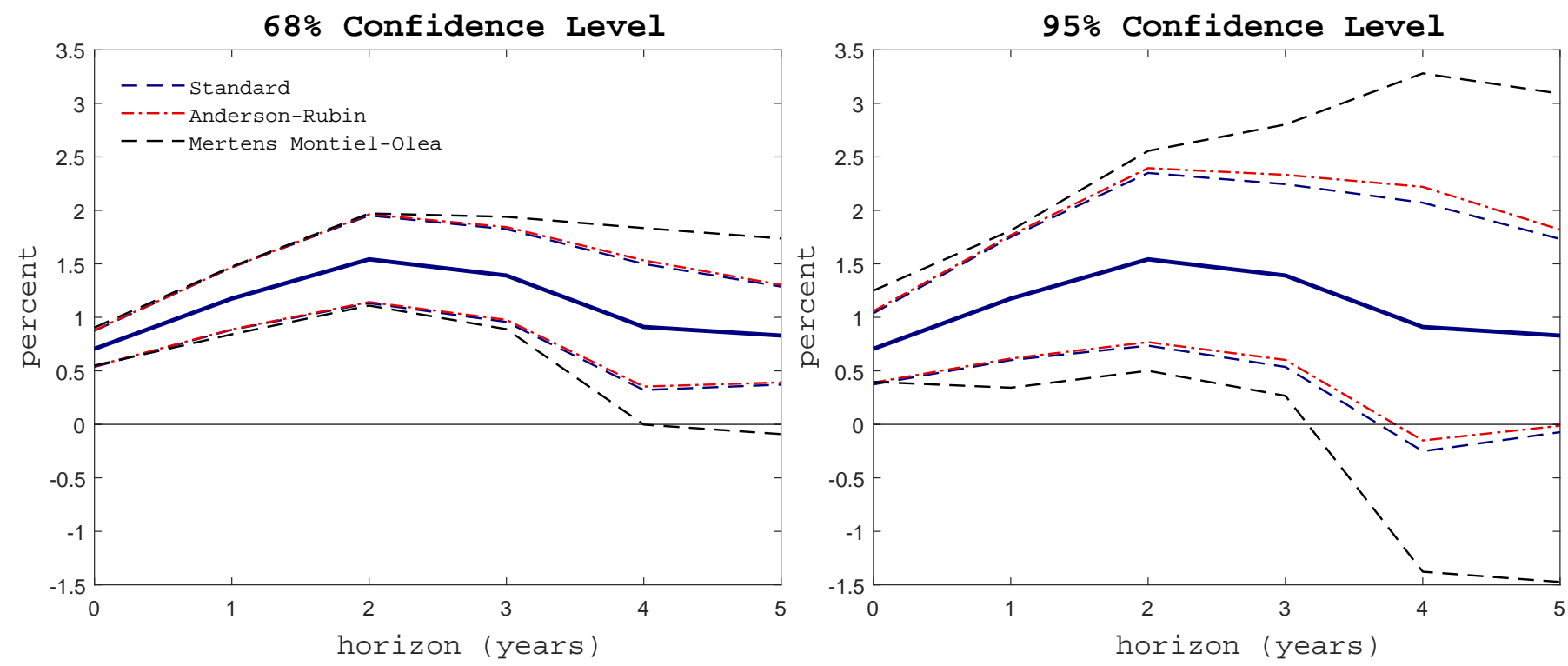

Figure B.2 Confidence Intervals for LP-IV Estimates of Aggregate Tax Elasticities of Income

Point estimates are obtained using the SVAR-IV model as in Figure 6. Broken lines compare Anderson and Rubin (1949) confidence intervals and the LP-IV intervals under the VAR high-level assumption, with the standard confidence intervals. All confidence bands are based on Newey and West (1987) HAC-robust standard errors. 
Table B.1 SVAR-IV Estimates with Weak-IV Robust Intervals, Sample: 1948-2012

\begin{tabular}{|c|c|c|c|c|c|c|c|c|c|}
\hline & All Ta & Units & Top 1\% & Top 5\% & Top $10 \%$ & Top 5-1\% & Top $10-5 \%$ & Btm. 99\% & Btm. 90\% \\
\hline & BR 2011 & PS 2003 & & & & & & & \\
\hline & A.Total I & arket Inc & ne (exclud & gg Capital & Gains) & & & & \\
\hline Same year & $0.71^{* * *}$ & $0.75^{* * *}$ & $0.71^{* * *}$ & $0.66^{* * *}$ & $0.65^{* * *}$ & $0.56^{* *}$ & $0.47^{* *}$ & $0.44^{*}$ & 0.51 \\
\hline & $(0.40,1.25)$ & $(0.45,1.49)$ & $(0.42,1.37)$ & $(0.39,1.41)$ & $(0.37,1.42)$ & $(0.12,1.01)$ & $(0.20,0.84)$ & $(-0.06,0.96)$ & $(-0.39,1.17)$ \\
\hline Following year & $1.37^{* * *}$ & $1.45^{* * *}$ & $1.35^{* *}$ & $1.21^{* * *}$ & $1.06^{* * *}$ & $0.91^{* *}$ & $0.79^{* * *}$ & $1.01^{* * *}$ & $0.98^{*}$ \\
\hline & $(0.77,2.20)$ & $(0.99,2.60)$ & $(0.73,1.86)$ & $(0.83,1.77)$ & $(0.68,1.71)$ & $(0.26,1.69)$ & $(0.40,1.56)$ & $(0.40,1.85)$ & $(-0.00,1.92)$ \\
\hline$F_{S V A R-I V}$ & 11.09 & 8.90 & 8.50 & 8.72 & 7.96 & 9.60 & 8.11 & 9.59 & 7.87 \\
\hline & B. Wage & icome & & & & & & & \\
\hline Same year & $0.50^{* * *}$ & $0.51^{* * *}$ & $0.67^{* * *}$ & $0.37^{* *}$ & $0.40^{* *}$ & -0.08 & $0.42^{* *}$ & 0.29 & $0.39^{*}$ \\
\hline & $(0.17,0.99)$ & $(0.20,1.22)$ & $(0.41,1.35)$ & $(0.06,1.11)$ & $(0.00,1.33)$ & $(-0.47,0.54)$ & $(0.03,1.06)$ & $(-0.16,0.80)$ & $(-0.95,1.02)$ \\
\hline Following year & $0.94^{* *}$ & $0.97^{* *}$ & $0.96^{* * *}$ & $0.70^{* *}$ & $0.50^{*}$ & 0.14 & $0.62^{* * *}$ & $0.82^{*}$ & $0.91^{*}$ \\
\hline & $(0.06,1.67)$ & $(0.30,1.89)$ & $(0.50,1.49)$ & $(0.19,1.34)$ & $(-0.08,1.15)$ & $(-0.39,0.65)$ & $(0.21,1.48)$ & $(-0.01,1.66)$ & $(-1.19,1.81)$ \\
\hline$F_{S V A R-I V}$ & 10.78 & 8.24 & 10.00 & 9.31 & 7.84 & 8.68 & 8.80 & 8.72 & 6.48 \\
\hline & C. Other & ncome (er & luding $\mathrm{Ca}$ & ital Gains & & & & & \\
\hline Same year & $1.66^{* * *}$ & $1.84^{* * *}$ & $0.88^{* * *}$ & $1.35^{* * *}$ & $1.46^{* *}$ & $2.15^{* *}$ & 0.79 & $1.60^{*}$ & 1.19 \\
\hline & $(0.83,2.63)$ & $(0.94,3.13)$ & $(0.43,1.57)$ & $(0.75,2.01)$ & $(0.62,2.26)$ & $(0.47,3.65)$ & $(-4.10,3.76)$ & $(-0.17,3.12)$ & $(-5.43,12.32)$ \\
\hline Following year & $3.29^{* * *}$ & $3.46^{* * *}$ & $1.94^{* *}$ & $2.57^{* * *}$ & $2.80^{* * *}$ & $3.32^{* *}$ & 2.21 & $2.35^{* * *}$ & 0.41 \\
\hline & $(2.15,5.84)$ & $(2.13,6.82)$ & $(0.93,2.77)$ & $(1.40,3.52)$ & $(1.63,3.82)$ & $(0.26,6.03)$ & $(-2.64,5.69)$ & $(0.79,6.49)$ & $(-2.61,71.19)$ \\
\hline$F_{S V A R-I V}$ & 10.67 & 8.21 & 9.55 & 10.50 & 9.67 & 8.97 & 8.94 & 8.56 & 4.04 \\
\hline
\end{tabular}

D.Total Market Income (including Capital Gains)

\begin{tabular}{|c|c|c|c|c|c|c|c|c|c|}
\hline Same year & 0.45 & 0.52 & 0.22 & 0.07 & 0.08 & -0.07 & 0.10 & 0.23 & 0.44 \\
\hline & $(-0.57,1.29)$ & $(-0.53,1.50)$ & $(-0.79,1.65)$ & $(-1.04,1.65)$ & $(-1.01,1.55)$ & $(-1.33,1.12)$ & $(-0.91,1.04)$ & $(-1.18,1.02)$ & $(-1.07,1.25)$ \\
\hline \multirow[t]{2}{*}{ Following year } & $1.38^{* *}$ & $1.49^{* *}$ & $1.07^{* *}$ & $0.92^{*}$ & $0.86^{*}$ & 0.33 & 0.65 & 0.97 & $1.13^{*}$ \\
\hline & $(0.08,2.55)$ & $(0.32,2.91)$ & $(0.09,2.46)$ & $(-0.13,2.28)$ & $(-0.08,1.99)$ & $(-1.26,1.80)$ & $(-0.70,2.04)$ & $(-0.46,1.91)$ & $(-0.46,2.27)$ \\
\hline \multirow[t]{2}{*}{$F_{S V A R-I V}$} & 10.58 & 9.79 & 13.29 & 12.58 & 11.73 & 11.98 & 11.02 & 8.99 & 6.16 \\
\hline & \multicolumn{9}{|c|}{ E. Other Income (including Capital Gains) } \\
\hline \multirow[t]{2}{*}{ Same year } & 1.35 & 1.59 & -0.35 & -0.59 & -0.62 & 0.01 & 1.08 & 1.04 & 0.81 \\
\hline & $(-1.20,3.95)$ & $(-0.97,4.71)$ & $(-1.89,2.20)$ & $(-3.44,3.69)$ & $(-4.71,5.11)$ & $(-4.19,5.86)$ & $(-5.42,6.18)$ & $(-2.32,4.26)$ & $(-1.68,6.29)$ \\
\hline \multirow{2}{*}{ Following year } & $4.41^{* * *}$ & $4.55^{* * *}$ & $1.22^{* *}$ & 1.46 & 1.94 & 1.35 & 4.13 & $3.21^{* * *}$ & $1.95^{*}$ \\
\hline & $(2.20,8.35)$ & $(2.35,9.43)$ & $(0.15,3.02)$ & $(-0.57,4.30)$ & $(-0.70,5.09)$ & $(-2.94,7.27)$ & $(-1.20,9.48)$ & $(0.92,7.99)$ & $(-0.47,14.17)$ \\
\hline$F_{S V A R-I V}$ & 12.62 & 11.33 & 15.78 & 12.80 & 11.07 & 10.44 & 11.57 & 9.97 & 5.99 \\
\hline
\end{tabular}

Notes: Estimates are as in Table 4, but the $95 \%$ confidence intervals are based on the weak-instrument robust intervals suggested by Montiel-Olea, Stock and Watson (2017) Asterisks denote 10\%, 5\% or 1\% significance. 
Table B.2 LP-IV Estimates with Weak-IV Robust Intervals, Sample: 1948-2012

\begin{tabular}{|c|c|c|c|c|c|c|c|c|c|}
\hline & All Ta: & Units & Top 1\% & Top 5\% & Top 10\% & Top 5-1\% & Top 10-5\% & Btm. 99\% & Btm. 90\% \\
\hline & BR 2011 & PS 2003 & & & & & & & \\
\hline & A.Total $\mathrm{N}$ & arket Inco & ee (exclud & g Capital & Gains) & & & & \\
\hline Same year & $0.71^{* * *}$ & $0.75^{* * *}$ & $0.71^{* * *}$ & $0.66^{* * *}$ & $0.65^{* * *}$ & $0.56^{* *}$ & $0.47^{* * *}$ & $0.44^{*}$ & 0.51 \\
\hline & $(0.29,1.13)$ & $(0.30,1.19)$ & $(0.30,1.12)$ & $(0.23,1.08)$ & $(0.23,1.07)$ & $(0.12,0.99)$ & $(0.18,0.76)$ & $(-0.06,0.94)$ & $(-0.18,1.21)$ \\
\hline Following year & $1.19^{* * *}$ & $1.24^{* * *}$ & $1.37^{* * *}$ & $1.24^{* * *}$ & $1.03^{* * *}$ & $0.85^{* *}$ & 0.50 & $0.73^{*}$ & 0.79 \\
\hline & $(0.45,1.93)$ & $(0.57,1.91)$ & $(0.60,2.15)$ & $(0.66,1.83)$ & $(0.50,1.56)$ & $(0.20,1.50)$ & $(-0.11,1.12)$ & $(-0.14,1.61)$ & $(-0.38,1.96)$ \\
\hline$F_{1 \text { st-Stage }}$ & 229.25 & 62.24 & 51.30 & 33.38 & 34.43 & 17.88 & 14.07 & 29.91 & 16.90 \\
\hline & B. Wage I & come & & & & & & & \\
\hline Same year & $0.50^{* *}$ & $0.51^{* *}$ & $0.67^{* * *}$ & 0.37 & 0.40 & -0.08 & $0.42^{*}$ & 0.29 & 0.39 \\
\hline & $(0.08,0.92)$ & $(0.07,0.95)$ & $(0.24,1.09)$ & $(-0.11,0.85)$ & $(-0.16,0.96)$ & $(-0.55,0.39)$ & $(-0.07,0.90)$ & $(-0.17,0.76)$ & $(-0.36,1.15)$ \\
\hline Following year & $0.81^{*}$ & $0.79^{*}$ & $1.21^{* * *}$ & $0.79^{* *}$ & 0.45 & -0.01 & 0.04 & 0.51 & 0.71 \\
\hline & $(-0.14,1.76)$ & $(-0.10,1.68)$ & $(0.41,2.00)$ & $(0.15,1.43)$ & $(-0.32,1.22)$ & $(-0.61,0.58)$ & $(-0.88,0.95)$ & $(-0.54,1.56)$ & $(-0.96,2.37)$ \\
\hline$F_{1 s t-S t a g e}$ & 206.89 & 50.97 & 39.62 & 35.60 & 42.07 & 11.13 & 14.18 & 25.98 & 15.87 \\
\hline & C. Other & ncome (ex & luding $\mathrm{Ca}$ & ital Gains) & & & & & \\
\hline Same year & $1.66^{* * *}$ & $1.84^{* * *}$ & $0.88^{* * *}$ & $1.35^{* * *}$ & $1.46^{* * *}$ & $2.15^{* * *}$ & 0.79 & $1.60^{* *}$ & 1.19 \\
\hline & $(0.73,2.59)$ & $(0.82,2.86)$ & $(0.32,1.44)$ & $(0.71,2.00)$ & $(0.64,2.29)$ & $(0.59,3.71)$ & $(-2.95,4.52)$ & $(0.01,3.18)$ & $(-1.29,3.68)$ \\
\hline Following year & $2.63^{* * *}$ & $2.78^{* * *}$ & $1.86^{* * *}$ & $2.58^{* * *}$ & $3.01^{* * *}$ & $3.07^{* *}$ & 4.12 & $1.80^{* * *}$ & 0.12 \\
\hline & $(0.97,4.29)$ & $(1.48,4.07)$ & $(0.69,3.03)$ & $(1.24,3.93)$ & $(1.61,4.41)$ & $(0.40,5.74)$ & $(-1.20,9.45)$ & $(0.62,2.99)$ & $(-2.30,2.55)$ \\
\hline$F_{1 s t-\text { Stage }}$ & 200.07 & 50.65 & 34.62 & 29.16 & 26.31 & 18.60 & 15.37 & 25.50 & 10.84 \\
\hline
\end{tabular}

D.Total Market Income (including Capital Gains)

$\begin{array}{lccccccccc}\text { Same year } & 0.45 & 0.52 & 0.22 & 0.07 & 0.08 & -0.07 & 0.10 & 0.23 & 0.44 \\ & (-0.51,1.41) & (-0.51,1.54) & (-1.09,1.54) & (-1.36,1.50) & (-1.27,1.43) & (-1.39,1.24) & (-0.92,1.12) & (-0.81,1.27) & (-0.44,1.32) \\ \text { Following year } & 0.98 & 1.14^{*} & 1.11^{*} & 1.03 & 0.88 & 0.55 & 0.46 & 0.62 & 0.82 \\ & (-0.24,2.20) & (-0.09,2.36) & (-0.10,2.32) & (-0.21,2.26) & (-0.20,1.97) & (-0.68,1.77) & (-0.78,1.70) & (-0.74,1.97) & (-0.60,2.24) \\ F_{1 \text { st-Stage }} & 63.14 & 44.17 & 41.80 & 27.89 & 30.42 & 25.30 & 13.72 & 28.02 & 18.76\end{array}$

E. Other Income (including Capital Gains)

$\begin{array}{lccccccccc}\text { Same year } & 1.35 & 1.59 & -0.35 & -0.59 & -0.62 & 0.01 & 1.08 & 1.04 & 0.81 \\ & (-1.44,4.14) & (-1.39,4.57) & (-2.58,1.89) & (-4.39,3.20) & (-5.70,4.46) & (-5.10,5.12) & (-5.03,7.18) & (-2.31,4.38) & (-2.06,3.68) \\ \text { Following year } & 3.03^{* *} & 3.41^{* * *} & 1.12 & 1.45 & 1.93 & 1.94 & 5.40 & 2.04 & 0.51 \\ & (0.75,5.32) & (1.15,5.67) & (-0.33,2.57) & (-0.966,3.85) & (-1.55,5.40) & (-1.70,5.57) & (-2.46,13.26) & (-0.51,4.58) & (-1.42,2.45) \\ F_{1 \text { st-Stage }} & 64.93 & 37.06 & 59.81 & 30.23 & 45.66 & 28.64 & 19.23 & 21.88 & 14.18\end{array}$

Notes: Estimates are as in Table 5 but with 95\% Anderson and Rubin (1949) confidence intervals. Asterisks denote 10\%, 5\% or $1 \%$ significance. 


\section{B.2 Robustness Analysis}

\section{B.2.1 Robustness of Aggregate ETI estimates}

Table B.3 summarizes results for a number of robustness checks for the SVAR-IV-based same- and following year ETI estimates. Table B.4 reports the corresponding results for the LP-IV approach. Each column present the first two impulse response coefficients of average market income associated with a one percent increase to the aggregate net-of-tax rate. These are derived from SVAR/LP-IV models identical to those discussed in in Sections 4.4 but with the specified modification.

Sensitivity to Selection of Tax Reforms. Previous studies have found significant variation in the income responses across tax reforms. This variation could driven by insufficient controlling for coincident but unrelated changes in the determinants of income or by the specific attributes of each reform. By substantially increasing corporate relative to individual tax rates, the 1986 Tax Reform Act provided for instance particularly large incentives for income shifting, see Slemrod $(1995,1996)$. Given the relatively low number of tax changes used for identification, the results are therefore potentially sensitive to the inclusion of particular reforms. Columns [1] to [9] in Tables B.3 and B.4 present the results using alternative proxies/instruments that each omit the specified tax reforms by replacing the corresponding observations in Table 3 by zero. This generally has the expected effect of widening the confidence bands somewhat, in particular when the large 1964 Kennedy tax reform is dropped. However, all of the point estimates remain highly statistically significant and close in size to the benchmark model. Omitting the 1986 reform or both of the 1980 reforms leads to moderately larger ETI estimates.

Sensitivity to Specification and Sample Choice. SVAR results are sometimes sensitive to lag length, the inclusion of time trends or sample modifications. Without further steps to reduce the dimension of the estimation problem, preserving a reasonably rich set of endogenous controls in the VAR system dictates a choice of lag length of either one, two or three. For the 9 variables benchmark system, the Schwarz, Hannan-Quinn and Akaike criteria disagree and recommend respectively one, two and three lags. Residual tests reveal clear evidence for residual autocorrelation when only one lag is used, in particular for the AMTR equation. Such evidence disappears with two or three lags. Columns [10] and [11] in Table B.3 report results when instead of the benchmark choice of two lags, one or three lags are included. Including just one lag leads to considerably lower estimates but is almost surely inadequate for obtaining plausible tax rate innovations. Including three lags of all the endogenous variables leads to point estimates that are very similar to the benchmark but with wider confidence intervals. The wider confidence intervals are partly due to the larger number of parameters, but also because the use of three lags excludes 1948 from the sample, which is one of the tax reform years used for identification. As long as the lag exogeneity of $z_{t}$ continues to hold, estimates from the LP-IV model should be less sensitive to the number of lags in the controls. The estimates in columns [10] and [11] of Table B.4 show that including only a single lag reduces also the LP-IV estimate substantially, although less than in the SVAR-IV model. Including three lags, on the other hand, raises the LP-IV ETI estimate.

Columns [12] and [13] assess the consequences of dropping the dummies for 1949 and 2008. As discussed in the main text, in the SVAR-IV model this lowers the point estimates for the following year ETIs from 1.37 to 0.96 and 1.15 respectively, although these estimates remain significant at the 5\% level. The large tax cuts under the 1948 Tax Reform Act and the brief deflationary 1949 recession were both somewhat unusual. Major elements in the recession were the backlogs built up during the war and monetary tightening, see Caplan (1956). The 1948 tax reform was also atypical because it introduced the split-income method for joint returns, which lowered tax rates for primary earners but raised them for secondary earners. The SVAR-IV results are much more sensitive to the 1949 dummy than to including the 1948 reform among the identifying variation. Restricting the sample to exclude the 1940s (column [15]) raises the SVAR-IV estimate to 1.41. In the 1950-2006 sample, which is the one used in the main analysis of 
Barro and Redlick (2011) and in Romer and Romer (2010) and Mertens and Ravn (2013), the estimated ETI in the SVAR-IV model rises to 1.50 (column [16]). In the 1960-2000 sample studied by Saez (2004) and Saez et al. (2012), the estimate equals 1.40 which is very close to the benchmark (column [16]). The confidence bands are considerably wider in this case because of the smaller sample and the omission of the 1948 and 2003 reforms in the identification. The corresponding LP-IV results in Table B.4 show that the dummy variables are, in contrast to the SVAR-IV estimates, not very influential for the point estimates. Shortening the sample also leads to considerably higher ETI estimates in the LP-IV model. To gain further insight into the role of the dummy variables and sample period, Figure B.3 provides full impulse responses estimates for various cases. The first row shows results for the full 1948-2012 sample, but without including the 1949 or 2008 dummies. The SVAR-IV estimates are substantially smaller for all horizons in the SVAR-IV model, but remain nearly identical in the LP-IV model. The second row still uses the full sample, but excludes only the 1949 dummy. The SVAR-IV estimates are again smaller for all horizons, while the LP-IV are barely different. Finally, the third row shows results for the shorter 1950-2006 sample and without any year dummies. This yields very similar SVAR-IV impulse responses as in the larger sample with the 1949 and 2008 dummies, and substantially larger LP-IV impulse responses. We note that despite the variations in size, the following year elasticities remain statistically significant in all cases.

As in Saez (2004) and Saez et al. (2012), column [16] adds a linear and quadratic time trend and in column [18] the model includes an additional cubic term. This leads to moderately lower but nevertheless highly significant ETI estimates of 1.19 and 1.17 in the SVAR-IV model, and to highly significant LP-IV estimates of 0.98 in both cases.

Sensitivity to Alternative Tax Rate Measures and Proxies. Column [19] in Panel C of Tables 4 and B.4 shows that the alternative AMTR measure based on the Piketty and Saez (2003) income concept leads to slightly larger ETI estimates at both horizons. Columns [20] and [21] replace the AMTR series with the series capturing only the federal individual income tax component, as shown in the upper panel of Figure 2. For both income concepts, omitting the social security component leads to higher point estimates in both the SVAR-IV and LP-IV models. Note that the implied level decrease in the marginal tax rate is slightly larger in this case. The higher estimates could therefore mean that the tax semi-elasticity of income is more stable than the elasticity. Overall, the inclusion of payroll taxes has no major impact on the findings of this paper. As discussed in the main text, almost all of the identifying variation in postwar US tax rates originates with the federal income tax.

Columns [22] and [23] of Tables 4 and B.4 show results based on alternative proxies for exogenous variation in marginal tax rates based on official estimates of the tax liability impact of the broader selection of 15 tax reforms. In column [22] the proxy is based on tax liability impact estimates associated with specific provisions of the reforms that made direct changes to the basic rate schedules. These numbers are obtained from a number of official government sources and are described in detail in appendix A. The proxy in this case is based on the sum of columns [1] and [3] in Table 3. The resulting elasticities are very similar to the benchmark. Column [23] uses estimates of the tax liability impact of all the provisions of the 15 tax reforms, including those with no or only indirect implications for marginal rates. This series is very similar to the narrative variables used by Romer and Romer (2010) and Mertens and Ravn (2013) as measures for shocks to average rates. The proxy is the sum of columns [1] through [4] in Table 3. As a measure of shocks to marginal rates it is less accurate, especially in case of reforms without provisions directly affecting marginal rates. This measure yields an SVAR-IV ETI estimate of 1.25 that is significant at the 5\% level, which is similar in size to the benchmark, but is also less precise. The LP-IV estimate of 0.98 is also similar to the benchmark estimate.

Sensitivity to the Inclusion of Additional Control Variables. The estimates in Panel D of Table B.3 are all derived from SVARs that add an additional endogenous variable relative to the benchmark nine variable system. Column 
[24] adds the average realized capital gains reported on income tax returns, which are very responsive to the timing of tax changes and may therefore have additional predictive power for marginal tax rates. Column [25] adds Ramey's (2011b) measure of news about future changes in defense spending. Because marginal tax rates have been systematically adjusted in reaction to changes in defense spending, this variable may also contain useful information for predicting future marginal tax rates. Following Slemrod (1996) and Barro and Redlick (2011), column [25] includes corporate bond rates as a measure of credit conditions and as a determinant of taxable interest. Columns [27] and [28] add educational attainment, measured by the fraction of college-educated adults, and the female labor participation rate to capture longer run trends relevant for income and tax rate dynamics. Similarly, columns [29] to [31] include measures of income inequality and earnings dispersion to help explain lower frequency movements in income and tax rates. While these additional control variables inevitably lead to variation in the elasticity estimates, none of them has any major impact. In all cases, the point estimates exceed unity and are significant at the 5\% level. Panel D of Table B.4 reports the corresponding LP-IV estimates, obtained after adding two lags of the new variables as additional controls. None of the additions has a major impact on the LP-IV point estimates or their statistical significance.

The last column in Table B.3 presents results derived from an SVAR-IV model that controls for the fact that corporate tax shocks may be correlated with AMTR innovations. The methodology is identical to Mertens and Ravn (2013) and relies on an annual version of the quarterly narrative series for corporate tax changes described in that paper. The VAR specification also includes the average corporate income tax rate as an additional endogenous variable. The estimates in column [32] measure the income response to a one percent increase in the net-of-tax rate while restricting the innovation to the corporate tax rate to zero. This yields very similar results as the benchmark model. 
A. Omitting Tax Reforms

\begin{tabular}{|c|c|c|c|c|c|c|c|c|c|}
\hline & $\begin{array}{c}{[1]} \\
\text { RA } \\
\mathbf{1 9 4 8}\end{array}$ & $\begin{array}{c}{[2]} \\
\text { RA } \\
\mathbf{1 9 6 4}\end{array}$ & $\begin{array}{c}{[3]} \\
\mathbf{R A} \\
\mathbf{1 9 7 8}\end{array}$ & $\begin{array}{c}{[4]} \\
\text { ERTA } \\
\mathbf{1 9 8 1}\end{array}$ & $\begin{array}{c}{[5]} \\
\text { TRA } \\
\mathbf{1 9 8 6} \\
\end{array}$ & $\begin{array}{c}{[6]} \\
\text { ERTA } 1981 \\
+ \text { TRA } 1986 \\
\end{array}$ & $\begin{array}{c}{[7]} \\
\text { OBRA } \\
1990\end{array}$ & $\begin{array}{c}{[8]} \\
\text { OBRA } \\
1993\end{array}$ & $\begin{array}{c}{[9]} \\
\text { JGTRRA } \\
\mathbf{2 0 0 3}\end{array}$ \\
\hline Same year & $0.69^{* * *}$ & $0.73^{* *}$ & $0.68^{* * *}$ & $0.68^{* * *}$ & $0.92^{* * *}$ & $0.88^{* * *}$ & $0.64^{* * *}$ & $0.55^{* * *}$ & $0.84^{* * *}$ \\
\hline & $(0.29,1.10)$ & $(0.16,1.31)$ & $(0.38,0.99)$ & $(0.34,1.03)$ & $(0.47,1.37)$ & $(0.45,1.31)$ & $(0.32,0.96)$ & $(0.21,0.88)$ & $(0.42,1.27)$ \\
\hline Following year & $1.39^{* * *}$ & $1.31^{* * *}$ & $1.31^{* * *}$ & $1.34^{* * *}$ & $1.61^{* * *}$ & $1.56^{* * *}$ & $1.31^{* * *}$ & $1.16^{* * *}$ & $1.61^{* * *}$ \\
\hline & $(0.84,1.94)$ & $(0.56,2.06)$ & $(0.75,1.86)$ & $(0.76,1.93)$ & $(0.92,2.29)$ & $(0.87,2.25)$ & $(0.74,1.88)$ & $(0.51,1.81)$ & $(0.87,2.35)$ \\
\hline \multirow[t]{4}{*}{$F_{S V A R-I V}$} & 7.86 & 6.79 & 9.86 & 11.38 & 6.09 & 6.71 & 11.02 & 10.48 & 6.65 \\
\hline & \multicolumn{9}{|c|}{ B. Alternative Specifications and Samples } \\
\hline & {$[10]$} & [11] & {$[12]$} & [13] & {$[14]$} & [15] & {$[16]$} & [17] & {$[18]$} \\
\hline & $\begin{array}{l}\text { One lag } \\
\text { in VAR }\end{array}$ & $\begin{array}{l}\text { Three lags } \\
\text { in VAR }\end{array}$ & $\begin{array}{l}\text { No } 1949 \\
\text { dummy }\end{array}$ & $\begin{array}{l}\text { No } 2008 \\
\text { dummy }\end{array}$ & $\begin{array}{c}\text { 1950-2012 } \\
\text { Sample }\end{array}$ & $\begin{array}{c}\text { 1950-2006 } \\
\text { Sample }\end{array}$ & $\begin{array}{c}1960-2000 \\
\text { Sample }\end{array}$ & $\begin{array}{l}\text { Quadr. } \\
\text { trend }\end{array}$ & $\begin{array}{l}\text { Cubic } \\
\text { trend }\end{array}$ \\
\hline \multirow[t]{2}{*}{ Same year } & $0.48^{* *}$ & $0.57^{* *}$ & $0.76^{* * *}$ & $0.62^{* * *}$ & $0.69^{* * *}$ & $0.73^{*}$ & $0.73^{* *}$ & $0.62^{* * *}$ & $0.61^{* * *}$ \\
\hline & $(0.11,0.85)$ & $(0.11,1.03)$ & $(0.26,1.25)$ & $(0.24,0.99)$ & $(0.23,1.14)$ & $(-0.01,1.47)$ & $(0.14,1.32)$ & $(0.29,0.94)$ & $(0.30,0.92)$ \\
\hline \multirow[t]{2}{*}{ Following year } & $0.51^{*}$ & $1.26^{* * *}$ & $0.96^{* * *}$ & $1.15^{* * *}$ & $1.41^{* * *}$ & $1.50^{* * *}$ & $1.40^{* * *}$ & $1.19^{* * *}$ & $1.17^{* * *}$ \\
\hline & $(-0.09,1.11)$ & $(0.33,2.20)$ & $(0.39,1.53)$ & $(0.61,1.70)$ & $(0.82,2.00)$ & $(0.55,2.45)$ & $(0.80,2.00)$ & $(0.71,1.66)$ & $(0.70,1.65)$ \\
\hline$F_{S V A R-I V}$ & 13.42 & 7.69 & 11.72 & 11.21 & 8.33 & 6.62 & 4.64 & 10.59 & 10.18 \\
\hline
\end{tabular}

C. Alternative Tax Rate Measures and Proxies

\begin{tabular}{|c|c|c|c|c|}
\hline $\begin{array}{c}{[19]} \\
\text { AMTR } \\
\text { PS } 2003\end{array}$ & $\begin{array}{c}{[20]} \\
\text { AMIITR } \\
\text { BR } 2011\end{array}$ & $\begin{array}{c}{[21]} \\
\text { AMIITR } \\
\text { PS } 2003\end{array}$ & $\begin{array}{c}{[22]} \\
\text { Marg. Tax } \\
\text { Liab. Proxy }\end{array}$ & $\begin{array}{c}{[23]} \\
\text { Total Tax } \\
\text { Liab. Prox }\end{array}$ \\
\hline $0.75^{* * *}$ & $0.81^{* * *}$ & $0.85^{* * *}$ & $0.70^{* * *}$ & $0.55^{* * *}$ \\
\hline$(0.39,1.10)$ & $(0.40,1.22)$ & $(0.41,1.29)$ & $(0.43,0.98)$ & $(0.24,0.85)$ \\
\hline $1.45^{* * *}$ & $1.52^{* * *}$ & $1.66^{* * *}$ & $1.41^{* * *}$ & $1.25^{* * *}$ \\
\hline$(0.90,2.00)$ & $(0.55,2.49)$ & $(0.78,2.55)$ & $(0.85,1.97)$ & $(0.68,1.82)$ \\
\hline 8.90 & 13.46 & 9.69 & 7.03 & 9.99 \\
\hline
\end{tabular}

D. Additional Controls

\begin{tabular}{|c|c|c|c|c|c|c|c|c|c|}
\hline & $\begin{array}{c}{[24]} \\
\text { Capital } \\
\text { Gains }\end{array}$ & $\begin{array}{c}{[25]} \\
\text { Ramey } \\
\text { News }\end{array}$ & $\begin{array}{c}{[26]} \\
\text { Corp. } \\
\text { Baa rate }\end{array}$ & $\begin{array}{c}{[27]} \\
\text { Educ- } \\
\text { ation }\end{array}$ & $\begin{array}{c}{[28]} \\
\text { Female } \\
\text { Part. Rate }\end{array}$ & $\begin{array}{c}{[29]} \\
\text { Top 10\% } \\
\text { Share }\end{array}$ & $\begin{array}{c}{[30]} \\
\text { Gini } \\
\text { Coeff. }\end{array}$ & $\begin{array}{l}{[31]} \\
\text { Wage } \\
\text { Ineq. }\end{array}$ & $\begin{array}{c}{[32]} \\
\text { Corp. } \\
\text { Tax }\end{array}$ \\
\hline Same year & $\begin{array}{c}0.43^{*} \\
(-0.03,0.89)\end{array}$ & $\begin{array}{l}0.61^{* * *} \\
(0.30,0.91)\end{array}$ & $\begin{array}{l}0.79^{* * *} \\
(0.41,1.17)\end{array}$ & $\begin{array}{c}0.59^{* *} \\
(0.04,1.13)\end{array}$ & $\begin{array}{l}0.70^{* * *} \\
(0.33,1.08)\end{array}$ & $\begin{array}{l}0.59^{* * *} \\
(0.23,0.94)\end{array}$ & $\begin{array}{l}0.66^{* *} \\
(0.12,1.20)\end{array}$ & $\begin{array}{l}0.54^{* * *} \\
(0.21,0.87)\end{array}$ & $\begin{array}{l}0.63^{* *} \\
(0.02,1.29)\end{array}$ \\
\hline Following year & $\begin{array}{l}1.06^{* * *} \\
(0.34,1.78)\end{array}$ & $\begin{array}{l}1.19^{* * *} \\
(0.66,1.72)\end{array}$ & $\begin{array}{l}1.47^{* * *} \\
(0.91,2.04)\end{array}$ & $\begin{array}{l}1.04^{* * *} \\
(0.30,1.78)\end{array}$ & $\begin{array}{l}1.44^{* * *} \\
(0.73,2.15)\end{array}$ & $\begin{array}{l}1.11^{* * *} \\
(0.66,1.57)\end{array}$ & $\begin{array}{l}1.30^{* * *} \\
(0.62,1.99)\end{array}$ & $\begin{array}{l}1.07^{* * *} \\
(0.55,1.59)\end{array}$ & $\begin{array}{l}1.35^{\text {*** }} \\
(0.25,2.29)\end{array}$ \\
\hline$F_{S V A R-I V}$ & 11.02 & 12.34 & 10.95 & 8.11 & 11.53 & 10.39 & 8.15 & 10.46 & -- \\
\hline
\end{tabular}

Notes: Elasticities are SVAR-IV estimates based on equation (4) estimated under assumptions (6) and (7). The instrument $z_{t}$ is given by the column of Table 3. Two exceptions are column [22], where $z_{t}$ is the sum of column [1] and [3] of Table 3, and column [23], where $z_{t}$ is the sum of column [1]-[4] of Table 3. PS 2003 and BR 2011 refer to the AMTR series using the income definition of Barro and Redlick (2011) and Piketty and Saez (2003) respectively. AMIITR refers to the tax rate series for the federal individual income tax only. The additional variables in the bottom panel are described in appendix A. In parentheses are the 95\% standard confidence intervals based on Delta Method suggested by Montiel-Olea, Stock and Watson (2017) with a Newey and West (1987) HAC-robust residual covariance matrix estimator for the SVAR-IV reduced-form parameters. The $F_{S V A R-I V}$ statistic is defined in equation (B.1). Asterisks denote $10 \%, 5 \%$ or $1 \%$ significance. 
A. Omitting Tax Reforms

\begin{tabular}{|c|c|c|c|c|c|c|c|c|c|}
\hline & $\begin{array}{c}{[1]} \\
\text { RA } \\
\mathbf{1 9 4 8}\end{array}$ & $\begin{array}{c}{[2]} \\
\text { RA } \\
\mathbf{1 9 6 4}\end{array}$ & $\begin{array}{c}{[3]} \\
\text { RA } \\
\text { 1978 }\end{array}$ & $\begin{array}{c}{[4]} \\
\text { ERTA } \\
1981\end{array}$ & $\begin{array}{c}{[5]} \\
\text { TRA } \\
1986\end{array}$ & $\begin{array}{c}{[6]} \\
\text { ERTA } 1981 \\
+ \text { TRA } 1986\end{array}$ & $\begin{array}{c}{[7]} \\
\text { OBRA } \\
1990\end{array}$ & $\begin{array}{c}{[8]} \\
\text { OBRA } \\
1993\end{array}$ & $\begin{array}{c}{[9]} \\
\text { JGTRRA } \\
\mathbf{2 0 0 3}\end{array}$ \\
\hline Same year & $0.69^{* * *}$ & $0.73^{* *}$ & $0.68^{* * *}$ & $0.68^{* * *}$ & $0.92^{* * *}$ & $0.88^{* * *}$ & $0.64^{* * *}$ & $0.55^{* * *}$ & $0.84^{* * *}$ \\
\hline & $(0.29,1.10)$ & $(0.16,1.31)$ & $(0.38,0.99)$ & $(0.34,1.03)$ & $(0.47,1.37)$ & $(0.45,1.31)$ & $(0.32,0.96)$ & $(0.21,0.88)$ & $(0.42,1.27)$ \\
\hline Following year & $1.37^{* * *}$ & $1.16^{* *}$ & $1.27^{* * *}$ & $1.14^{* * *}$ & $1.16^{* * *}$ & $1.12^{* * *}$ & $1.11^{* * *}$ & $0.96^{* * *}$ & $1.26^{* * *}$ \\
\hline & $(0.77,1.97)$ & $(0.22,2.10)$ & $(0.85,1.69)$ & $(0.55,1.74)$ & $(0.42,1.91)$ & $(0.34,1.89)$ & $(0.56,1.66)$ & $(0.37,1.56)$ & $(0.56,1.95)$ \\
\hline \multirow[t]{4}{*}{$F_{1 \text { st-Stage }}$} & 96.66 & 68.18 & 230.94 & 211.75 & 93.94 & 106.06 & 246.95 & 218.75 & 184.42 \\
\hline & \multicolumn{9}{|c|}{ B. Alternative Specifications and Samples } \\
\hline & {$[10]$} & [11] & {$[12]$} & [13] & [14] & {$[15]$} & {$[16]$} & {$[17]$} & {$[18]$} \\
\hline & $\begin{array}{l}\text { One lag } \\
\text { in RHS }\end{array}$ & $\begin{array}{l}\text { Three lags } \\
\text { in RHS }\end{array}$ & $\begin{array}{l}\text { No } 1949 \\
\text { dummy }\end{array}$ & $\begin{array}{l}\text { No } 2008 \\
\text { dummy }\end{array}$ & $\begin{array}{c}\text { 1950-2012 } \\
\text { Sample }\end{array}$ & $\begin{array}{c}\text { 1950-2006 } \\
\text { Sample }\end{array}$ & $\begin{array}{c}1960-2000 \\
\text { Sample }\end{array}$ & $\begin{array}{l}\text { Quadr. } \\
\text { trend }\end{array}$ & $\begin{array}{l}\text { Cubic } \\
\text { trend }\end{array}$ \\
\hline Same year & $0.48^{* *}$ & $0.57^{* *}$ & $0.76^{* * *}$ & $0.62^{* * *}$ & $0.69^{* * *}$ & $0.73^{*}$ & $0.73^{* *}$ & $0.62^{* * *}$ & $0.61^{* * *}$ \\
\hline & $(0.11,0.85)$ & $(0.11,1.03)$ & $(0.26,1.25)$ & $(0.24,0.99)$ & $(0.23,1.14)$ & $(-0.01,1.47)$ & $(0.14,1.32)$ & $(0.29,0.94)$ & $(0.30,0.92)$ \\
\hline Following year & $0.66^{* *}$ & $1.46^{* *}$ & $1.19^{* * *}$ & $1.01^{* * *}$ & $1.54^{* * *}$ & $1.80^{* * *}$ & $1.57^{* * *}$ & $0.98^{* * *}$ & $0.98^{* * *}$ \\
\hline & $(0.11,1.20)$ & $(0.17,2.76)$ & $(0.61,1.77)$ & $(0.34,1.69)$ & $(0.80,2.27)$ & $(0.69,2.91)$ & $(0.75,2.39)$ & $(0.47,1.48)$ & $(0.50,1.46)$ \\
\hline$F_{1 s t-\text { Stage }}$ & 41.56 & 38.47 & 231.83 & 248.29 & 101.40 & 44.16 & 24.37 & 168.02 & 156.80 \\
\hline
\end{tabular}

C. Alternative Tax Rate Measures and Proxies

\begin{tabular}{|c|c|c|c|c|}
\hline [19] & [20] & [21] & [22] & [23] \\
\hline AMTR & AMIITR & AMIITR & Marg. Tax & Total Tax \\
\hline PS 2003 & BR 2011 & PS 2003 & Liab. Proxy & Liab. Prox \\
\hline $0.75^{* * *}$ & $0.81^{* * *}$ & $0.85^{* * *}$ & $0.70^{* * *}$ & $0.55^{* * *}$ \\
\hline$(0.39,1.10)$ & $(0.40,1.22)$ & $(0.41,1.29)$ & $(0.43,0.98)$ & $(0.24,0.85)$ \\
\hline $1.23^{* * *}$ & $1.35^{* * *}$ & $1.42^{* * *}$ & $1.12^{* * *}$ & $0.98^{* * *}$ \\
\hline$(0.70,1.75)$ & $(0.58,2.13)$ & $(0.70,2.14)$ & $(0.56,1.68)$ & $(0.34,1.61)$ \\
\hline 62.24 & 86.57 & 65.33 & 42.65 & 25.69 \\
\hline
\end{tabular}

D. Additional Controls

\begin{tabular}{|c|c|c|c|c|c|c|c|c|}
\hline & $\begin{array}{c}{[24]} \\
\text { Capital } \\
\text { Gains }\end{array}$ & $\begin{array}{c}{[25]} \\
\text { Ramey } \\
\text { News }\end{array}$ & $\begin{array}{c}{[26]} \\
\text { Corp. } \\
\text { Baa rate }\end{array}$ & $\begin{array}{l}{[27]} \\
\text { Educ- } \\
\text { ation }\end{array}$ & $\begin{array}{c}{[28]} \\
\text { Female } \\
\text { Part. Rate }\end{array}$ & $\begin{array}{c}{[29]} \\
\text { Top 10\% } \\
\text { Share }\end{array}$ & $\begin{array}{c}{[30]} \\
\text { Gini } \\
\text { Coeff. }\end{array}$ & $\begin{array}{l}{[31]} \\
\text { Wage } \\
\text { Ineq. }\end{array}$ \\
\hline Same year & $0.43^{*}$ & $0.61^{* * *}$ & $0.79^{* * *}$ & $0.59^{* *}$ & $0.70^{* * *}$ & $0.59^{* * *}$ & $0.66^{* *}$ & $0.54^{* * *}$ \\
\hline Following year & $\begin{array}{l}(-0.03,0.89) \\
0.94^{* * *} \\
(0.34,1.54)\end{array}$ & $\begin{array}{l}(0.30,0.91) \\
1.08^{* * *} \\
(0.59 .1 .57)\end{array}$ & $\begin{array}{l}(0.41,1.17) \\
1.29^{* * *} \\
(0.66 .1 .91)\end{array}$ & $\begin{array}{l}(0.04,1.13) \\
1.09^{* * *} \\
(0.41 .1 .77)\end{array}$ & $\begin{array}{l}(0.33,1.08) \\
1.12^{* * *} \\
(0.51 .1 .73)\end{array}$ & $\begin{array}{l}(0.23,0.94) \\
0.93^{* * *} \\
(0.37,1.49)\end{array}$ & $\begin{array}{l}(0.12,1.20) \\
1.49^{* * *} \\
(0.64 .2 .33)\end{array}$ & $\begin{array}{l}(0.21,0.87) \\
0.85^{* * *} \\
(0.21,1.48)\end{array}$ \\
\hline$F_{1 \text { st-Stage }}$ & 52.06 & 224.13 & 174.27 & 79.83 & 176.53 & 166.26 & 72.80 & 194.38 \\
\hline
\end{tabular}

Notes: Elasticities are LP-IV estimates based on equation (9) estimated under assumptions (10) and (11). The instrument $z_{t}$ is given by the column [5] of Table 3. Two exceptions are column [22], where $z_{t}$ is the sum of column [1] and [3] of Table 3, and column [23], where $z_{t}$ is the sum of column [1]-[4] of Table 3. PS 2003 and BR 2011 refer to the AMTR series using the income definition of Barro and Redlick (2011) and Piketty and Saez (2003) respectively. AMIITR refers to the tax rate series for the federal individual income tax only. The additional variables in the bottom panel are described in appendix A. The first-stage F statistic and $95 \%$ confidence intervals in parentheses are based on Newey and West (1987) HAC adjusted standard errors using 8 lags. Asterisks denote 10\%, 5\% or 1\% significance. 

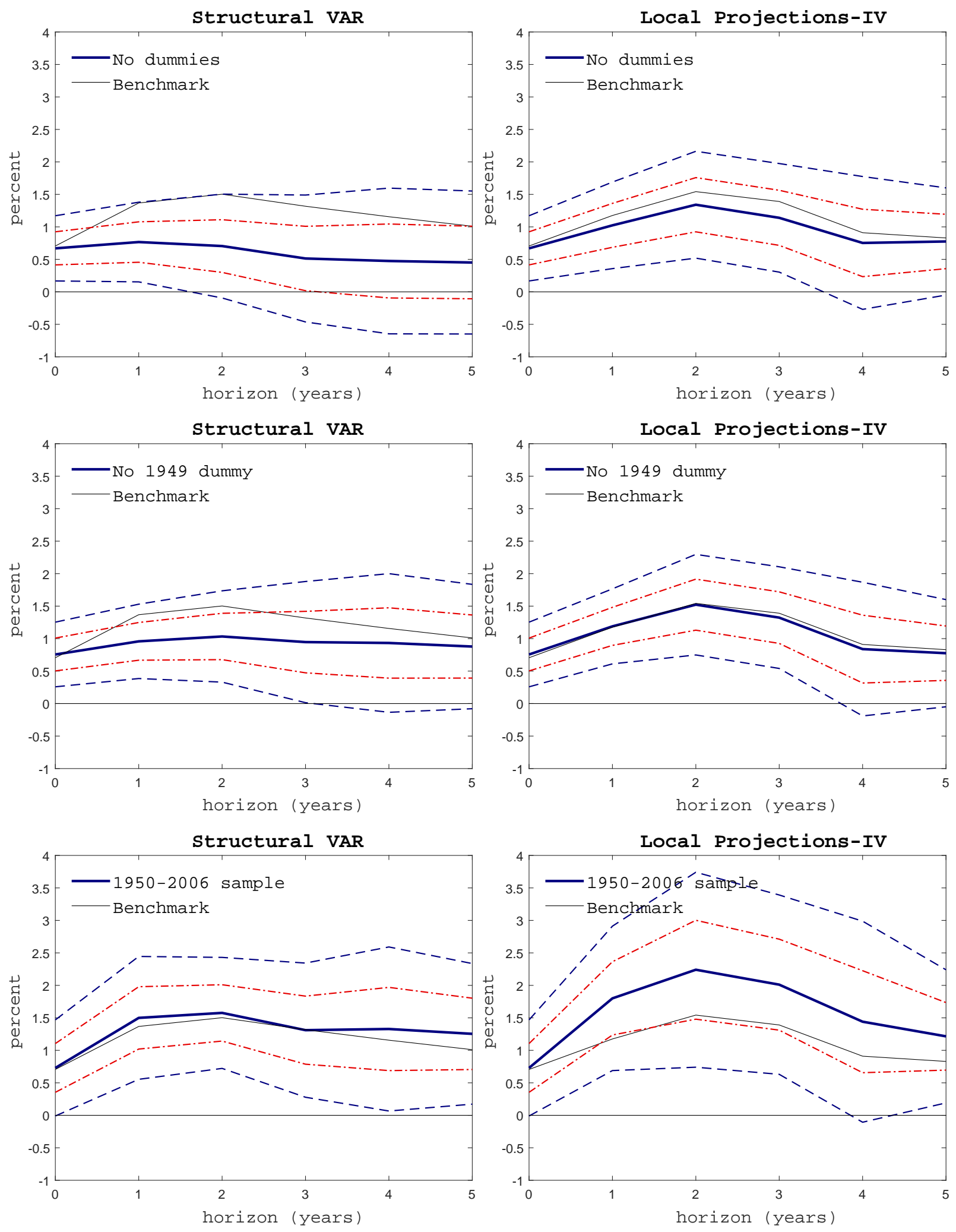

Figure B.3 Estimates of Tax Elasticities of Income-Different Sample Periods

Notes: Estimates in the left column are obtained using SVAR-IV as in Figure 5, and in the right column using LP-IV as in Figure 6, but with the following modifications: First row: the effective sample is 1948-2012, the dummies for 1949 and 2008 are excluded. Second row: the effective sample is 1948-2012, the 2008 dummy is included, but the 1949 dummy. Third row: the effective sample is 1950-2006, and no year dummies are included. 